\title{
Role of Balloon Pulmonary Valvuloplasty in the Management of Pulmonary Stenosis
}

\author{
P. Syamasundar Rao
}

Professor of Pediatrics and Medicine, Emeritus Chief of Pediatric Cardiology, University of Texas-Houston McGovern Medical School, and Children's Memorial Hermann Hospital, Houston, Texas

Corresponding Author: P. Syamasundar Rao, MD, Professor and Emeritus Chief of Pediatric Cardiology, UT-Houston McGovern Medical School, 6410 Fannin, UTPB Suite \# 425, Houston, TX. 77030.

Received Date: July 07, 2021; Accepted Date: September 06, 2021; Published Date: September 21, 2021

Citation: P. Syamasundar Rao (2021) Role of Balloon Pulmonary Valvuloplasty in the Management of Pulmonary Stenosis. J. Clinical Cardiology and Cardiovascular Interventions, 4(15); DOI:10.31579/2641-0419/195

Copyright: @ 2021 P. Syamasundar Rao, This is an open-access article distributed under the terms of the Creative Commons Attribution License, which permits unrestricted use, distribution, and reproduction in any medium, provided the original author and source are credited.

\begin{abstract}
Although there is definitive evidence for pressure gradient relief both immediately after and at follow-up after balloon pulmonary valvuloplasty (BPV) for pulmonary stenosis (PS), the progression of pulmonary insufficiency (PI) at late follow up emerged as a concern. To address the concern for development of PI during late follow-up, balloon/annuls ratio used for BPV was reduced to 1.2 to 1.25. Recurrence of stenosis was seen in nearly $10 \%$ of patients. The causes of recurrence were identified to be balloon/annulus ratio less than 1.2 and immediate post-BPV gradients in excess of $30 \mathrm{mmHg}$. Recurrent obstructions can be effectively relieved by repeat BPV. The BPV procedure is safe and effective in fetal, neonatal and adult subjects as well. The BPV is also effective in palliating cyanotic congenital heart disease patients with valvar PS. Despite the limitations, BPV is currently considered as therapeutic procedure of choice in the management of congenital PS in both the pediatric and adult populations. BPV provides an excellent alternative to surgical intervention and has become the preferred intervention for initial treatment for PS in neonates, infants, children, adolescents, and adults. Careful follow-up to detect development of significant PI and investigate methods to prevent PI are recommended.

Keywords: pulmonary stenosis; balloon pulmonary valvuloplasty; balloon:annulus ratio; restenosis; pulmonary insufficiency; immediate results; intermediate-term results; long-term results; congenital heart defects; historical aspects; indications; cyanotic heart defects
\end{abstract}

\section{Introduction}

Pulmonary valve stenosis may be an isolated lesion or may be seen in association with other congenital heart defects [1-4]. The most common pathology is a "dome-shaped" pulmonary valve with fusion of pulmonary valve leaflets protruding into the pulmonary artery as a conical, windsocklike structure. The valve leaflets are usually thickened and domed. The pathologic, pathophysiologic, clinical, chest x-ray, electrocardiographic (ECG), echo-Doppler and angiographic features of pulmonary stenosis (PS) were reviewed by the author elsewhere [1-8] and will not be repeated here. Surgical pulmonary valvotomy [9] has been a standard management approach for this lesion until Kan and her associates [10] reported on the application of the techniques of Dotter and Grüntzig and their associates to successfully treat pulmonary valve stenosis. In this paper the role of balloon pulmonary valvuloplasty (BPV) in the management of PS will be reviewed.

\section{Historical Aspects}

Historical aspects of percutaneous BPV were reviewed by the author in the past [11-13] and will only be briefed here. Rubio-Alverez and associates $[14,15]$ were the first to attempt relief of pulmonary valve obstruction by using an ureteral catheter with a wire; this was in the early 1950s. In 1979, Semb et al [16] accomplished relief of pulmonary valve obstruction by forcefully pulling an inflated balloon of a Berman angiographic catheter across the pulmonary valve. There were no other reports of usage of this technique by these or other investigators. As stated above, Kan and her associates [10] applied the techniques of Dotter and Judkins [17] and Grüntzig and associates [18] to relieve pulmonary valve obstruction; this was reported in 1982. This type of static balloon dilatation is currently used all over the world to treat pulmonary valve stenosis. The author's group was among the first to recommend balloon/annulus (B/A) ratio of 1.2 to 1.4 for BPV [19,20], examine causes of restenosis after BPV [21], call attention to the development of pulmonary insufficiency (PI) during follow-up [22], and revise B/A ratio to 1.2 to 1.25 for BPV to reduce the probability of PI at follow-up [23,24].

\section{Indications for Balloon Pulmonary Valvuloplasty}

There is a general consensus that indications for percutaneous transcatheter therapy should be same as those used for surgical 
intervention; however, some investigators were using gradients of 40 $\mathrm{mmHg}$ as an indication for BPV instead of surgical criteria for intervention of peak-to-peak gradient in excess of $50 \mathrm{mmHg}$. The author was concerned with this lowered criteria and examined this issue in a greater detail [25]. The reported results of BPV in patients with peak-topeak systolic pressure gradients less than $50 \mathrm{mmHg}$ [25] and the natural history study [26] were reviewed to see if the author's concern is valid. Fifty-three patients from the published literature as of that time had BPV which resulted in reduction $(\mathrm{p}<0.01)$ of right ventricular $(\mathrm{RV})$ peak systolic pressures $(60 \pm 9$ vs. $43 \pm 11 \mathrm{mmHg})$ and pulmonary valve peakto-peak gradients $(38 \pm 6$ vs. $20 \pm 11 \mathrm{mmHg}$ ). At follow-up, the pulmonary valve gradients $(24 \pm 12 \mathrm{mmHg})$ and $\mathrm{RV}$ peak systolic pressures ( $45 \pm 12 \mathrm{mmHg}$ ) remained low. However, the RV peak systolic pressures were only $75 \pm 18 \%$ lower than pre-BPV values. The author questioned whether this modest reduction of RV peak systolic pressure is worth the morbidity, risk, and expense associated with the BPV procedure. In addition, review of the natural history study of 184 patients indicated that the prognosis of trivial and mild pulmonary stenosis (gradients $<50 \mathrm{mmHg}$ ) without intervention is excellent [26]. Our analysis concluded [25] that 1 . There was marginal reduction of RV peak systolic pressure when mild PS was treated by balloon valvuloplasty, 2 . Previous natural history studies point out that trivial and mild PS (gradients less than $50 \mathrm{mmHg}$ ) stayed mild at follow-up [26], and 3 . Severity of obstruction can easily be monitored and quantified by echoDoppler studies (and should the gradient increase, BPV may then be performed). On the basis of this analysis [25] and the author's extensive personal experience with this procedure, it was recommended that balloon valvuloplasty should be performed only if the peak-to-peak gradient across the pulmonary valve is more than $50 \mathrm{mmHg}$ [25].

This editorial was written more than three decades ago and the author continues to maintain these assertions [8,22,24,27,28]. In addition, the reports of significant PI at late follow-up after BPV [22,23,29,30] further support the idea of non-intervention in patients with mild PS. Unfortunately, the American Heart Association' Committee [31] on guidelines for intervention in pediatric cardiac disease use gradients of 40 $\mathrm{mmHg}$ or right ventricular peak systolic pressure of $50 \mathrm{mmHg}$ for balloon therapy.

At the present time, most percutaneous interventional procedures in children are performed under general anesthesia and the pulmonary valve gradients are lower with general anesthesia than with conscious sedation. Therefore, the criteria alluded to above are not necessarily applicable. Accordingly, the pre-procedural Doppler gradients are usually used in making a decision on the need for BPV. Because of effects of pressure recovery phenomenon [32,33], correction to account for pressure recovery should be applied.

Dysplastic pulmonary valve is generally considered a relative contraindication for balloon dilatation. Our own experience [34] and that of others [35] imply that balloon valvuloplasty is the initial treatment of option and $\mathrm{B} / \mathrm{A}$ ratios of 1.4 to 1.5 are likely to be effective in children with dysplastic valves [34]. It should be understood that favorable result will occur only in the presence of commissural fusion.

Some cardiologists do not recommend BPV in adult patients with moderate to severe stenosis if they are asymptomatic [36]. Because of poor response to exercise [37] and possible development of myocardial fibrosis, we recommend balloon valvuloplasty to relieve the obstruction in adults with moderate to severe PS, irrespective of the symptoms $[1,8,27,28]$.

\section{Technique of Balloon Pulmonary Valvuloplasty Preparation for BPV}

The diagnosis and assessment of severity of PS are made by standard clinical, roentgenographic, ECG, and echo-Doppler data. After a diagnosis of moderate to severe PS (gradients $\geq 50 \mathrm{mmHg}$ ) is confirmed, arrangements for cardiac catheterization, selective cineangiography, and BPV are made [1,4,24,27,28]. A full explanation of the cardiac catheterization and balloon valvuloplasty procedure along with the risks associated with such procedures is given to the patients/parents. Such informed consent is crucial because of probability of acute complications and limited long-tem results.

\section{Sedation and Anesthesia}

In the past, BPV has been performed by sedating the patient with a mixture of meperidine, promethazine and chlorpromazine, administered intramuscularly and supplemented with intermittent doses of midazolam (versed) (0.05 to $0.1 \mathrm{mg} / \mathrm{kg}$ IV) and/or Fentanyl (0.5 to 1.0 microgram $/ \mathrm{kg}$ IV), as necessary. General anesthesia with endotracheal ventilation was reserved to infants below the age of 3 months. Other cardiologists use ketamine for sedating these patients. More recently, most institutions are using general anesthesia for all transcatheter interventional cases including BPV in the pediatric population. The author recommends that institutional practices should be respected with regard to the type of sedation/anesthesia used and availability personnel to provide such services should also be considered.

\section{Vascular Access}

Percutaneous femoral venous route [38] is preferred entry site for cardiac catheterization including BPV. In the absence of femoral venous access, other sites such as axillary [39] or jugular [40] venous or transhepatic [41] routes may be used, although such entry sites are awkward compared to traditional femoral venous route. A \# 5 to \# 7 French sheath is inserted into the femoral vein by Deselets-Hoffman modification of the Seldinger technique; the size of the sheath is largely dependent on the expected size of the balloon valvuloplasty catheter.

A \#3, 4 or 5 French blood pressure monitoring arterial line is introduced percutaneously into the femoral artery in infants, children and adolescents and adults respectively to continuously monitor the arterial blood pressure and to intermittently monitor $\mathrm{O}_{2}$ saturation and blood gases.

\section{Hemodynamic Evaluation}

I usually start the procedure with Berman angiographic catheter. The RV and pulmonary arterial pressures are recorded and the peak-to-peak gradient across the pulmonary valve is measured. This gradient is used to appraise the severity of PS. If the Berman angiographic catheter can't be advanced into the pulmonary artery, the catheter is replaced with either a multipurpose, right coronary artery or cobra catheter and with the help of a soft-tipped guide wire such as straight Benson (Cook), the pulmonary valve is crossed and pressure pullback recordings made to obtain the pulmonary valve gradients. While pressure pullback recording is important, if it was very difficult to cross the pulmonary valve, it may not be wise to record such a pressure pullback tracing. In such cases, separately recorded RV and pulmonary arterial pressures may be used to evaluate the pulmonary valve gradient.

The RV and femoral artery pressures are simultaneously recorded; such recordings also help assess the severity of PS. RV peak systolic pressure equal to or greater than $75 \%$ of aortic or left ventricular peak systolic 
pressure is considered significant and such degree of pulmonary valve obstruction requires relief of obstruction.

Heart rate, aortic (or femoral artery) pressure and cardiac index are measured both before and after balloon valvuloplasty to ensure that a change in pulmonary valve gradient after the procedure is not related to a change in cardiac output, but indeed is related to the balloon procedure. We currently calculate the cardiac index with assumed oxygen consumption instead of former methods of computing cardiac index by thermodilution method and Fick technique with measured oxygen consumption.

\section{Cineangiography}

RV cineangiogram in a sitting-up $\left(15^{\circ} \mathrm{LAO}\right.$ and $35^{\circ}$ cranial - Figure $\left.1 \mathrm{~A}\right)$ and straight lateral views (Figure $2 \mathrm{~A}$ ) is performed to confirm pulmonary valvar obstruction, to assess the size and function of the right ventricle, to detect tricuspid insufficiency, and most importantly, to measure the pulmonary valve annulus. Berman angiographic catheter is positioned in the right ventricular apex with the balloon inflated during right ventricular cineangiogram.

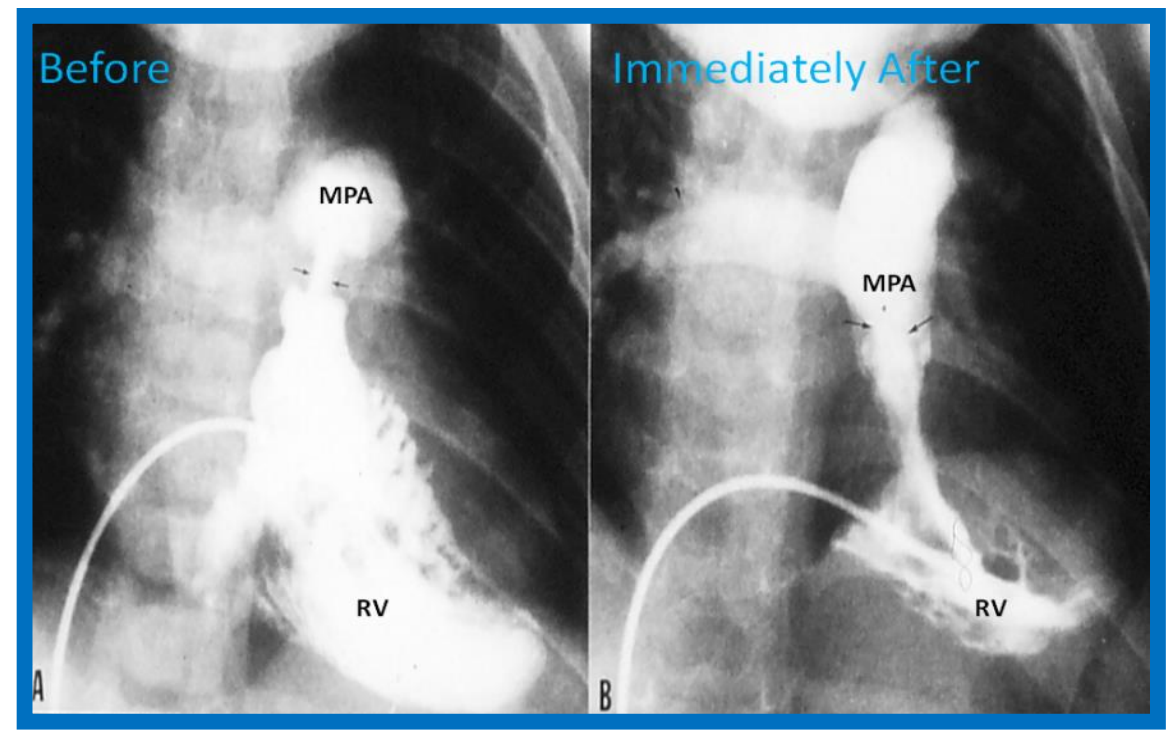

Figure 1. Selected frames from right ventricular $(R V)$ cineangiograms in a sitting-up $(15 \rightarrow$ left anterior oblique and $35 \rightarrow$ cranial $)$ view before $(A)$ and immediately after $(B)$ balloon pulmonary valvuloplasty. Note the thin jet (arrows in A) prior to valvuloplasty which increased in width (arrows in B) after valvuloplasty. C, Catheter; MPA, main pulmonary artery. Reproduced from. Rao PS (ed), Transcatheter Therapy in Pediatric Cardiology. Wiley-Liss, Inc., New York, 1993:59-104 [4].

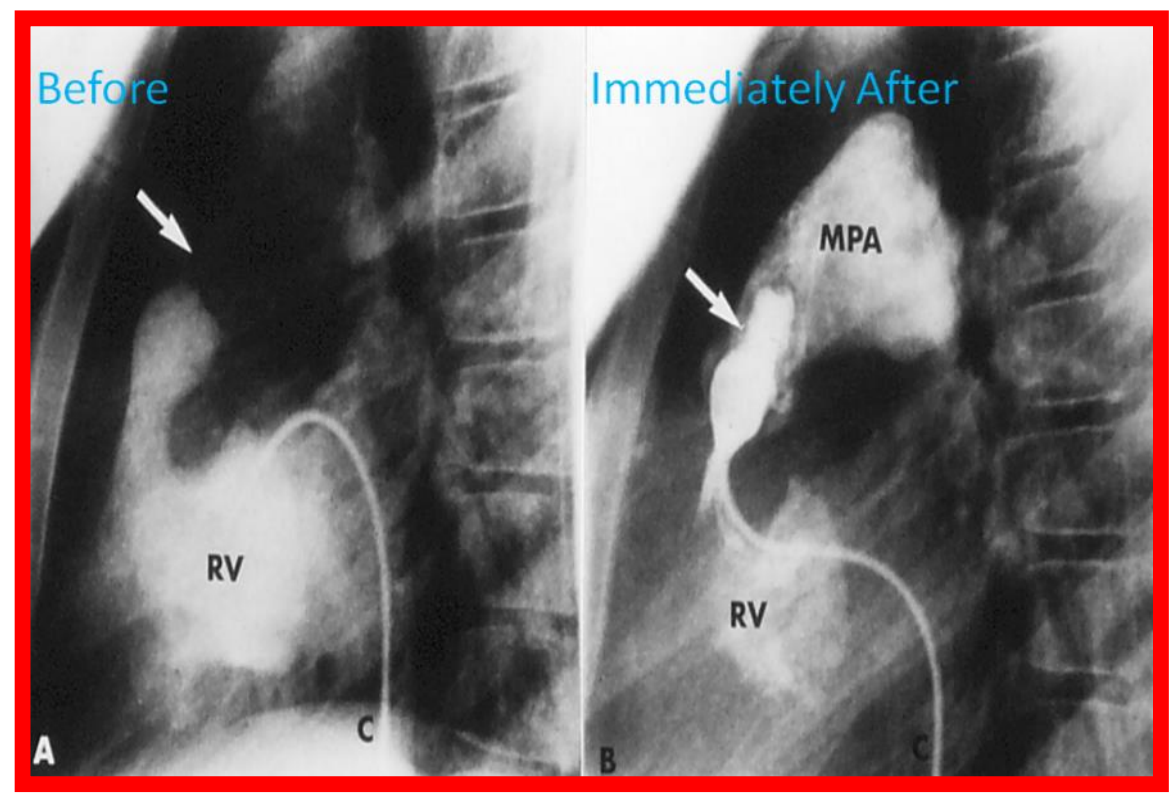

Figure 2. Selected frames from right ventricular $(R V)$ cineangiograms in lateral views before $(A)$ and immediately after $(B)$ balloon pulmonary valvuloplasty. Note the thin jet (barely seen) (arrow in A) prior to valvuloplasty which increased in width (arrow in B) after valvuloplasty. $C$, Catheter; MPA, main pulmonary artery. Reproduced from Rao PS, Current Problems in Cardiology 1989; 14(8): 417-500 [42]. 
Other angiograms are not usually necessary unless the echocardiographic or hemodynamic information necessitates exclusion of other defects. Selective angiography of the left ventricle and coronary arteries are performed in patients older than 50 years, depending on the institutional practices or in patients in whom coronary artery disease is suspected.

\section{Balloon Valvuloplasty Procedure}

The BPV procedure consists of positioning a balloon dilatation catheter across the narrowed pulmonary valve over an extra-stiff, exchange-length guide wire and inflating the balloon until the waisting of the balloon is abolished (Figures 3 and 4).

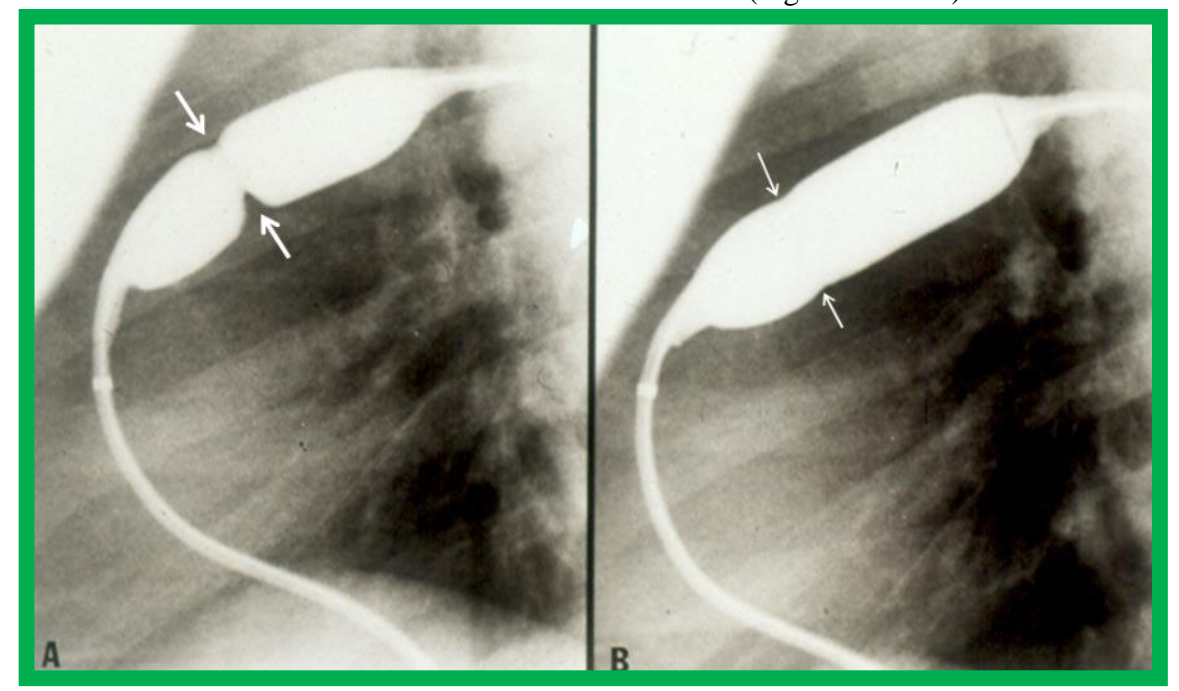

Figure 3. Balloon dilatation catheter placed across the pulmonary valve showing "waisting" of the balloon (A) in the early phases of inflation (thick arrows) which is almost completely abolished with further balloon inflation (B) (thin arrows). Modified from Rao PS (ed), Transcatheter Therapy in Pediatric Cardiology. Wiley-Liss, Inc., New York, 1993:59-104 [4].

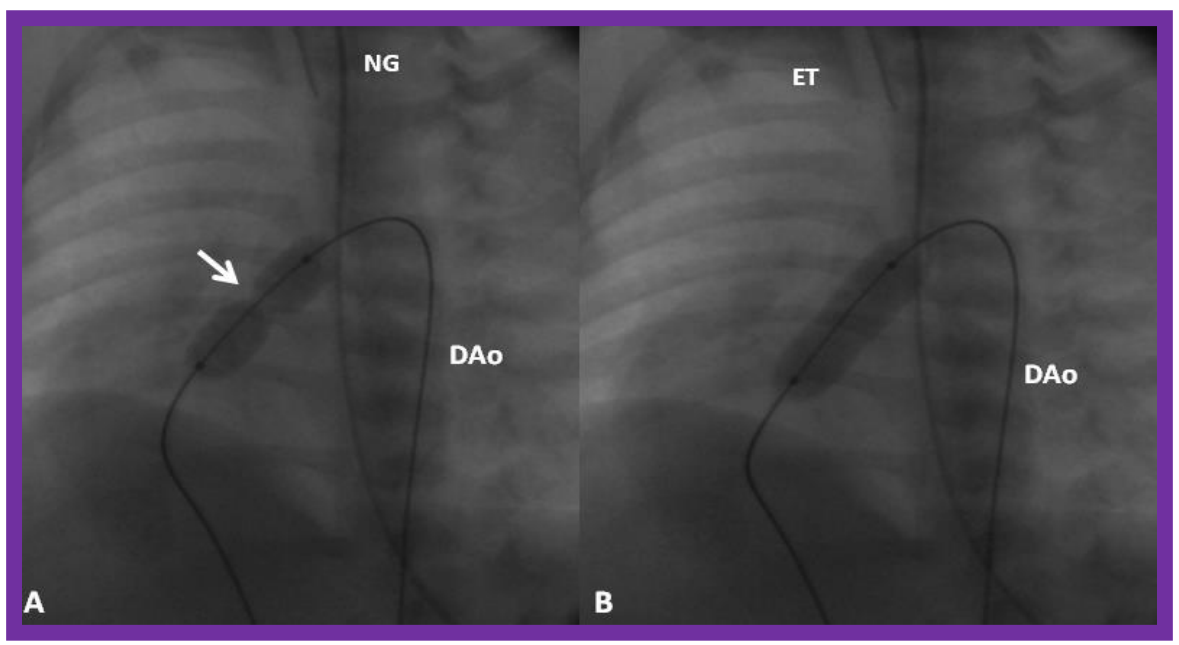

Figure 4. A. A selected cine frame in 150 left anterior oblique with 350 cranial angulated view demonstrates the position of a balloon angioplasty catheter across the stenotic pulmonary valve. Note the waisting of the balloon (arrow) during the early phase of balloon inflation. B. The waist has been completely abolished on further inflation of the balloon. Note that the guide wire is passing through the ductus into the descending aorta (DAo). ET, endotracheal tube; NG, nasogastric tube. Reproduced from Rao PS, Neonatology Today 2007; 2(10):1-12 [43].

A \#4- to \# 6-French balloon wedge, multi-purpose, right coronary artery, cobra, angled Glidecath or any other end-hole catheter, depending on the cardiologist's choice and the patients' anatomy, is positioned in the RV outflow tract. A soft-tipped guide wire (my preference is 0.035 -inch Benston straight guide wire [Cook]) is used to cross the pulmonary valve. In neonates and young infants, a 0.014-inch coronary guide wire with a floppy end is used to cross the pulmonary valve. The guide wire and then the tip of the catheter are advanced into the distal left (preferable) or right pulmonary artery. In neonates and young infants the catheter may be situated in the descending aorta via patent ductus arteriosus (Figure 4).
The above guide wire is removed while leaving the catheter in place. Then, a 0.014-in to 0.035-in, J-tipped, exchange-length, extra-stiff guide wire is passed through the catheter and the catheter is removed. The selection of the wire diameter is entirely dependent upon the selected balloon valvuloplasty catheter. If the size of the sheath already in the femoral vein does not house the chosen balloon dilatation catheter, the sheath is up-sized to the correct size at this juncture.

The chosen balloon valvuloplasty catheter (see the next few sections for balloon catheter selection) is advanced over the guide wire, but within the sheath and placed across the pulmonary valve (Figures $3 \mathrm{~A}$ and $4 \mathrm{~A}$ ). A frozen video frame of the right ventricular cineangiogram is displayed on 
the screen and the bony landmarks, namely, ribs, sternum, or other fixed land marks are used to verify the position of the balloon catheter.

Sometimes it may not be possible to place an appropriate-sized balloon dilatation catheter across a markedly narrowed pulmonary valve, particularly in newborn infants. In those occasions, a smaller, 3-6 mm diameter balloon catheters may used first to predilate, then go with a larger, more appropriate-sized balloon catheters (Figure 5).

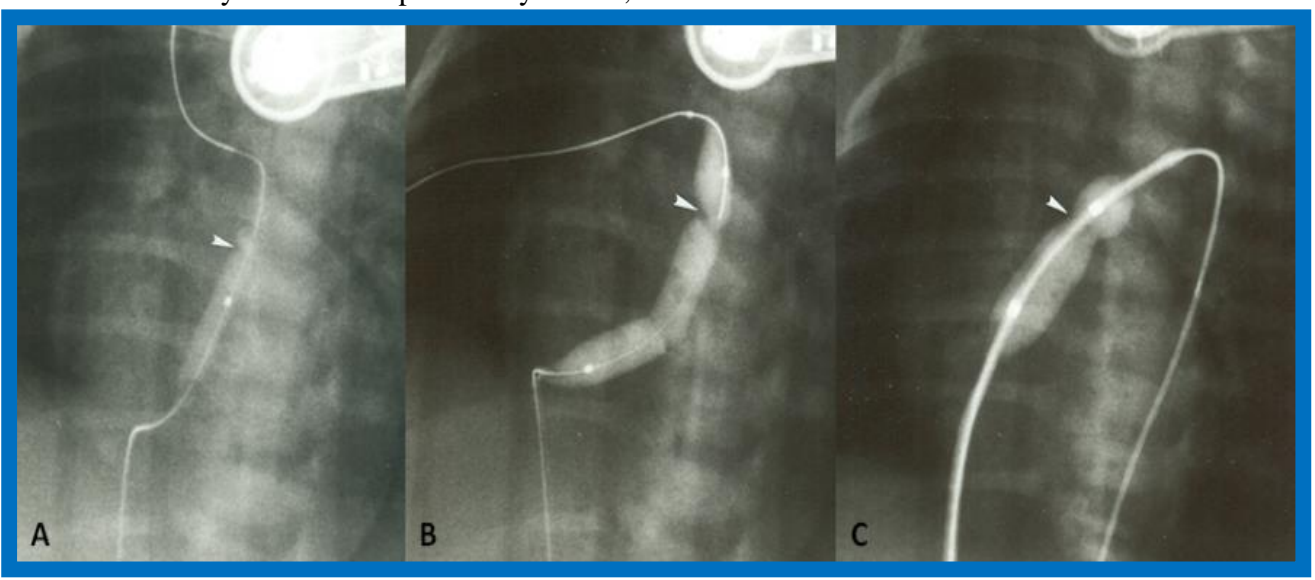

Figure 5. Selected cineflorographic frames in a sitting-up view demonstrating the use of progressively larger balloons in a one-day-old baby with critical pulmonary stenosis. A coronary guide wire was positioned across the pulmonary valve and a 3.5- $F$ catheter carrying a 4 mm diameter balloon was used to dilate the pulmonary valve (A); this is followed by $6 \mathrm{~mm}(B)$ and $8 \mathrm{~mm}(C)$ diameter balloons. The waisting of the balloons in the initial phases of balloon dilatation is shown. Further inflation of the balloons resulted in the abolition of the waiting (not shown). Reproduced from Rao PS, Neonatology Today 2007; 2(10):1-12 [43].

The balloon is inflated with contrast material, diluted 1 in 4 , while monitoring the pressure of balloon inflation; any of the commercially available inflators may be used. The pressure of inflation is gradually increased to the maximum of manufacturer-recommended inflation pressure or until disappearance of the balloon waisting (Figures $3 \mathrm{~B}$ and 4B). If the balloon is not correctly centered across the pulmonary valve, the catheter is repositioned and balloon re-inflated. I usually perform one additional balloon inflation after satisfactory balloon inflation is achieved.

\section{Balloon Dilatation Catheters}

Several types of balloon catheters were used in the past; these were reviewed elsewhere [8]. At present, most cardiologists, including our group, use Tyshak II balloon dilatation catheters for BPV because they have low profile, permitting their passage through small sheaths and easily track over the guide wire. The Inoue balloon was used in adult subject with good results [44]. The chief advantage of the Inoue balloon compared with conventional balloon catheters is that that balloon diameter is adjustable allowing stepwise dilation possible.

\section{Balloon Diameter}

The original suggestion was to utilize a balloon diameter 1.2 to 1.4 times the pulmonary valve annulus; these recommendations were devised on the basis of immediate [45] and immediate plus follow-up [19,20,46] results. Large balloons ( $\geq 1.5$ times the pulmonary valve annulus) are likely damage to right ventricular out flow tract [47] and therefore, should not be used. In addition, such large balloon have no benefit over and above that offered by balloons with B/A ratio of 1.2 to $1.4[20,46]$.

The recommendations of using balloons 1.2 to 1.4 time the valve annulus have generally been followed by most cardiologists performing BPV. However, more recent observations of pulmonary insufficiency at late follow-up [22,23,29,48-50] brought forward concerns regarding the use of large balloons $[23,24,51,52]$. Based on thorough examination of all the available data $[23,24,51,52]$ it was recommended that we should attempt for a B/A ratio of 1.2 to 1.25 instead of the previously recommended 1.2 to $1.4[19,20,45,46]$. Such smaller balloons will probably result in good relief of pulmonary valve stenosis whilst at the same time may thwart development of significant PI at late follow-up.

In children with dysplastic pulmonary valves, balloons as large as $150 \%$ (B/A ratio of 1.5) of pulmonary valve annulus [34] may be necessary to produce adequate relief of obstruction. High pressure balloons [53] may also increase the effectiveness of balloon valvuloplasty in patients with dysplastic pulmonary valves.

\section{Balloon Length}

The length of the balloon used is largely dependent on the size of the patient; $20 \mathrm{~mm}$-long balloons in neonates and infants, $30 \mathrm{~mm}$-long balloons in children and $40 \mathrm{~mm}$ - or $50 \mathrm{~mm}$-long balloons in adolescents and adults are generally recommended. However, no data exist either from the literature or from our own series to evaluate whether one balloon length is better than the other in producing successful relief of PS. Shorter balloons tend to slip and may not center across the pulmonary valve during balloon inflation. Long balloons tend to impinge on the tricuspid valve, producing tricuspid insufficiency [54] or on the conduction system, resulting in heart block [55]. Consequently, use of 20, 30 and 40/50 mmlong balloons for neonates and infants, children and adolescents and adults, respectively appears appropriate.

\section{Number of Balloons}

Prior to the availability of large diameter balloons, two balloons placed across the pulmonary valve (Figure 6) were used if the pulmonary valve annulus is too large to dilate with a single balloon. When two balloons are utilized in such situations, the formula listed below may be used to calculate the effective balloon size [56]:

$$
\mathrm{D}_{1}+\mathrm{D}_{2}+\Pi\left(\mathrm{D}_{1} / 2+\mathrm{D}_{2} / 2\right)
$$

\section{$\Pi$}

Where, $\mathrm{D}_{1}$ and $\mathrm{D}_{2}$ are diameters of the balloons used.

This formula was simplified to $0.82\left(\mathrm{D}_{1}+\mathrm{D}_{2}\right)$ by Narang et al [57]. 


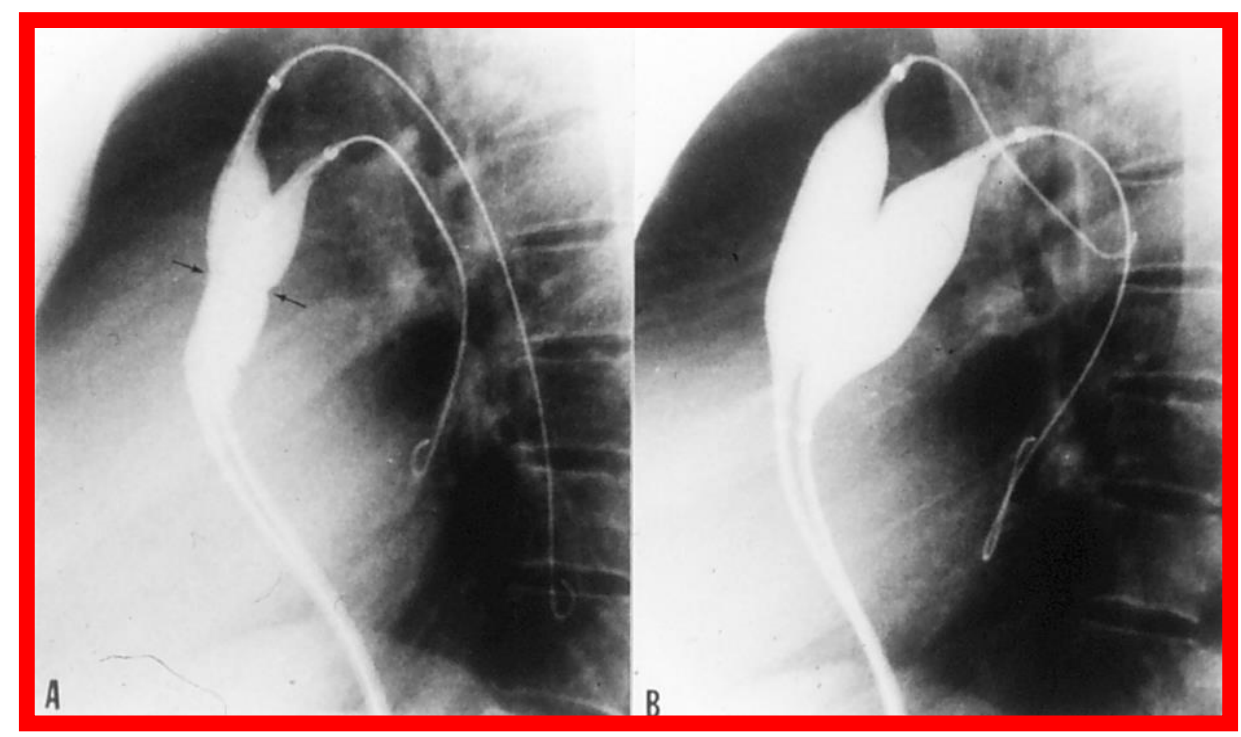

Figure 6. Selected cine-radiographic frames in lateral view, demonstrating two balloon catheters placed across the pulmonary valve, showing "waisting" of the balloons (arrows) during the initial phases of balloon inflation (A), which was completely abolished after the complete inflation of the balloons (B). Reproduced from Rao PS (ed), Transcatheter Therapy in Pediatric Cardiology. Wiley-Liss, Inc., New York, 1993:59-104 [4].from Reference 4.

Use of double balloon technique in place of single balloon for pulmonary valvuloplasty was advocated by some interventionalists [58], especially for adult subjects. We compared the results of single balloon with double balloon valvuloplasty techniques [56] and found that the results of double balloon valvuloplasty are good and similar to, but not better than those seen with single balloon valvuloplasty (Figures 7, 8 \& 9), provided B/A annulus ratios are equivalent $[56,59]$. Additionally, the double balloon technique does indeed lengthen the BPV procedure and requires a second femoral venous access. Furthermore, large diameter balloon catheters are currently available and make the use of single balloon instead of two balloons possible. Nonetheless, the double balloon method may be more helpful in sustaining stable balloon position across the pulmonary valve in some adolescents and adults.

\section{DATA PRIOR TO BALLOON DILATION}

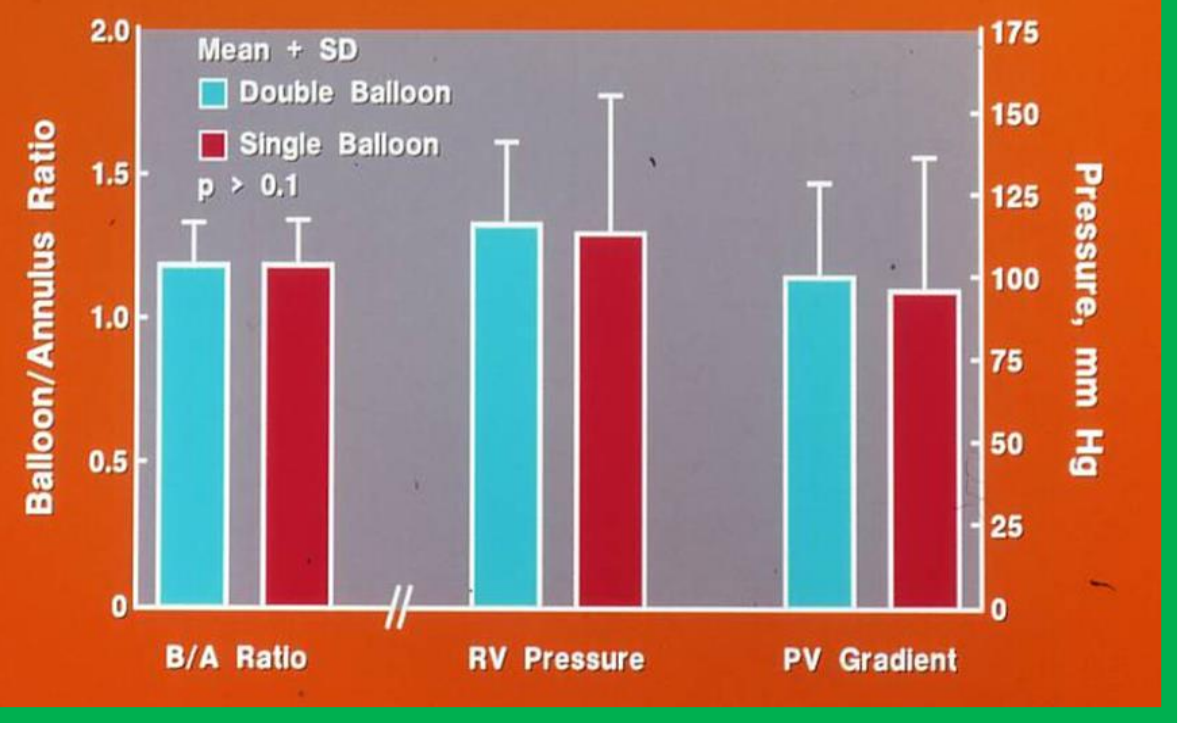

Figure 7. Bar graph demonstrating that the balloon/annulus (B/A) ratios (left panel), right ventricular (RV) peak systolic pressures (middle panel) and pulmonary valve (PV) peak-to-peak systolic pressure gradients (right panel) in the group with double balloons (light blue bars) are similar ( $p>$

$0.1)$ to those of the group with single balloons (red bars) prior to balloon pulmonary valvuloplasty. The mean and standard deviation (SD) are

shown. These data indicate that the severity of pulmonary valve stenosis was similar in both groups. Modified from Rao PS, Fawzy ME, J Interventional Cardiol 1988; 1:257-62 [56]. 


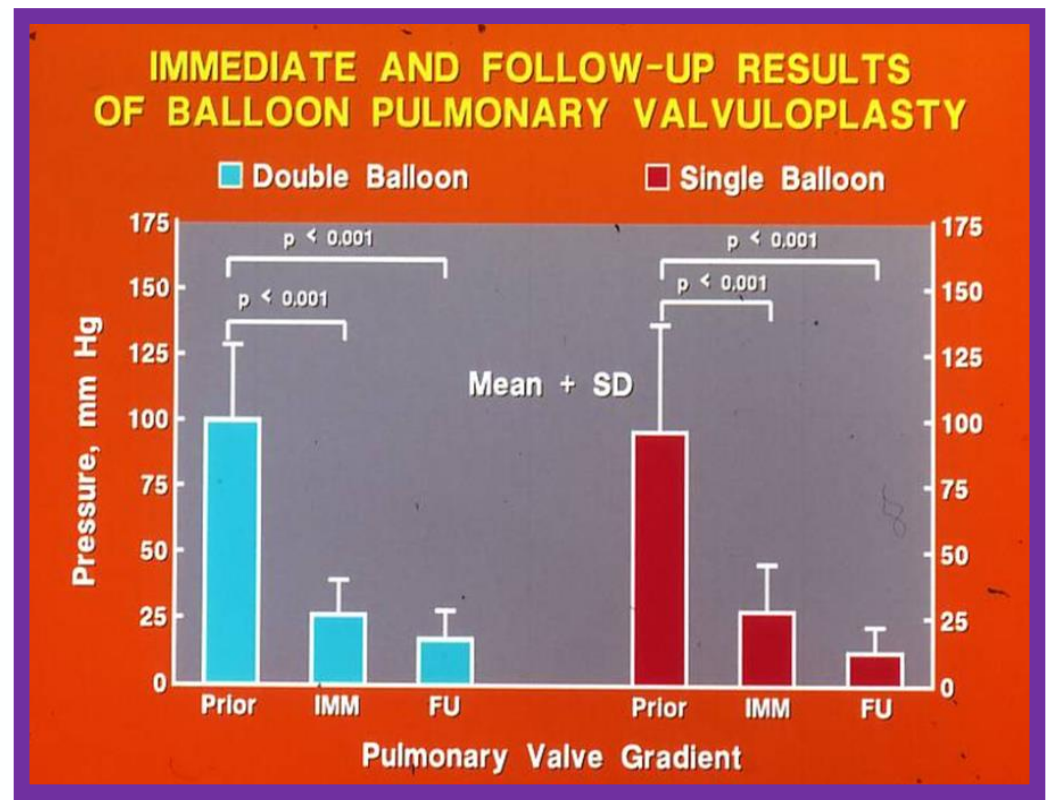

Figure 8. Bar graph illustrating the immediate (IMM) and follow-up (FU) results of balloon pulmonary valvuloplasty using double (left panel) (light blue bars) and single (right panel) (red bars) balloon techniques with equivalent-sized balloon/annulus ratios (Figure 10-40, left panel). Note the significant $(p<0.001)$ decrease in pulmonary valve gradients both immediately after balloon valvuloplasty and at follow-up in both groups. The degree of reduction is similar ( $p>0.1)$ in both groups. The mean and standard deviation (SD) are shown. Prior, prior to balloon valvuloplasty. Modified from Rao PS, Fawzy ME, J Interventional Cardiol 1988; 1:257-62 [56].

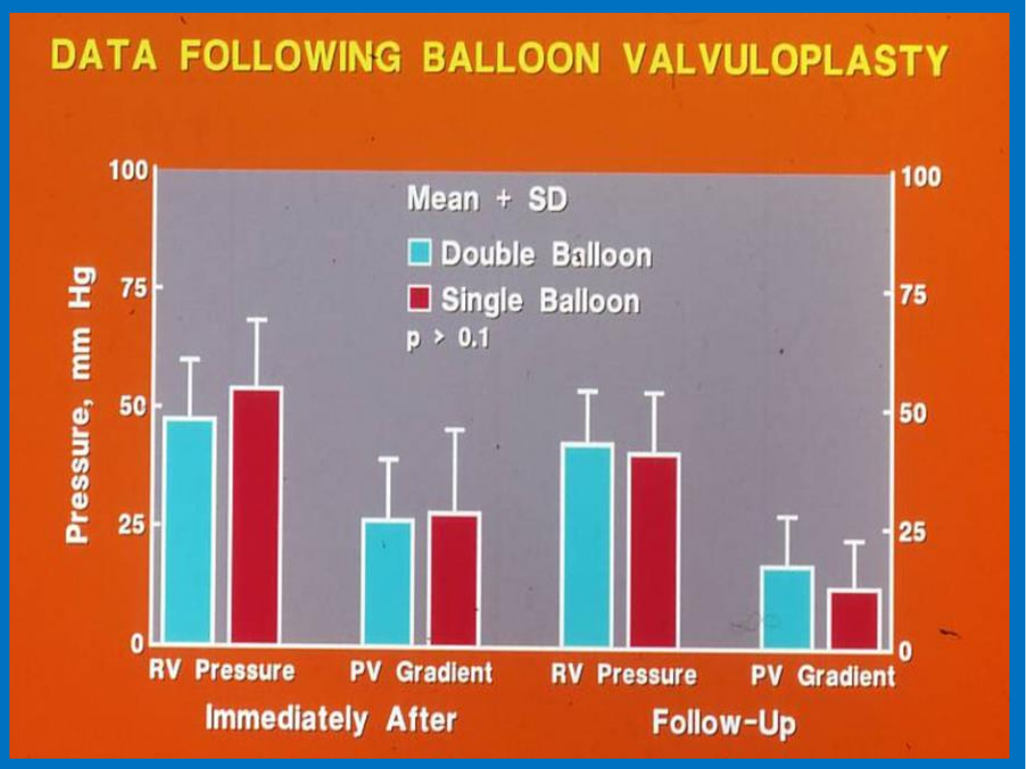

Figure 9. Bar graph demonstrating the right ventricular $(R V)$ peak systolic pressure and pulmonary valve (PV) gradients immediately (left panel) and at follow-up (right panel) after balloon pulmonary valvuloplasty with double (light blue bars) and single (red bars) balloon techniques with equivalent-sized balloon/annulus ratios. No significant difference $(p>0.1)$ between the double and single balloon techniques was seen. The mean and standard deviation (SD) are shown. Modified from Rao PS, Fawzy ME, J Interventional Cardiol 1988; 1:257-62 [56].

\section{Maintaining the Position of the Balloon across the Pulmonary Valve during Balloon Inflation}

At times it may not be possible to maintain the position of the balloon across the pulmonary valve during balloon inflation. Utilizing appropriate length of the balloon depending upon the age of the patient (as mentioned in a preceding paragraph) and holding the balloon catheter tight to curtail its movement is expected to circumvent this problem. Double balloon technique, especially in adolescents and adults may be useful. Use Adenosine [60] or rapid right ventricular pacing [61] to induce transient cardiac standstill, thus achieve stable position of the balloon during valvuloplasty have been advocated and such techniques may be used at the discretion of the cardiologist performing the procedure. However, we have not found these techniques necessary for PS, although they may be useful for balloon aortic valvuloplasty [62]. Inoue balloon catheters [44], because of their configuration may help hold the balloon across the valve during valvuloplasty. Nucleus balloon (NuMed) with a "barbell" configuration and hourglass-shaped V8 aortic valvuloplasty balloons (Venus Medtech) may also help keep the balloon across the pulmonary 
valve. However, these balloon catheter are bulky and their usefulness has not been validated.

\section{Pressure, Number and Duration of Balloon Inflation}

Balloon inflation pressure (2.0 to $8.5 \mathrm{~atm}$ ) used, number of balloon inflations (one to four) employed and duration balloon inflation (5 to 60 seconds) are diverse and differed from one study to the other. However, there are no data to support use one parameter over the other. We have scrutinized these parameters from our study subjects [42,59]. The balloon inflation characteristics of the patients with good results were compared with those of poor results. No significant differences were detected indicating that the results of valvuloplasty are not linked to the above mentioned balloon inflation characteristics. We have also analyzed these data [42,59] with random cutoffs of maximum pressure, number of balloon inflations and duration of balloon inflation and found that higher pressure, larger number of inflations and longer duration of balloon inflation did not positively influence residual gradients at follow-up, especially when the effect of B/A ratio is accounted for. Based on these and other considerations, I suggest that balloon inflation at or below the level of balloon burst pressure stated by the balloon catheter manufacturer and continue balloon inflation until the waisting of the balloon abolished (Figures 3B, 4B and 6B). The duration of balloon inflation should be as short as possible, usually just until after the waist disappears. Shorter balloon inflation cycles produce less hypotension and more rapid return of aortic pressures towards normal. We generally perform one additional balloon inflation following disappearance of waisting, to ensure satisfactory valvuloplasty.

\section{Post-Balloon Hemodynamic Evaluation and Follow-up}

After completion of BPV, pressure gradient across the pulmonary valve, simultaneous femoral artery and RV pressures, and pulmonary and femoral arterial oxygen saturations are recorded in an attempt to evaluate the result of the procedure. Either a Tuohy-Borst or a multi-Track catheter [63] may be used to measure the pulmonary valve pressure gradients. This would allow retaining the guide wire across the pulmonary valve in place should the result prove to be not satisfactory (peak-to-peak valvar gradient $\geq 30 \mathrm{mmHg}$ ). In such instances, a repeat balloon valvuloplasty may be performed with a larger balloon ( $2 \mathrm{~mm}$ larger than the initial balloon used). Then, the guide wire and catheter are withdrawn and right ventricular cineangiogram is performed with a Berman angiographic catheter positioned in the RV apex; this will help assess the mobility of the pulmonary valve leaflets, visualize the jet of contrast across the dilated pulmonary valve (Figures $1 \mathrm{~B}$ and $2 \mathrm{~B}$ ), detect infundibular stenosis and identify tricuspid insufficiency.

The patients are observed in an intermediate care setting until next morning while monitoring heart rate, pulse oximetry, blood pressure, pulses, and bleeding at the puncture site. An ECG and an echocardiogram are usually performed on the morning after the valvuloplasty. Clinical, ECG and echo-Doppler assessment is performed at 1, 6, and 12 months and 2 and 5 years after the procedure. We would also recommend followup every 5 years there afterwards, particularly to evaluate PI.

\section{Immediate Results}

Immediate results of BPV were presented by the author in the mid-1980s $[64,65]$ with subsequent publication of immediate results in larger groups of patients $[4,22,42,66]$. Reduction of peak-to-peak systolic pressure gradients across the pulmonary valve and right ventricular peak systolic pressures along with mild increase in pulmonary artery pressures occurred (Figures 10 and 11) after balloon dilatation without a change in the cardiac index. The jet width of contrast material across the PV become wider (Figures 1 and 2). The size of the right ventricle decreased (Figures 12 and 13). On post-balloon cine-angiographic and echocardiographic studies, excursion of the pulmonary valve leaflets appeared freer with less doming. Right-to-left shunt across the atrial septum, if present prior to balloon valvuloplasty, decreased, abolished or reversed (Figure 14). However, some children with very severe PS developed infundibular obstruction [68], some requiring beta-blocker therapy [68,69]. The issues related to development of infundibular obstruction will be discussed in a later section of this chapter. Surgery was avoided in most, if not all patients. All patients with the exception of neonates were discharged home within 24 to 48 hours after balloon valvuloplasty [4,22,42,64-66].

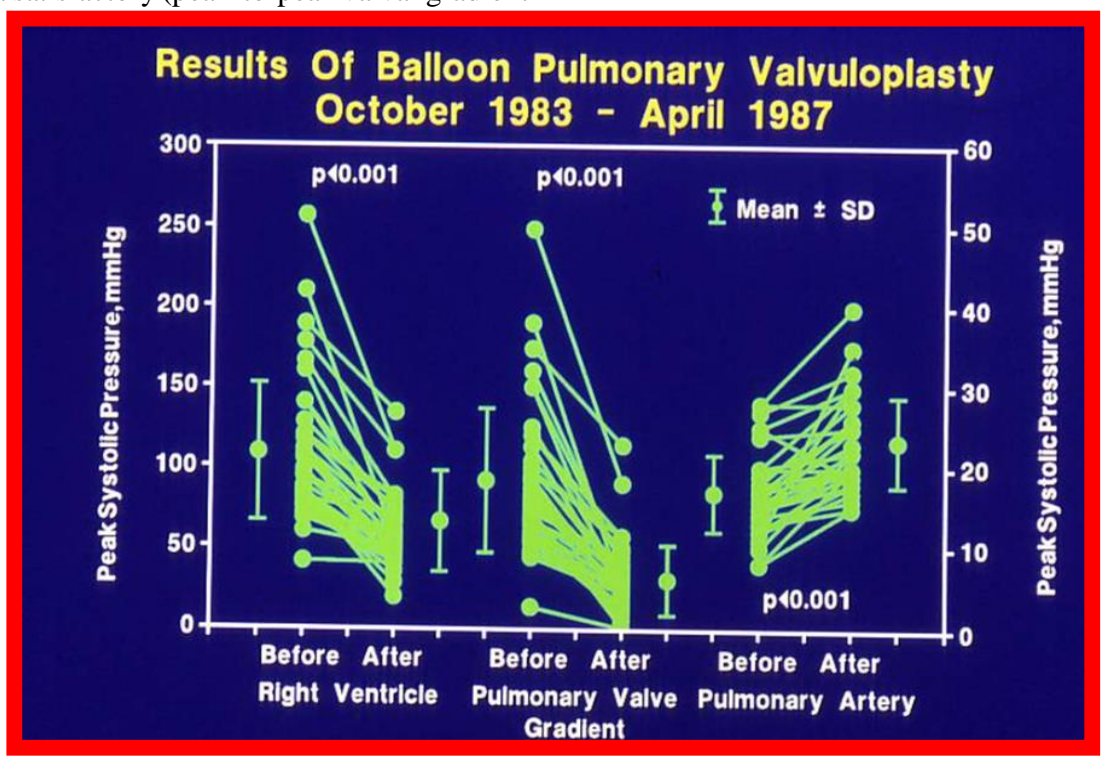

Figure 10. Line graph showing the immediate results of balloon pulmonary valvuloplasty. Note a significant (p $\mathcal{L} 0.001)$ decrease in the right ventricular peak systolic pressure (left panel) and the peak-to-peak systolic pressure gradient across the pulmonary valve (middle panel). Also shown is a slight but significant ( $p \quad \hat{L}$ 0.001) increase in the peak systolic pressure in the pulmonary artery (right panel). The mean \pm standard deviation (SD) are shown. Reproduced from Reference 8. 


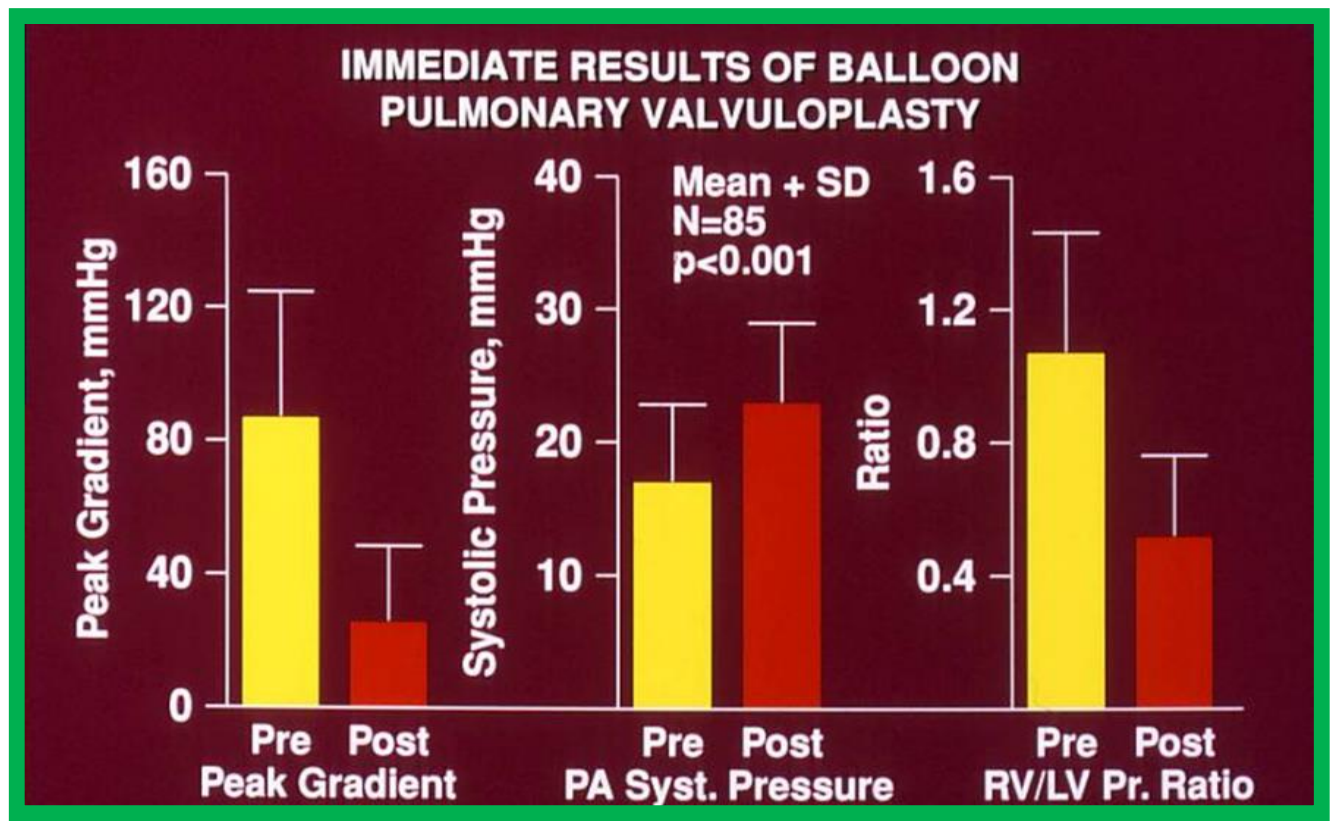

Figure 11. Bar graph showing the immediate results of balloon pulmonary valvuloplasty in 85 consecutive patients. Note a significant ( $p$ L 0.001$)$ decrease in the peak-to-peak systolic pressure gradient across the pulmonary valve (left panel), a significant (p $L$ L.001) increase in the peak systolic (syst) pressure in the pulmonary artery (PA) (middle panel) and a significant ( $p \quad L$ 0.001) decrease in the right ventricle (RV) to left ventricle (LV) systolic pressure (Pr.) ratio (right panel). The mean + standard deviation (SD) are shown. Pre, prior to balloon pulmonary valvuloplasty; Post, following balloon pulmonary valvuloplasty. Reproduced from Reference 67.

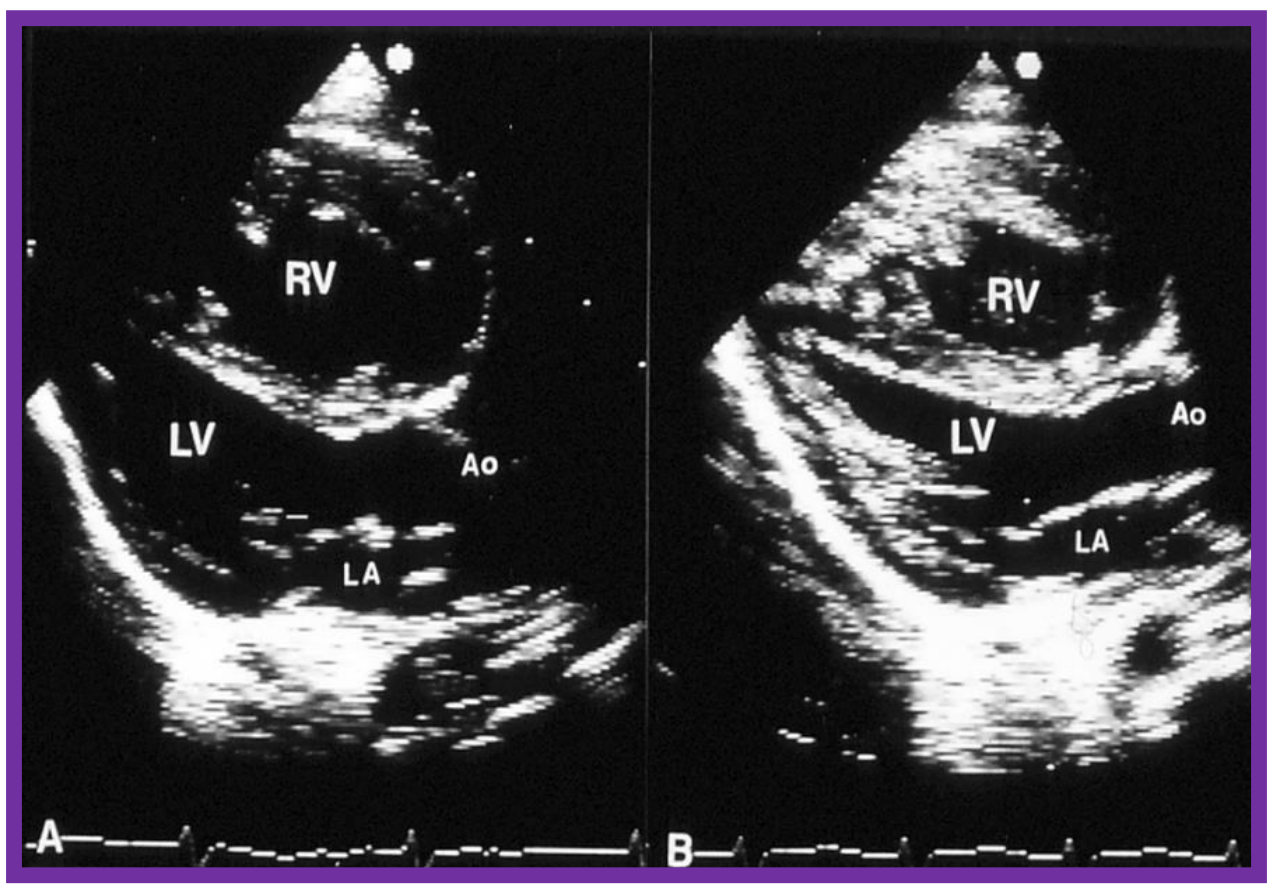

Figure 12. Selected video frames of two-dimensional images from parasternal long axis view prior to (A) and following (B) balloon pulmonary valvuloplasty, demonstrating a decrease in the size of the right ventricle (RV). Ao, aorta; LA, left atrium; LV, left ventricle. Reproduced from Reference 67. 


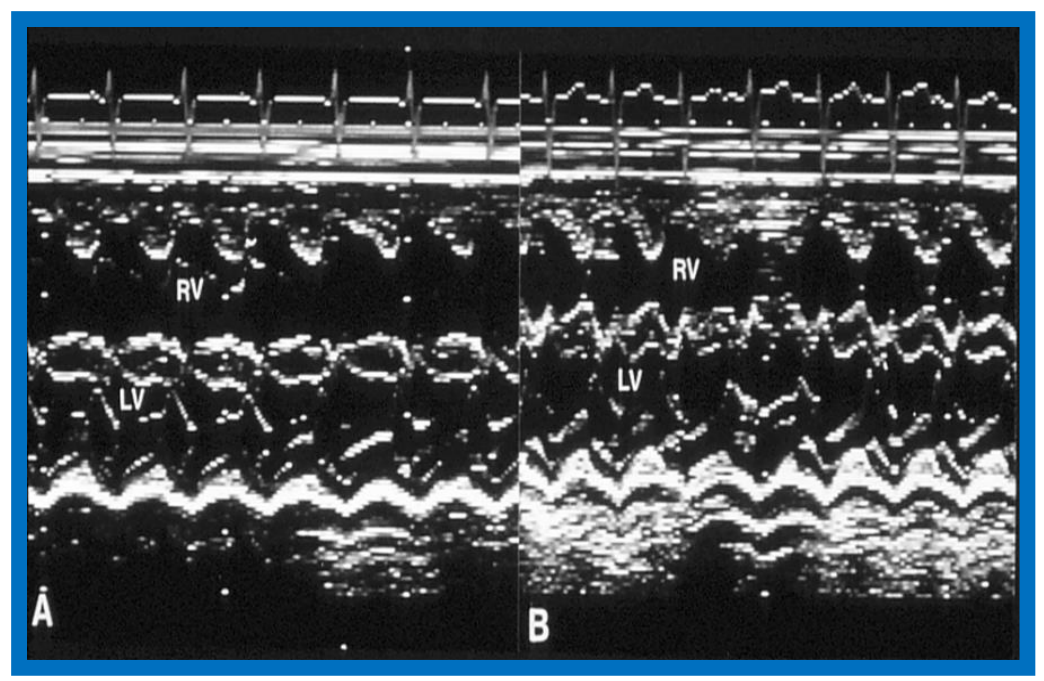

Figure 13. Selected m-mode tracings from parasternal long axis view prior to (A) and following (B) balloon pulmonary valvuloplasty, demonstrating a decrease in the size of the right ventricle $(R V)$. LV, left ventricle. Reproduced from Reference 67.

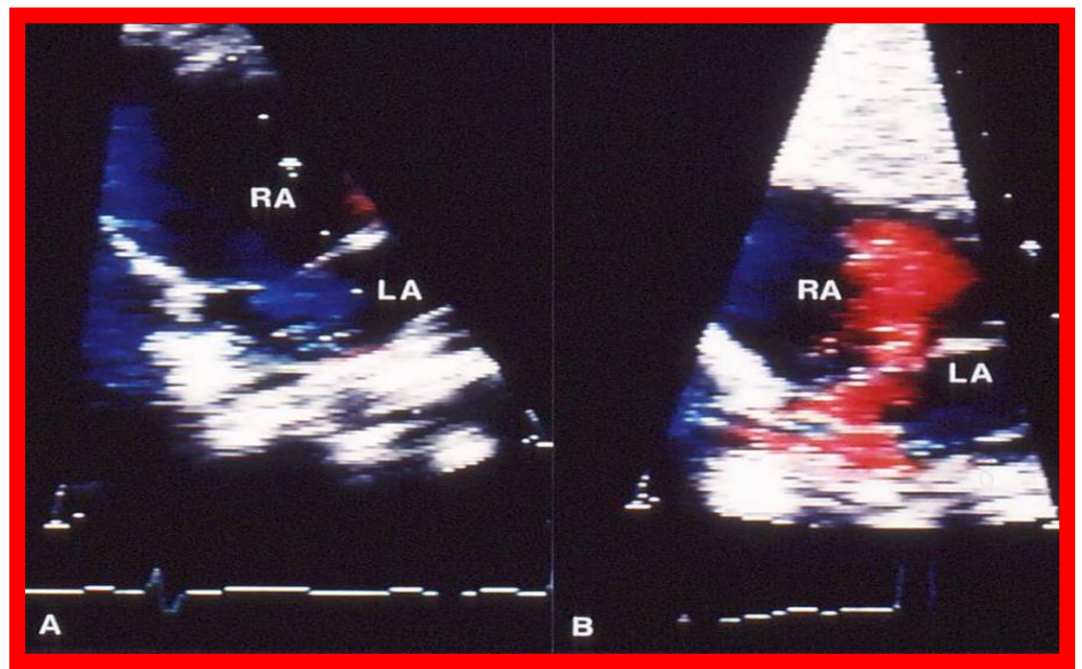

Figure 14. Selected video frames of the atrial septum, demonstrating a right-to-left shunt by color Doppler, across the patent foramen ovale prior to balloon pulmonary valvuloplasty (A) which has changed to a left-to-right shunt (B) 24 hours later. LA, left atrium; RA, right atrium. Reproduced from Reference 8.

\section{Acute Complications}

Complications related to balloon valvuloplasty have been extremely low. The Valvuloplasty and Angioplasty of Congenital Anomalies (VACA) registry reported results of $822 \mathrm{BPV}$ procedures performed at 26 institutions, representing initial experience at these centers [70]. The death rate was $0.24 \%$ with a major complication rate of $0.35 \%$ [70]. Since this is initial experience of the participating centers, the complication rate should become even lower with increasing experience.

Decrease in arterial pressure during balloon inflation, transient bradycardia and premature beats have been uniformly observed by most investigators. However, these abnormalities rapidly revert to normal once the balloon is deflated [67]. Hypotension may be less if a patent foramen ovale (PFO) is present [71]; probably related to right-to-left shunting across PFO filling the left ventricle. Double, bifoil or trefoil balloons have been advocated by some cardiologists to avoid the hypotension problem, but these catheters are bulky and do not truly have space to allow forward flow. The author recommends short periods of balloon inflation, which are likely to decrease the degree and duration of hypotension [67].

Blood loss, right bundle branch block, transient or permanent heart block, cerebrovascular accidents, loss of consciousness, cardiac arrest, convulsions, balloon rupture at high balloon inflation pressures, rupture of tricuspid valve papillary muscle, and pulmonary artery tears have been reported, though rare [4,70]. Meticulous attention to the technique, use of appropriate diameter and length of the balloon, avoiding high balloon inflation pressures and short inflation/deflation cycles may thwart or decrease the complications [4]. Infundibular obstruction [68,69] may also develop and will be reviewed in a later section of this paper.

Transient prolongation of the QTc interval [72,73] and premature ventricular contractions [74] after BPV have been reported, raising concerns for development of R-on- $\mathrm{T}$ phenomenon with resultant ventricular arrhythmia. Occasional instances of ventricular arrhythmia have been seen, but none of the patients in our large series [22] and many other studies were known to develop significant ventricular arrhythmia. 
However, it is prudent to monitor patients' ECG after balloon valvuloplasty.

\section{Intermediate-Term Follow-Up Results}

At intermediate-term (defined as six months to 2 years) follow-up, the pulmonary valve gradients remain improved compared to prevalvuloplasty values and are unchanged when compared immediate postvalvuloplasty gradients for the group as a whole. This reduction in the gradients was demonstrated by both catheterization-measured peak-topeak systolic pressure gradients (Figure 15) and Doppler-calculated peak instantaneous gradients (Figures 16 and 17) $[4,22,24,42,59,66]$. The size of the heart on a chest x-ray (Figure 18), right-to-left atrial shunt (Figure 14), right ventricular function, tricuspid insufficiency (Figure 19) and infundibular constriction (Figures 20 and 21) continued to improve during follow-up $[4,24,59,66,67]$.

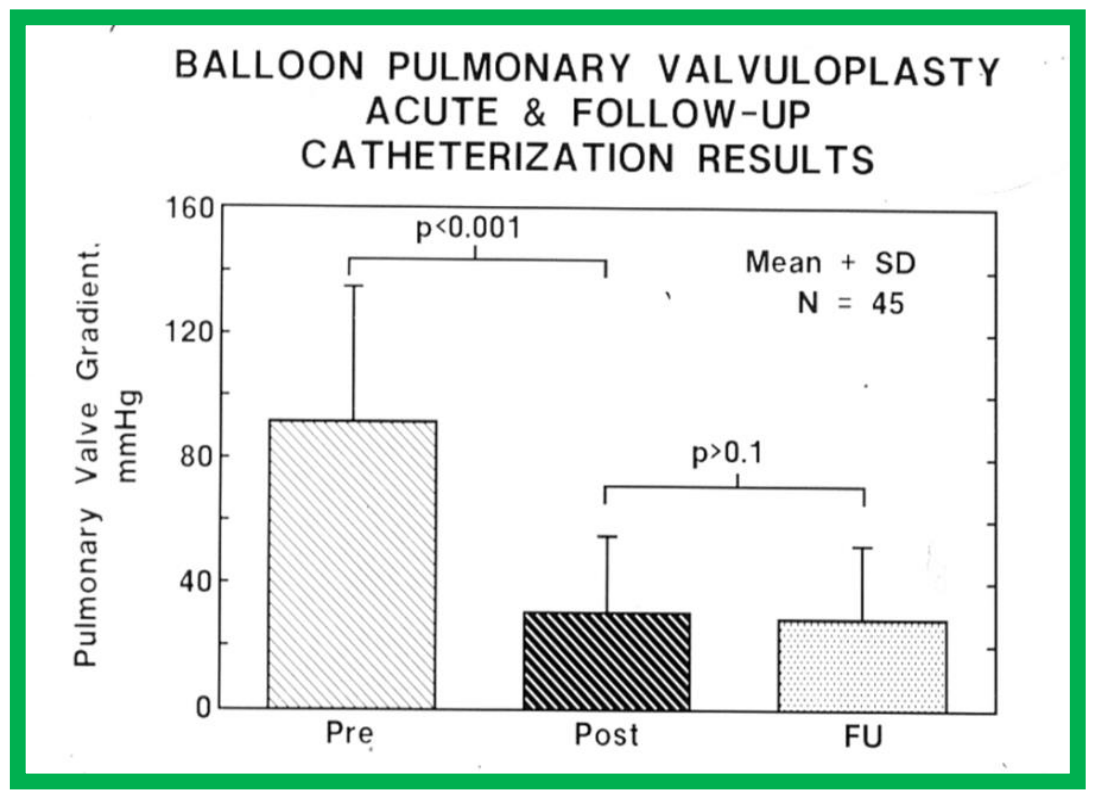

Figure 15. Bar graph showing the immediate and follow-up peak-to-peak pulmonary valve systolic pressure gradients in 45 unselected patients who underwent cardiac catheterization at a mean of 11 months following balloon pulmonary valvuloplasty. Note the significant (p $L$ 0.001) fall in the gradient immediately after (Pre vs. Post) balloon dilatation, which remained unchanged ( $p \Gamma 0.1)$ at follow-up (FU). N, number of patients. The mean + standard deviation (SD) are shown. Reproduced from Rao PS (ed), Transcatheter Therapy in Pediatric Cardiology. Wiley-Liss, Inc., New York, 1993:59-104 [4].

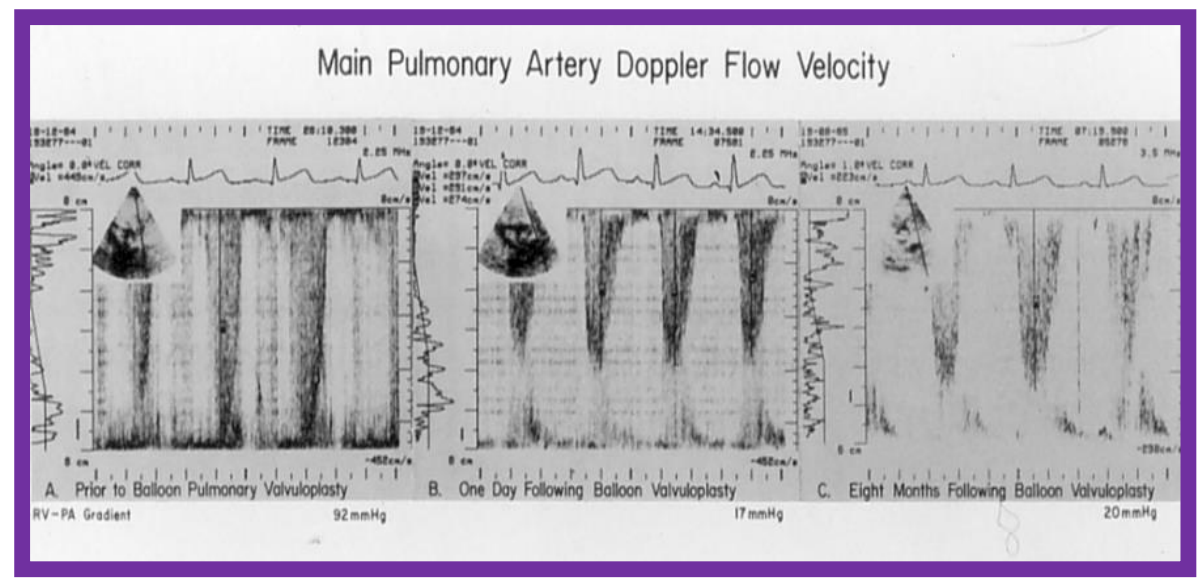

Figure 16. Doppler flow velocity recordings from the main pulmonary artery prior to $(A)$, one day (B) and eight months (C) after balloon pulmonary valvuloplasty are shown. Note that there was a remarkable decrease in the peak flow velocity and calculated gradient (92 $\mathrm{mmHg} v \mathrm{~s} .17 \mathrm{mmHg}$ ) one day after the procedure, and these remained low (20 mmHg) at follow-up. Reproduced from Rao PS, International J Cardiol 1987; 15:195-203 [75]. 


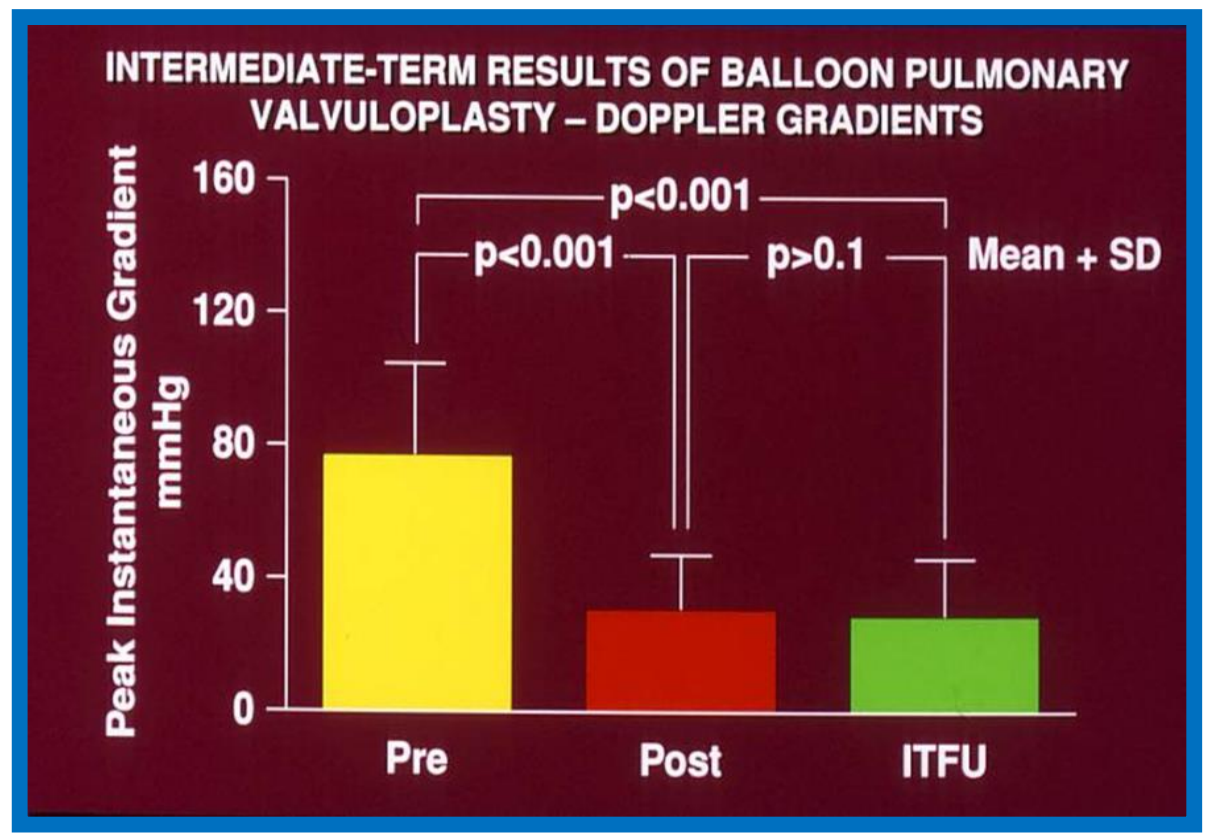

Figure 17. Bar graph demonstrating maximum peak instantaneous Doppler gradients prior to (Pre) and one day following (Post) balloon pulmonary valvuloplasty, and at intermediate-term follow-up (ITFU). Note the significant reduction ( $p$ L 0.001) after valvuloplasty which remains unchanged ( $p$ [ 0.1) at ITFU. The mean + standard deviation (SD) are shown. Modified from Rao PS et al., Heart 1998; 80:591-5 [22].

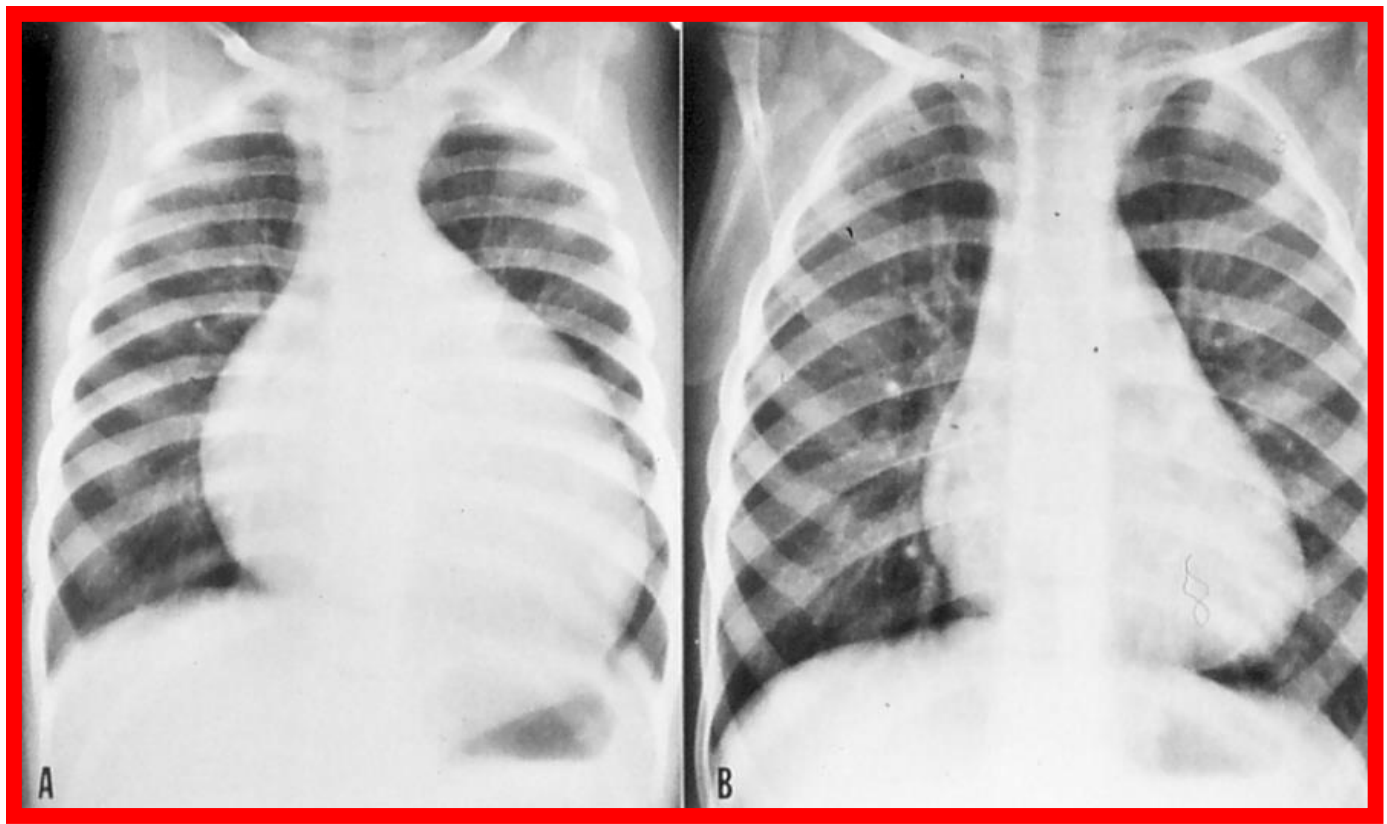

Figure 18. The size of the heart prior to $(A)$ and 1 year following $(B)$ balloon pulmonary valvuloplasty, demonstrating the decreased size of the heart at follow-up. Reproduced from Reference 67. 


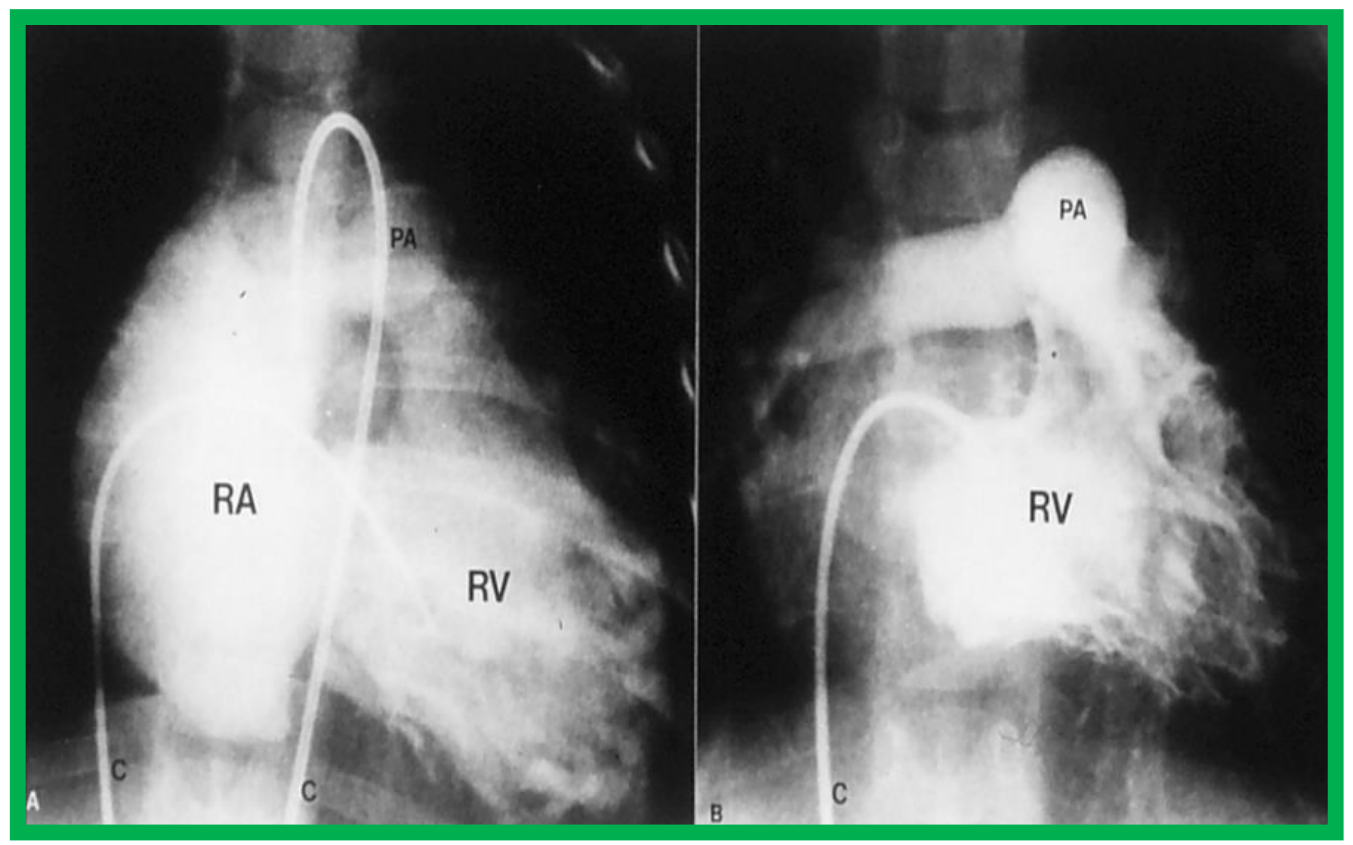

Figure 19. Right ventricular $(R V)$ cineangiographic frames prior to $(A)$ and 1 year following $(B)$ balloon pulmonary valvuloplasty, demonstrating the almost complete disappearance of tricuspid insufficiency. C, catheter; PA, pulmonary artery, RA, right atrium. Reproduced from Rao PS (ed), Transcatheter Therapy in Pediatric Cardiology. Wiley-Liss, Inc., New York, 1993:59-104 [4].

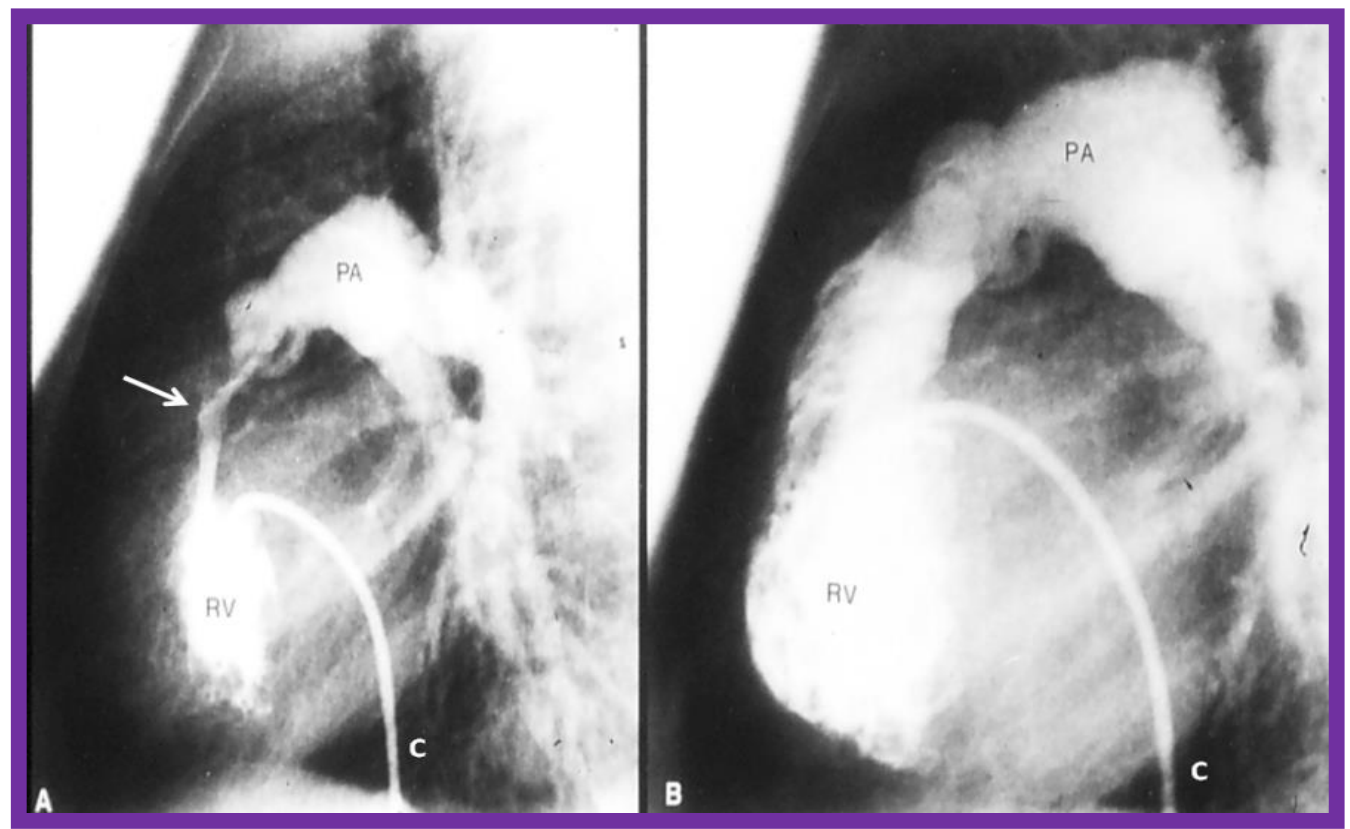

Figure 20. Selected cine frames from right ventricular $(R V)$ angiogram in lateral view, showing severe infundibular stenosis (arrow) (A) immediately after balloon pulmonary valvuloplasty. Note the wide-open right ventricular outflow tract (B) at cardiac catheterization 10 months after balloon valvuloplasty. The peak-to-peak pulmonary valvar pressure gradient at follow-up catheterization was 20 mmHg; there was no infundibular gradient. C, catheter; PA, pulmonary artery. Reproduced from Rao PS, International J Cardiol 1987; 15:195-203 [75]. 


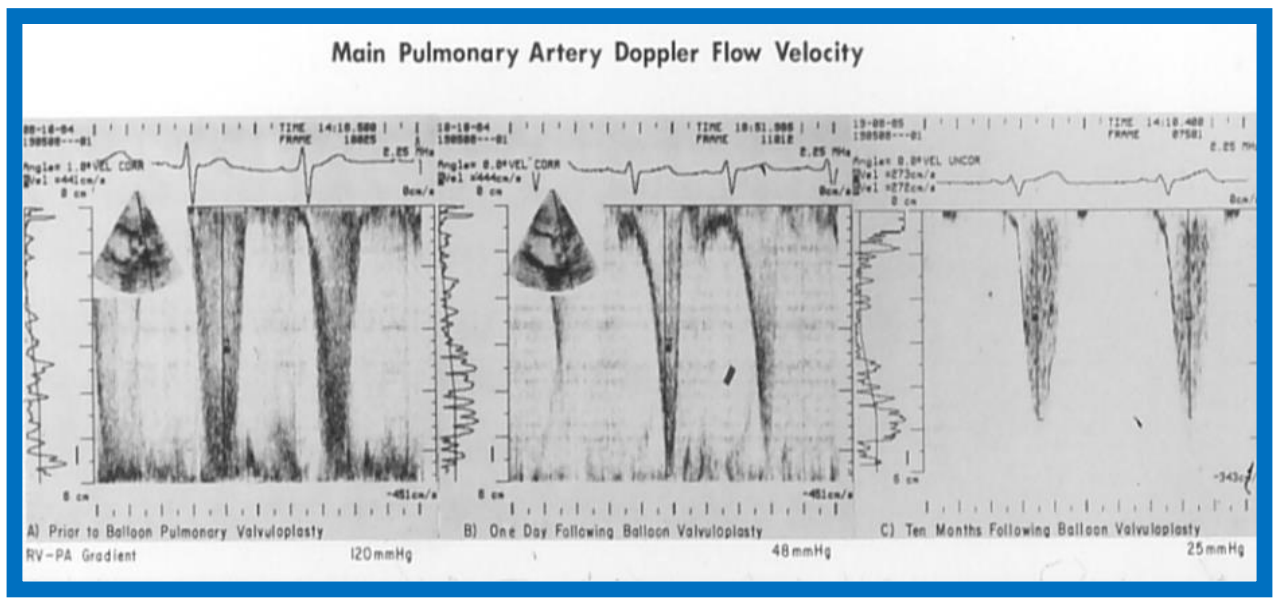

Figure 21. The main pulmonary artery Doppler flow velocities prior to $(A)$, and one day $(B)$ and ten months $(C)$ following balloon pulmonary valvuloplasty are shown. Note that there is a significant fall in the peak flow velocity immediately after valvuloplasty, but a moderate (48 mmHg) gradient that has a characteristic triangular pattern, highly suggestive of infundibular obstruction (corresponding to Figure 20A) persisted. At 10month follow-up, the flow velocity has markedly diminished, indicating the resolution of the infundibular obstruction (corresponding to Figure 20B). The residual calculated gradients are shown at the bottom of each panel. Reproduced from Rao PS, International J Cardiol 1987; 15:195-203 [75].

However, when results of each patient are separately reviewed, 8 to $10 \%$ patients developed restenosis (Figure 22) defined as gradient in excess of $50 \mathrm{~mm} \mathrm{Hg}[21,22]$. The causes of restenosis [21] will be reviewed in a subsequent section of this paper. Patients with restenosis have been successfully treated by repeat dilatation with balloons larger than those used at the time of initial balloon procedure [76]. However, if the reason for recurrence is pulmonary valve annular hypoplasia, pulmonary valve leaflet dysplasia, fixed infundibular obstruction (not controlled by betablocker therapy) or significant supravalvar pulmonary artery stenosis, surgical intervention is indicated. Improvement in atrial right-to-left shunting (Figure 14), right ventricular function and tricuspid insufficiency (Figure 19) continued during follow-up [22].

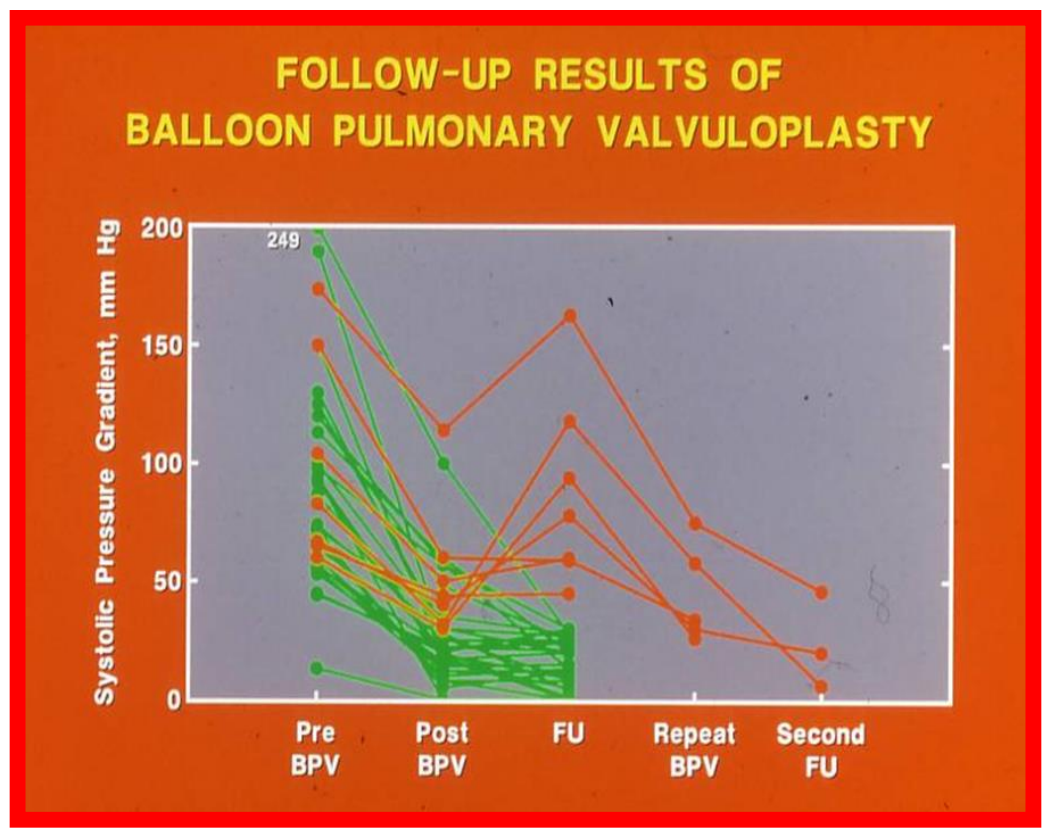

Figure 22. Line graph showing pulmonary valve gradients prior to (Pre) and immediately following (Post) balloon pulmonary valvuloplasty (BPV), and at follow-up (FU). The patients with good results are shown in green while those with poor results are shown in orange. Repeat BPV was performed in five patients; the gradients fell and remained low at the second FU. Modified from Rao PS, Clin Cardiol 1989; 12: 55-72 [59].

\section{Long-Term Follow-Up Results}

At long-term follow-up, the results of 80 patients who were monitored for three to ten years (median seven years) were scrutinized [22] and will be discussed under the following headings:

\section{Residual Gradients}

The long-term follow-up results of BPV are excellent, with very low (17 $\pm 12 \mathrm{mmHg}$ ) residual pulmonary valve gradients (Figure 23); these gradients were lower than the pre-valvuloplasty gradients $(\mathrm{p}<0.001)$ and the gradients seen at intermediate-term follow-up $(\mathrm{p}<0.01)$. 


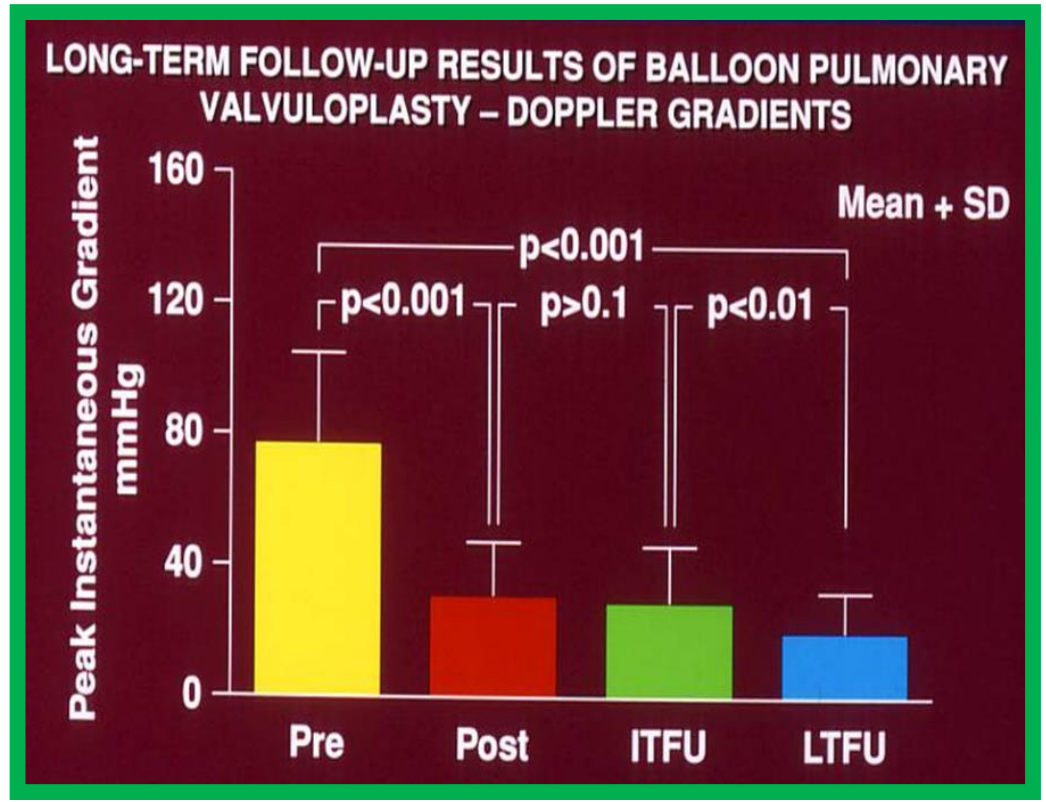

Figure 23. Bar graph demonstrating maximum peak instantaneous Doppler gradients prior to (Pre) and one day following (Post) balloon pulmonary valvuloplasty, and at intermediate-term (ITFU) and long-term (LTFU) follow-up. Note the significant reduction ( $p \quad \mathcal{L} 0.001)$ after valvuloplasty, which remains unchanged ( $p$ I 0.1) at ITFU. However, at LTFU there was a further fall $(p \quad L$ 0.001) in the Doppler gradients. The mean + standard deviation (SD) are shown. Modified from Rao PS, et al., Heart 1998; 80:591-5 [22].

\section{Re-interventions and Actuarial Event-Free Rates}

Four children had re-interventions during long-term follow-up, in addition to seven children requiring repeat balloon valvuloplasty to treat restenosis and two children requiring the resection of fixed infundibular obstruction during intermediate-term follow-up. These late re- interventions consisted of surgery to relieve supravalvar pulmonary artery stenosis $(\mathrm{N}=1)$ and infundibular pulmonary stenosis $(\mathrm{N}=1)$, and repeat balloon valvuloplasty to relieve recurrent valvar stenosis $(\mathrm{N}=2)$. The actuarial re-intervention-free rates were in the high and mid-80s at five and ten years, respectively (Figure 24) [22].

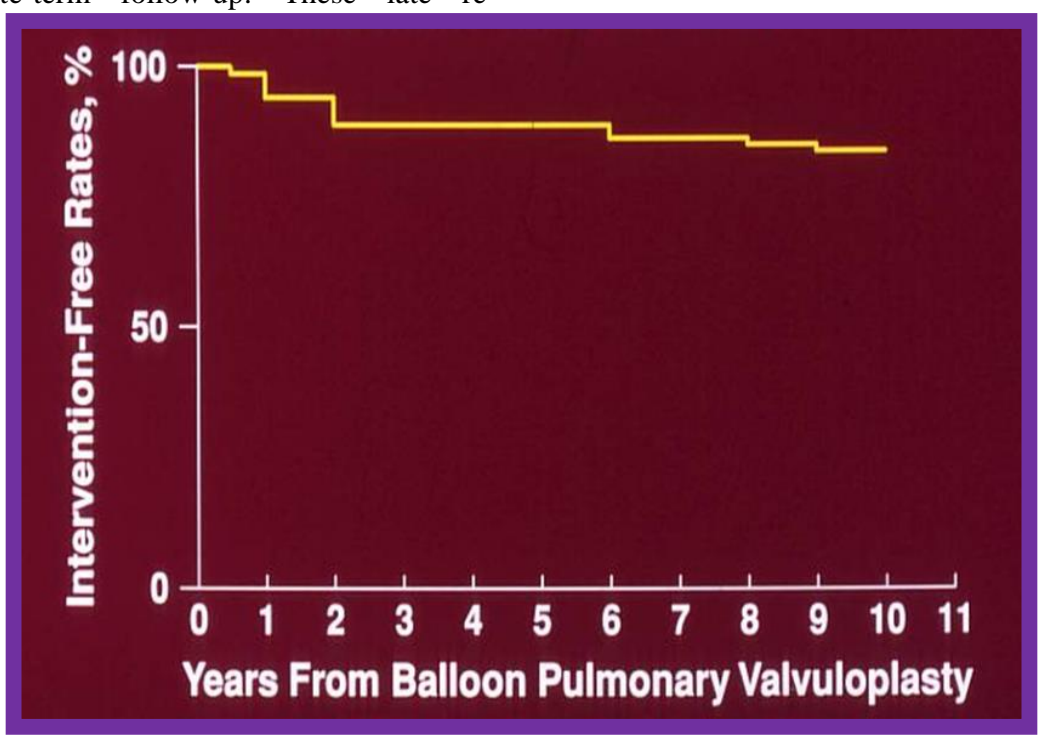

Figure 24. Actuarial event free rates after balloon pulmonary valvuloplasty. The re-intervention-free rates at one, two, five, and ten years after the procedure are 94\%, 89\%, 88\%, and 84\%, respectively. Modified from Rao PS, et al., Heart 1998; 80:591-5 [22].

\section{Ventricular Dimensions}

While there was a significant decrease $(\mathrm{p}<0.05)$ in the right ventricular end-diastolic dimension immediately following the balloon procedure, there was no further change $(\mathrm{p}>0.1)$ at intermediate and long-term follow-up (Figure 25) [22]. In addition, the RV dimension was within the normal values for the square root of the body surface area for the given age. The left ventricular end-diastolic dimension had increased $(\mathrm{p}<0.01)$ at long-term follow-up when compared with the pre-valvuloplasty values; this was thought to be due to the growth of the left ventricle, commensurate with the patient's increasing age. Furthermore, the left ventricular dimension was within the normal values for the square root of the body surface area for the given age [22]. 


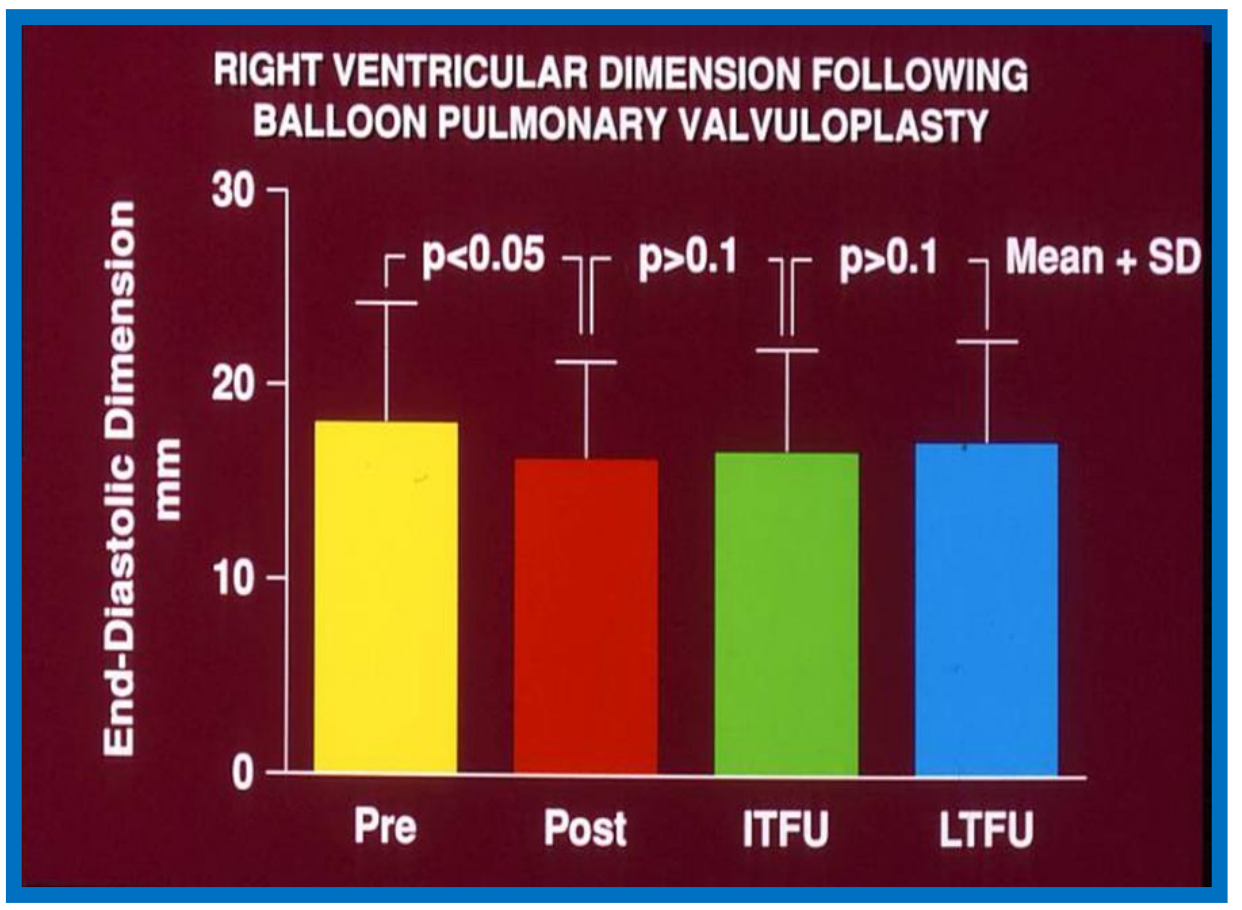

Figure 25. Bar graph showing the right ventricular end diastolic dimensions prior to (Pre) and one day after (Post) balloon pulmonary valvuloplasty, and at intermediate-term (ITFU) and at long-term (LTFU) follow up. There was a significant decrease ( $p<0.05)$ in right ventricular size immediately following the balloon procedure. There was no further change at ITFU and LTFU. A significant increase ( $p<0.05)$ in the incidence of flat septal motion was observed at LTFU (see Figure 10-19). No patient had paradoxical septal motion. The mean + standard deviation (SD) are shown. Reproduced from Rao PS, et al., Heart 1998; 80:591-5 [22].

\section{Pulmonary Insufficiency}

A grading system was developed to evaluate the degree of PI (see Table I) [22]. A gradual but significant $(\mathrm{p}<0.05$ to $\mathrm{p}<0.001)$ increase in the prevalence of PI was seen from pre-valvuloplasty to one day after BPV, and then throughout intermediate-term and long-term follow up (Figure 26). There was also an increase in the prevalence of flat septal motion (Figure 27) which may indicate the development of a right ventricular volume overload secondary to PI; however, no patient developed paradoxical septal motion.

\begin{tabular}{|l|l|}
\hline None & No pulmonary insufficiency on Doppler study \\
\hline Grade I & $\begin{array}{l}\text { Pulmonary insufficiency jet width* } \leq 10 \% \text { of pulmonary valve annulus diameter in parasternal short axis view. } \\
\text { No right ventricular volume overload.** }\end{array}$ \\
\hline Grade II & $\begin{array}{l}\text { Pulmonary insufficiency jet width } 10-25 \% \text { of pulmonary valve annulus diameter. } \\
\text { No right ventricular volume overload. }\end{array}$ \\
\hline Grade III & $\begin{array}{l}\text { Pulmonary insufficiency jet width } 26-50 \% \text { of pulmonary valve annulus diameter. } \\
\text { No right ventricular volume overload with or without flat septal motion. }\end{array}$ \\
\hline Grade IV & $\begin{array}{l}\text { Pulmonary insufficiency jet width }>50 \% \text { of pulmonary valve annulus diameter. } \\
\text { Right ventricular volume overload is present. }\end{array}$ \\
\hline
\end{tabular}

*Jet width was measured at the origin of the pulmonary insufficiency jet, rather than jet length. The jet width was used for grading because the jet width is not influenced by the pulmonary artery pressure.

$* *$ Right ventricular volume overload is defined as an enlarged right ventricle (> 95th percentile for age) and flat or paradoxical septal motion.

Reproduced from Rao PS, et al., Heart, 1998; 80:591-5 [22]. 


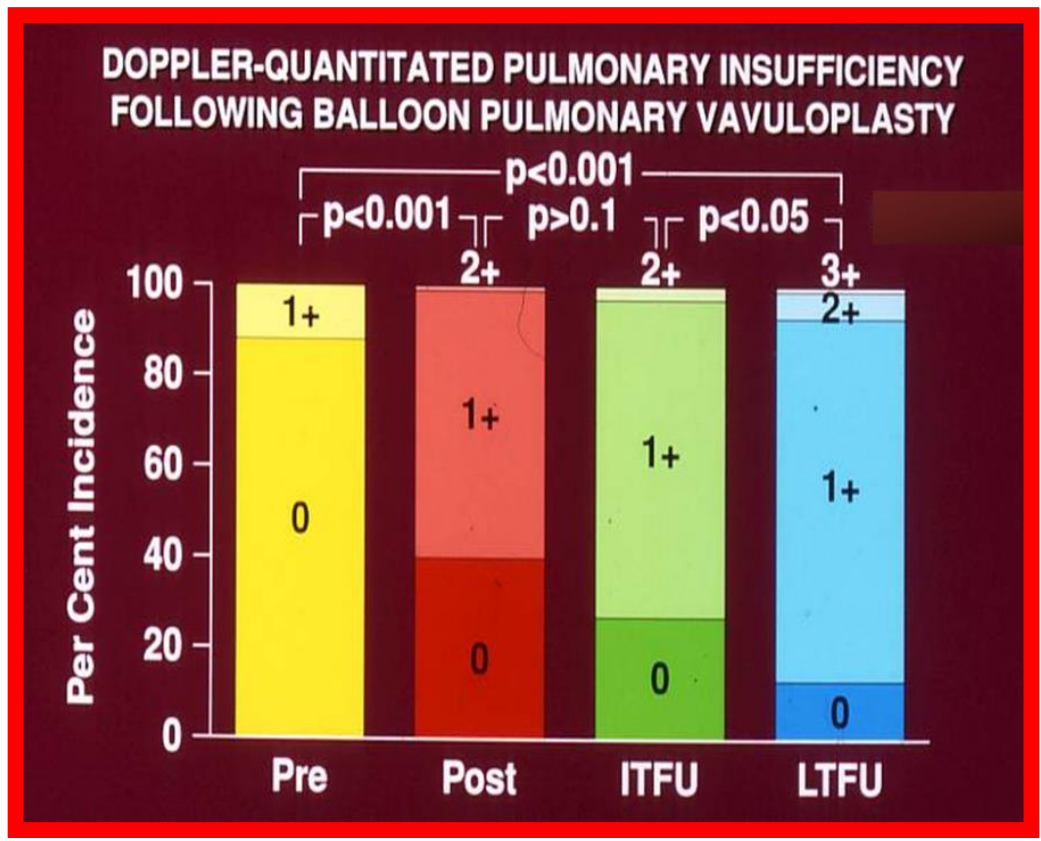

Figure 26. Bar graph showing Doppler graded pulmonary insufficiency (PI) prior to (Pre) and one day after (Post) balloon pulmonary valvuloplasty and at intermediate-term (ITFU) and long-term (LTFU) follow up. O, No PI; 1+, 2+, 3+, PI grade as per table above. A gradual but significant increase $(p<0.05$ to $p<0.001)$ in the incidence of PI is seen. Modified from Rao PS, et al., Heart 1998; 80:591-5 [22].

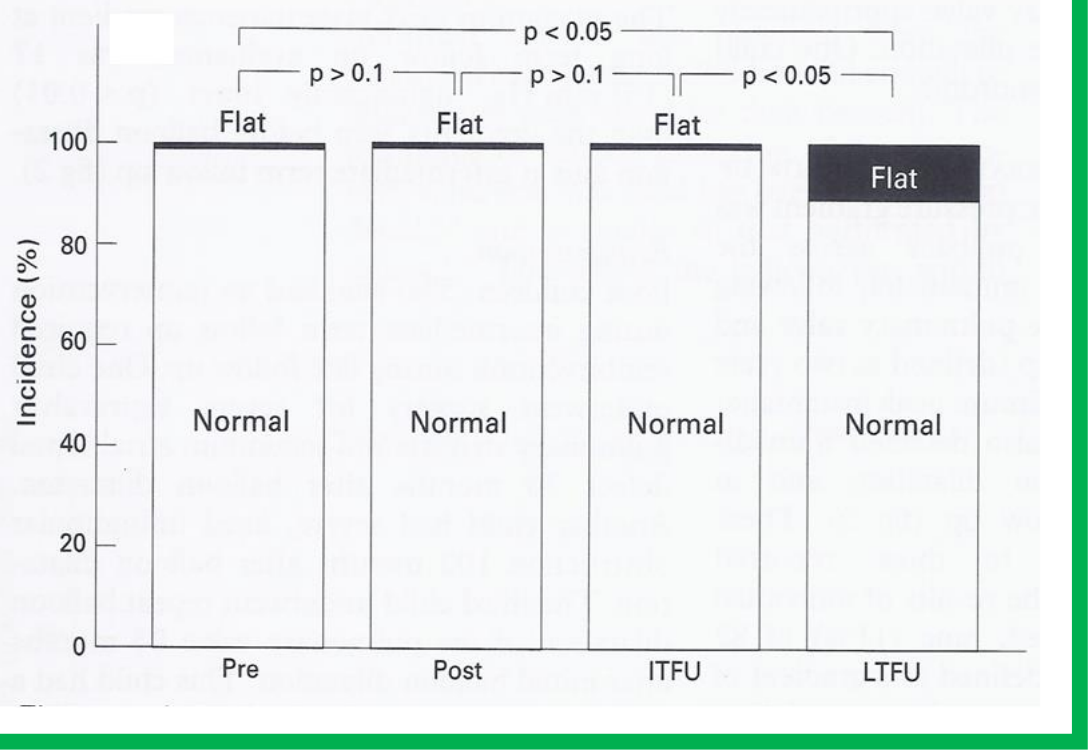

Figure 27. Bar graph showing the prevalence of inter-ventricular septal motion prior to (Pre) and one day after (Post) balloon pulmonary valvuloplasty, and at intermediate-term (ITFU) and long-term (LTFU) follow up. Note the significant increase ( $p<0.05)$ in the incidence of flat septal motion at LTFU. No patient was observed to have paradoxical septal motion. Reproduced from Rao PS, et al., Heart 1998; 80:591-5 [22].

\section{Summary of Long-term Results}

In summary, the long-term results of BPV are excellent, with an infrequent need for re-intervention, and this affirms that BPV is the treatment of choice in the management of valvar PS; however, our study raises concern regarding the development of PI at late follow-up [22].

\section{Complications at Long-Term Follow-Up}

The complications at long-term follow-up include femoral venous obstruction, pulmonary valve restenosis, and PI. Femoral venous obstruction may develop [5] and has been seen in 7 to $19 \%$ of the patients; such obstruction is more likely in small babies. Additional pulmonary valve obstruction is minimal beyond what was seen at mid-term followup [22]. If dysplastic valves without commissural fusion, supravalvar pulmonary artery stenosis or severe fixed infundibular obstruction are the reasons for recurrence, surgical intervention may be needed. PI has been observed during long-term follow-up [22,52] and will discussed in a later section of this paper. 


\section{Restenosis and Predictors of Restenosis}

As mentioned above, restenosis following BPV does occur (Figure 22). The causes of restenosis after balloon pulmonary valvuloplasty were investigated by scrutinizing the follow-up results of 36 children [21]. The study subjects were divided into two groups: Group I - 29 children who had good results with residual peak-to-peak systolic pressure gradients of less than $30 \mathrm{mmHg}$ at follow-up, and Group II - 7 children who had poor results with gradients $\geq 30 \mathrm{mmHg}$ at follow-up. In Group I, the peak-topeak pulmonary valve gradients decreased $(\mathrm{p}<0.001)$ from $90 \pm 48$ to 25 $\pm 19 \mathrm{mmHg}$ immediately following BPV, which diminished further to 16 $\pm 10 \mathrm{~mm} \mathrm{Hg}(\mathrm{p}<0.01)$ at follow-up (Figure 28, left panel). None of these patients required re-intervention. In Group II, the peak-to-peak systolic pressure gradients marginally decreased from $102 \pm 44$ to $52 \pm 30 \mathrm{mmHg}$ ( $\mathrm{p}>0.05$ ) which increased to $81 \pm 41 \mathrm{mmHg}$ at follow-up (Figure 28, right panel). Of these seven children, five had repeat balloon dilatation with significant $(p<0.01)$ reduction of the pulmonary valve gradients and the remaining two children (gradients of 45 and $60 \mathrm{mmHg}$ ) were clinically followed without re-intervention, as per the desire of the primary cardiologist. The gradient data of the individual patients were depicted in Figure 22.

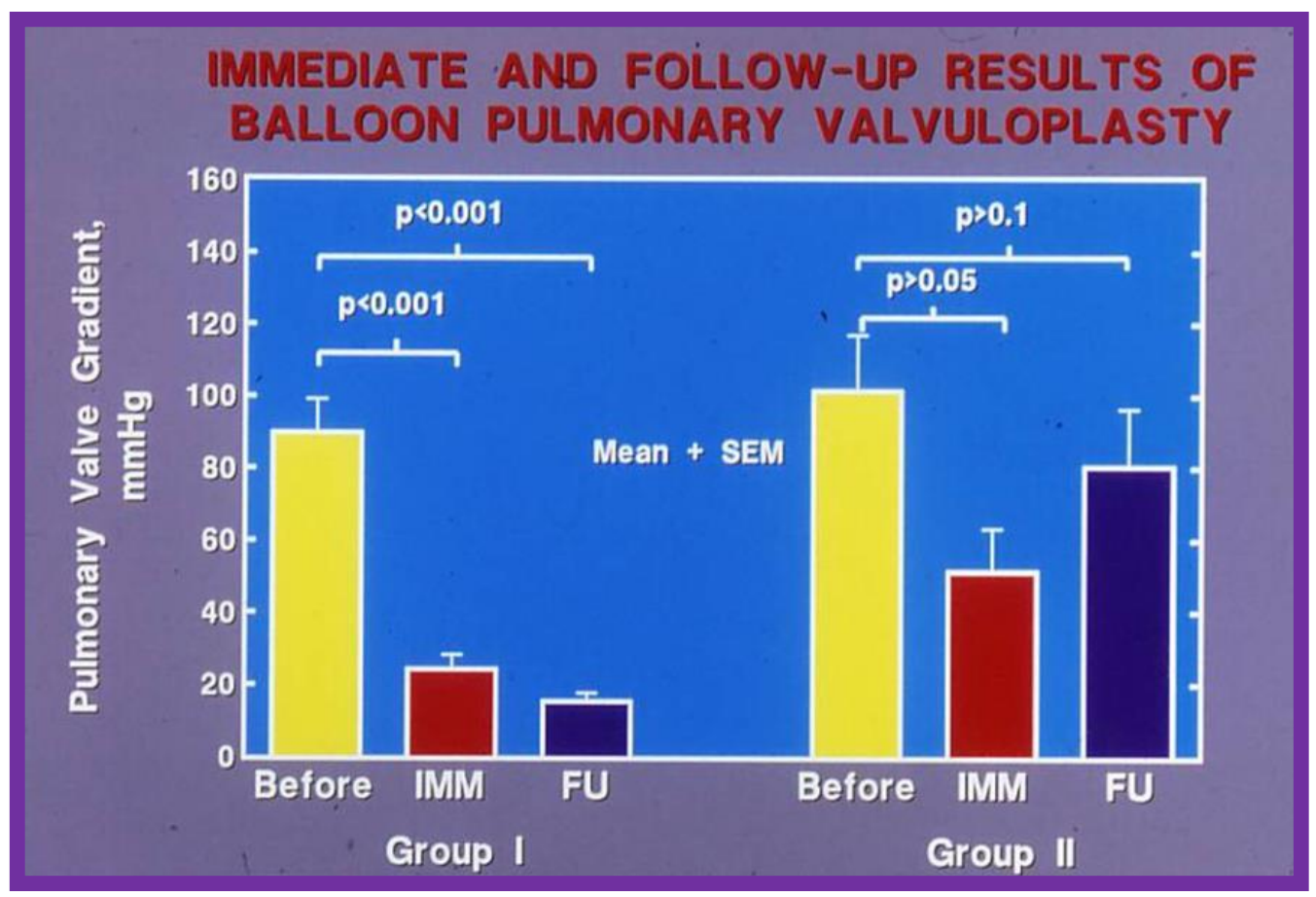

Figure 28. Bar graph showing the immediate (IMM) and follow-up (FU) results of balloon pulmonary valvuloplasty in Group I (with good results)

(left panel) and in Group II (with poor results) (right panel). In Group I, the pulmonary valve gradient decreased significantly ( $p<0.001)$

immediately after valvuloplasty and remained low ( $p<0.001)$ at follow-up. In Group II, the pulmonary valve gradient fell slightly $(p>0.05)$ immediately after valvuloplasty and returned to the pre-valvuloplasty values $(p>0.1)$ at follow-up. The mean + standard error of mean (SEM) are shown. Reproduced from Reference 8.

Fourteen sets of biographic, anatomic, physiologic, and technical data were examined by multivariate logistic regression analysis to identify the factors causing recurrence [21]. The age at valvuloplasty, duration of follow-up, frequencies of pulmonary valve dysplasia, valve annulus hypoplasia, infundibular PS, RV hypoplasia, RV peak systolic pressure, pulmonary valvar and infundibular systolic pressure gradients, the number of balloon inflations, balloon inflation pressure, and duration of balloon inflation were similar $(\mathrm{p}>0.1)$ between the two groups (for the interested reader, see Tables I, II and III of our publication [21]). However, stepwise logistic regression analysis identified two factors responsible for restenosis: 1 . A B/A ratio $<1.2$ and 2 . An immediate postvalvuloplasty pulmonary valve gradient $>30 \mathrm{mmHg}$. The relationship between the B/A ratio (Figure 29) and immediate post-valvuloplasty gradients (Figure 30) on the one hand and the recurrence at follow-up on the other is shown in Figures 29 and 30. The rate of restenosis decreases ( $\mathrm{p}=0.001$ to 0.002 ) as the $\mathrm{B} / \mathrm{A}$ ratio increases. With a $\mathrm{B} / \mathrm{A}$ ratio of $>1.2$, there were no recurrences (Figure 29). Immediate post-valvuloplasty peak-to-peak pulmonary valve gradients $\lceil 30 \mathrm{mmHg}$ are associated with a higher rate of recurrence $(\mathrm{p}=0.001)$ when compared with post-BPV gradients $<30 \mathrm{mmHg}$ (Figure 30 ). 


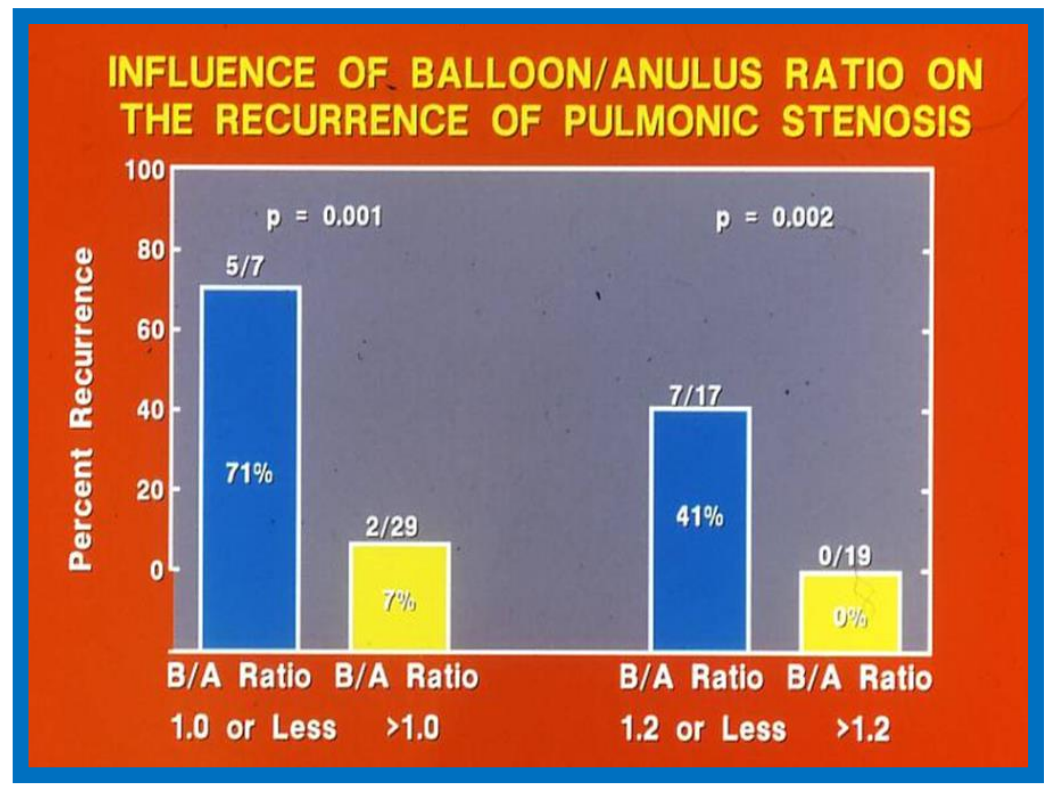

Figure 29. Bar graph demonstrating the influence of the balloon/annulus ratio (B/A) on rates of recurrence of pulmonary valve stenosis after balloon pulmonary valvuloplasty. Note that the rate of restenosis decreases as the balloon/annulus ratio increases $(p=0.001$ to 0.002$)$. Percentages are marked within the bars and actual numbers are shown on the top of each bar. Modified from Rao PS (ed), Transcatheter Therapy in Pediatric Cardiology. Wiley-Liss, Inc., New York, 1993:59-104 [4].

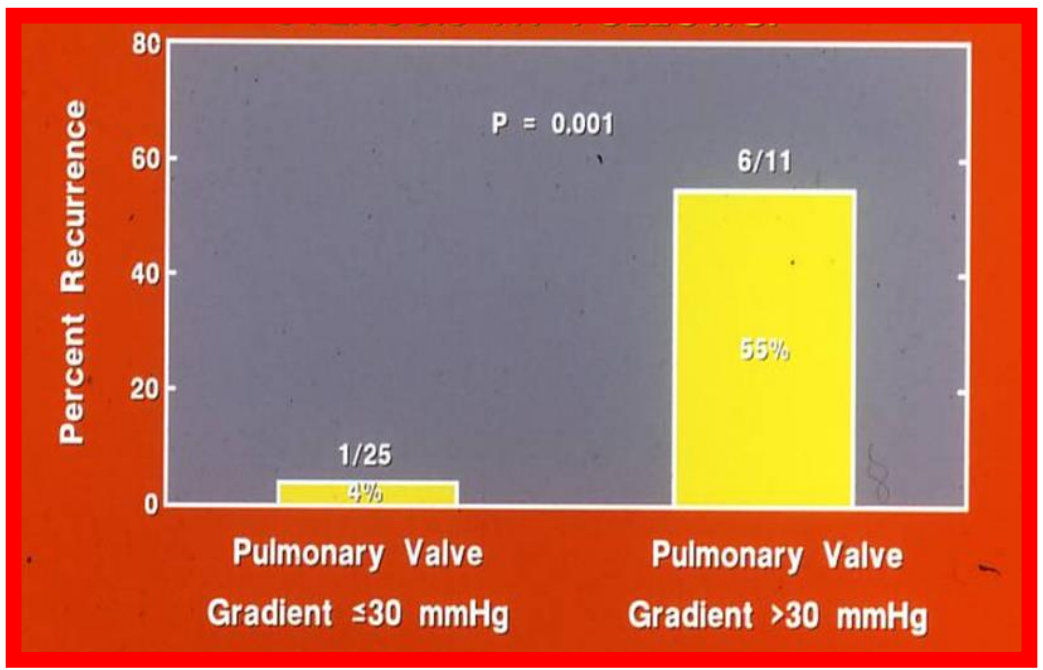

Figure 30. Bar graph similar to Figure 29, except that the immediate post-valvuloplasty peak-to-peak pulmonary valve gradients are used instead of balloon/annulus ratios. Note the higher $(p=0.001)$ rate of recurrence at follow-up when the gradient is $\Gamma 30 \mathrm{mmHg}$. Percentages are marked within the bars and actual numbers are shown on the top of each bar. Modified from. Rao PS (ed), Transcatheter Therapy in Pediatric Cardiology. WileyLiss, Inc., New York, 1993:59-104 [4].

On the basis on these data, we extrapolated that a B/A ratio of less than 1.2 is likely to be the reason for recurrence at intermediate follow-up and such recurrences may be foreseen by an immediate post-valvuloplasty gradient in excess of $30 \mathrm{mmHg}$ [21]. Therefore, we supported the use of larger balloons to decrease the valvar (not infundibular) gradients to $<30$ mmHg during balloon valvuloplasty for valvar pulmonary stenosis. In a subsequent study [22], while examining the long-term results of 80 children, the risk factors for recurrence at intermediate-term follow-up were exactly the same as those seen in our initial study [21]. Additionally, in a large multi-institutional VACA Registry study [70], the B/A ratio and immediate post-valvuloplasty gradient were also found to be predictive of recurrence.
Since the role of balloon size in recurrence is now known, most cardiologists use balloons larger than the valve annulus for BPV, and therefore the reasons for recurrence at the present time are more likely to be local anatomic abnormalities such as valve ring hypoplasia, PV dysplasia, and supravalvar pulmonary artery stenosis [8].

\section{Repeat Balloon Dilatation for Restenosis After Prior BPV}

As indicated above, the recurrence of PS after balloon valvuloplasty was observed. We have studied the feasibility and effectiveness of repeating balloon valvuloplasty to relieve the recurrent obstruction [76]. Eighty-five children underwent balloon pulmonary valvuloplasty between 1983 and 
1993, with a reduction in pulmonary valve peak gradients from $91 \pm 41$ $\mathrm{mmHg}$ to $25 \pm 19 \mathrm{mmHg}$ ( $\mathrm{p}<0.01)$. At the intermediate-term $(10.4 \pm 7.3$ months) follow-up of 80 patients, the residual gradients $(26 \pm 26 \mathrm{mmHg}$ ) remained low $(\mathrm{p}<0.01)$ for the entire group. However, when the individual patient data were scrutinized, nine of the 80 patients $(11 \%)$ developed restenosis, which was defined as residual peak-to-peak gradients in excess of $50 \mathrm{mmHg}$. These patients underwent repeat BPV. In these patients, the peak-to-peak systolic pressure gradients decreased from $98 \pm 45 \mathrm{mmHg}$ to $46 \pm 33 \mathrm{mmHg}(\mathrm{p}<0.05)$ after the initial balloon valvuloplasty (Figure 31 ). Repeat studies at a mean of 11 months after the procedure revealed residual gradients of $89 \pm 40 \mathrm{mmHg}$ - an increase (p
$<0.05)$ when compared with those seen immediately following balloon valvuloplasty (Figure 31). Repeat balloon valvuloplasty was undertaken with a resultant reduction ( $\mathrm{p}<0.01$ ) of peak-to-peak pulmonary valve gradients from $89 \pm 40 \mathrm{mmHg}$ to $38 \pm 20 \mathrm{mmHg}$ (Figure 31). Subsequent echo-Doppler studies at 2 to 6.5 years following repeat balloon valvuloplasty continued to reveal excellent results, with residual peak instantaneous Doppler gradients of $24 \pm 13 \mathrm{mmHg}$ (Figure 31). On the basis of this experience, we concluded that repeat balloon valvuloplasty is feasible and effective in relieving restenosis that develops following initial balloon valvuloplasty [76].

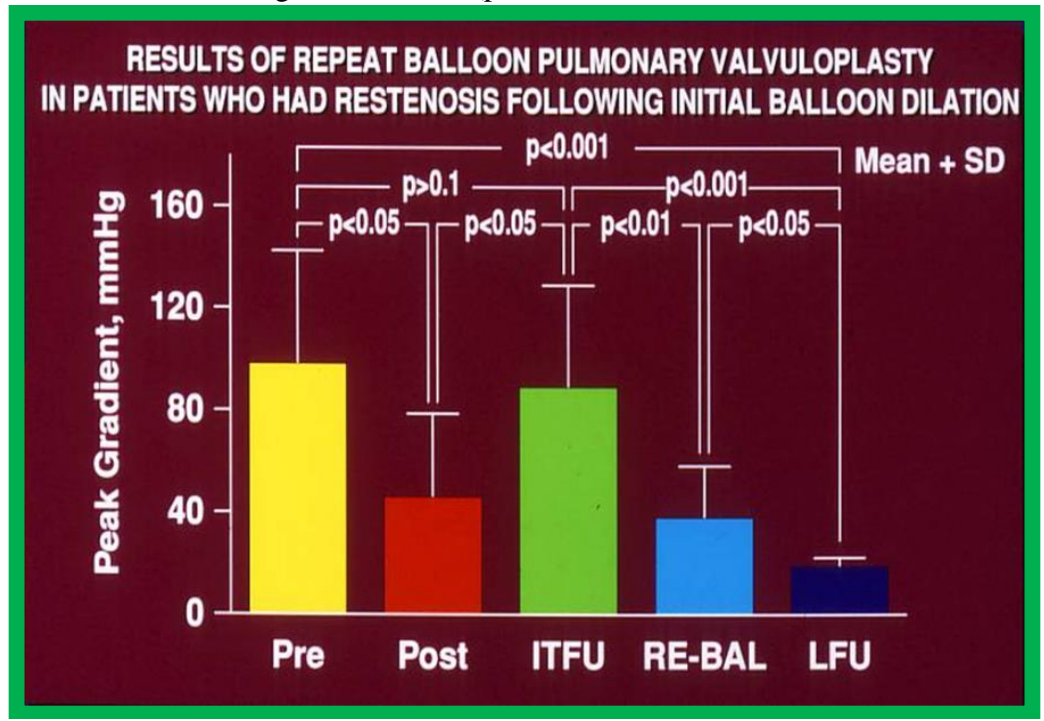

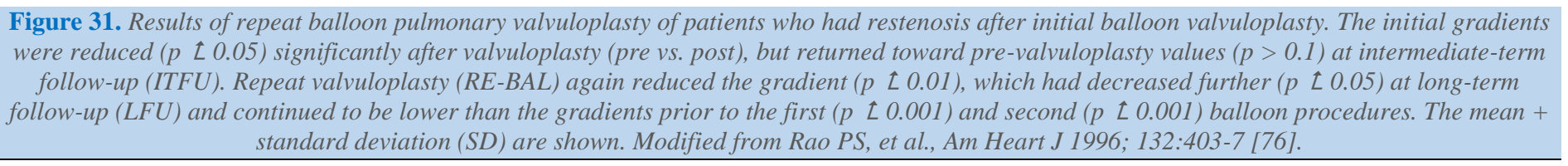

However, at the present time, most cardiologists use balloons larger than the pulmonary valve annulus and therefore, the recurrences described above may not occur as frequently as before. If the reason for recurrence is pulmonary valve annular hypoplasia, pulmonary valve leaflet dysplasia, fixed infundibular obstruction (not controlled by beta-blocker therapy) or significant supravalvar pulmonary artery stenosis, surgical intervention is indicated.

\section{Management of Restenosis After Prior Surgery}

The recurrence of PS following prior surgical valvotomy has been reported. There are limited reports of managing such post-surgical PS by BPV. From our BPV group [4], there were two patients, aged three and 14 years, who had pulmonary valve gradients of 120 and $146 \mathrm{mmHg}$ at post-surgical follow-up cardiac catheterization. BPV was performed in both of these children, with a reduction of the pulmonary valve gradients to 48 and $34 \mathrm{mmHg}$, respectively. In one of these children, a follow-up echo-Doppler study 10 months after BPV showed a peak instantaneous gradient of $25 \mathrm{mmHg}$. These results are encouraging. It was concluded that BPV is the treatment of choice for restenosis following prior surgical therapy [4].

\section{Infundibular Stenosis \& BPV}

Occurrence of infundibular narrowing after balloon pulmonary valvuloplasty has been studied [68,69]. Fontes and his colleagues [69] have reported the emergence of important infundibular obstruction after BPV. They reviewed the results of 33 patients with severe PS who had supra-systemic systolic pressures in the RV; 24 (73\%) patients developed infundibular stenosis. These authors suggested administration of propranolol for gradients $\geq 50 \mathrm{mmHg}$. They also showed that the infundibular obstruction regresses during follow-up. They conclude that infundibular stenosis is reactive and reversible and in spite this balloon valvuloplasty should remain the treatment of preferred option even in patients with severe pulmonary stenosis [69].

We have designed a study to investigate the prevalence and significance of this problem and its clinical implications [68]. We analyzed the data on 62 consecutive children (aged seven days to 20 years [median, six years]) who had BPV during a 55-month period ending in May 1988 [68]. The peak-to-peak systolic pressure gradient across the pulmonary valve decreased from $93 \pm 43$ to $27 \pm 19 \mathrm{mmHg}$ (p $\uparrow$ 0.001) immediately following BPV. Infundibular systolic pressure gradients were present in $13(21 \%)$ of the 62 patients prior to balloon dilatation and varied between 10 to $137 \mathrm{mmHg}(49 \pm 42 \mathrm{mmHg})$. Immediately following balloon valvuloplasty, the infundibular gradients were abolished in five patients. In the remaining eight patients, gradients of $33 \pm 26 \mathrm{mmHg}$ (range of 5 to $80 \mathrm{mmHg})$ persisted. New infundibular gradients $(40 \pm 21 \mathrm{mmHg}$ with a range of 15 and $60 \mathrm{mmHg}$ ) appeared in five other patients who had no measured infundibular gradients prior to balloon valvuloplasty. Infundibular gradients seen prior to and immediately after balloon 
valvuloplasty and at follow-up are shown in Figure 32. Examples of infundibular obstruction as visualized on RV angiography (Figure 20A) and on Doppler echocardiography (Figure 21B [middle panel]) are shown in the respective figures. Six (10\%) patients received propranolol either during or following the procedure to reduce the right ventricular systolic pressure and to relieve the infundibular obstruction acutely [68].

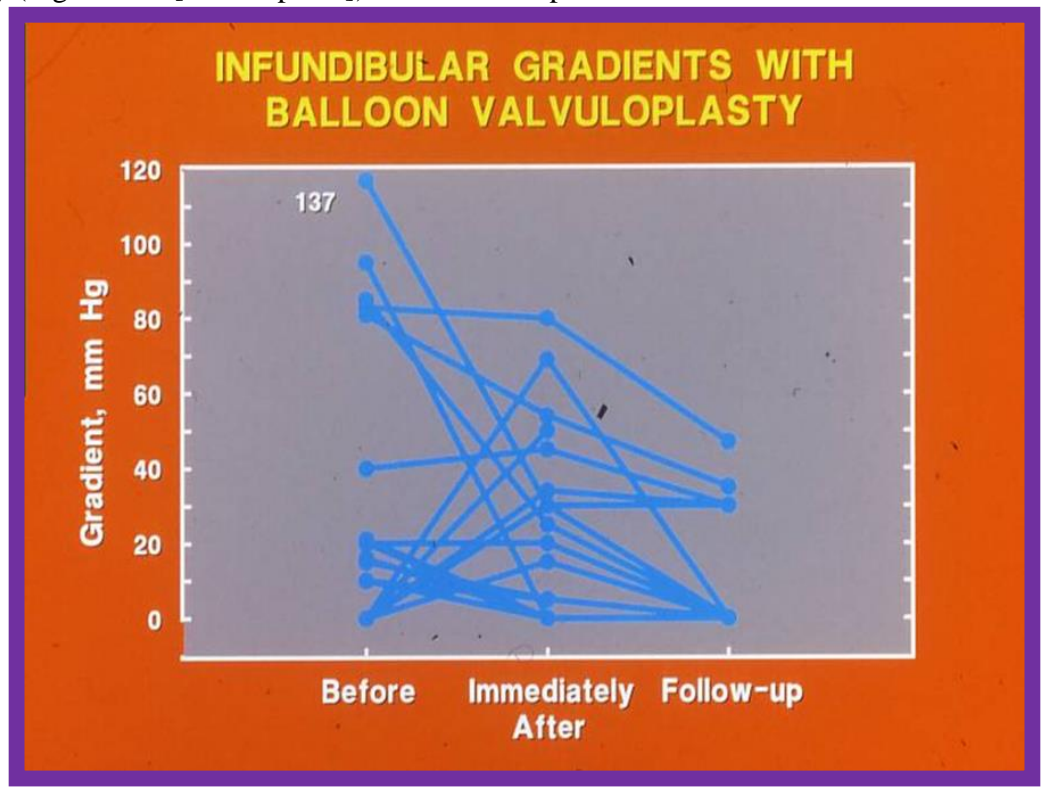

Figure 32. Line graph showing infundibular gradients before and immediately after balloon pulmonary valvuloplasty and at follow-up. Thirteen children had initial gradients; five disappeared immediately after valvuloplasty. New gradients appeared in 5 other patients. The gradients either improved or disappeared at follow-up. Modified from Thapar MK, Rao PS, Am Heart J 1989; 118:99-103 [68].

At intermediate-term follow-up, the infundibular obstruction either disappeared or further decreased (Figures 20A, 21C, and 32). At the time of the conclusion of this study [68], no child required surgical intervention. Nevertheless, at follow-up after a longer duration [22], three (4\%) of 80 children required surgical intervention to relieve fixed infundibular stenosis, months or years following initial balloon valvuloplasty.
A total of 18 (29\%) of 62 PS patients had infundibular gradients. The influences of the patient's age at valvuloplasty and the severity of the pulmonary valve stenosis on the development of infundibular obstruction was examined; the prevalence of infundibular obstruction was higher with increasing age and an increasing degree of PV obstruction (Figure 33) [68].

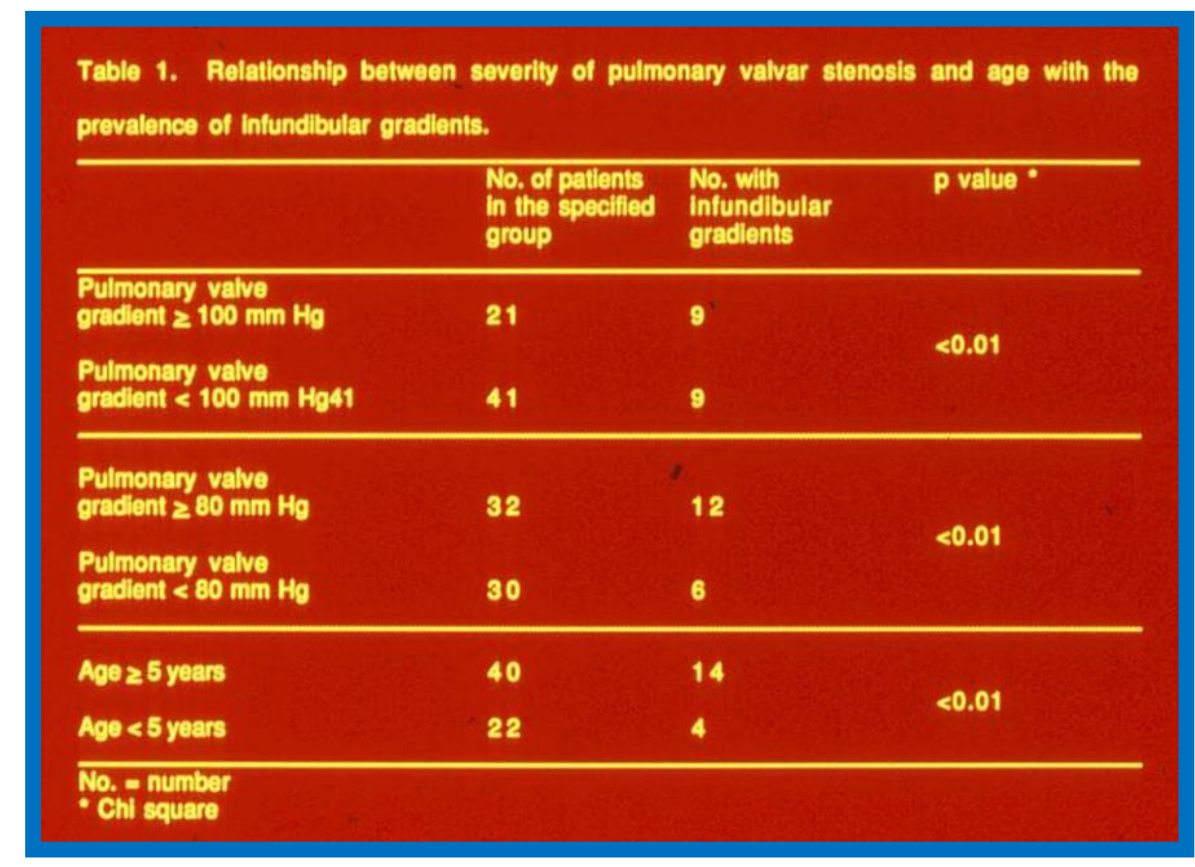

Figure 33. The relationship between the prevalence of infundibular obstruction and age at valvuloplasty and severity of pulmonary valve obstruction. The prevalence of infundibular obstruction is higher with increasing age and increasing degree of pulmonary valve stenosis. Modified from Thapar MK, Rao PS, Am Heart J 1989; 118:99-103 [68]. 
We concluded that infundibular gradients are seen following BPV in nearly $30 \%$ patients, with a higher incidence $(75 \%)$ in patients with severe PS with supra-systemic right ventricular pressure $[68,69]$. The prevalence of infundibular obstruction is more common with increasing age and severity of PS. Children who develop systemic or supra-systemic right ventricular pressure secondary to a hyper-reactive infundibulum should receive beta blockade therapy $[68,69]$. The recommendation to use a beta blockade for infundibular gradients $\lceil 50 \mathrm{mmHg}$ is appropriate [68.69].
(Figures 20A, 21C, and 32) and the need for surgical intervention is rare. The probability for the development of infundibular gradients should not deter cardiologists from the use of balloon valvuloplasty in the management of valvar PS. BPV should be performed prior to the age of five years and prior to the development of pulmonary valve peak-peak systolic gradients more than $80 \mathrm{mmHg}$, to prevent/reduce infundibular obstruction. The recommendations for the management of post-balloon infundibular PS [77] are summarized in Table II.

The infundibular obstruction does regress to a great degree at follow-up

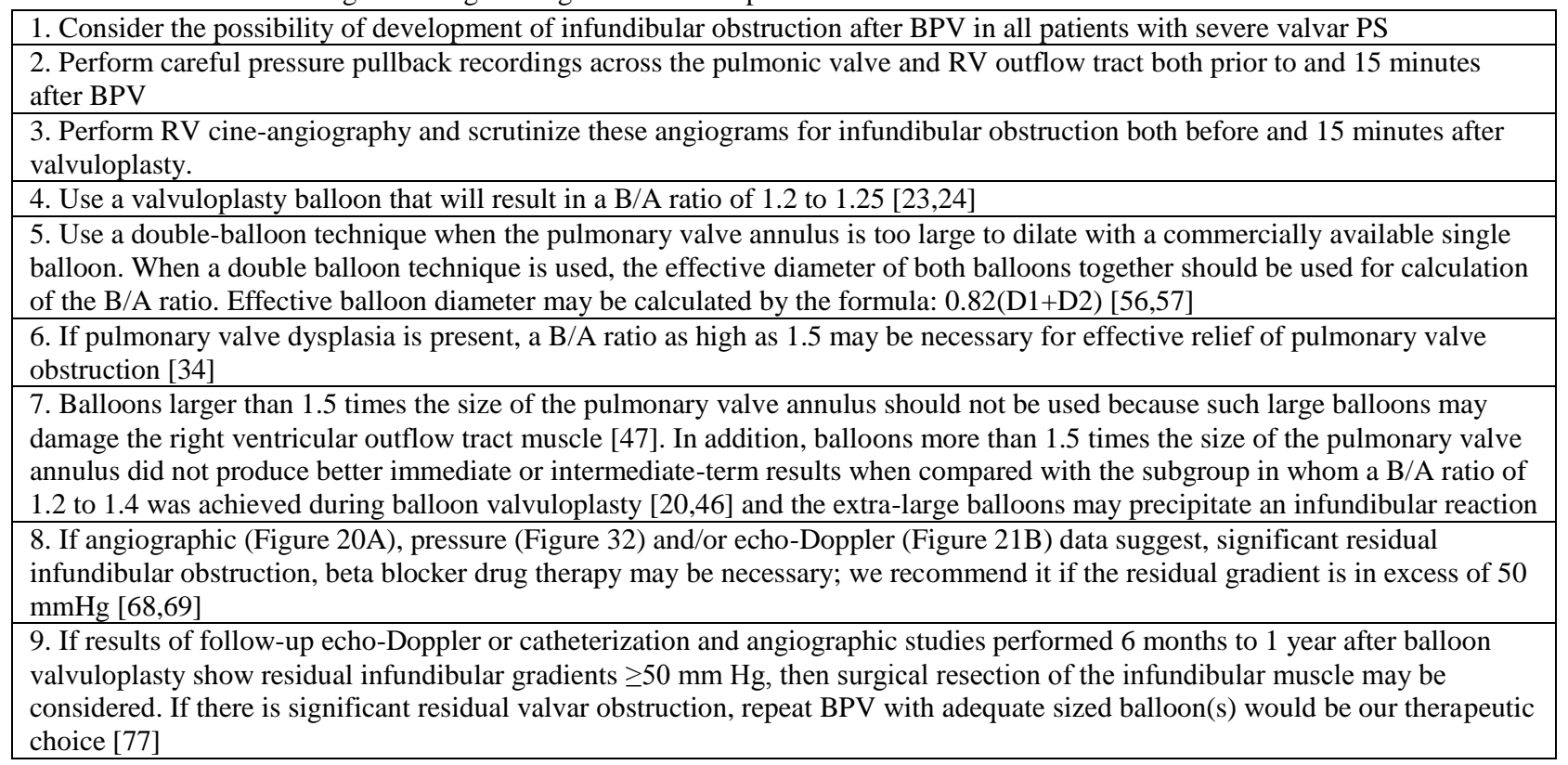

Modified from Rao PS, Thapar MK. Am Heart J 1991; 121: 1839-1840 [77].

Table II. Management of Infundibular Obstruction

\section{Pulmonary Insufficiency}

We were among the first to point out that PI may become a significant problem during long-term follow-up after BPV [22]; there was a progressive increase in the prevalence and severity of PI (Figure 26). PI was also observed in $40-90 \%$ of patients by other investigators. But RV dilatation (volume overloading) did not develop in most studies, including ours (Figure 27). However, in one study [29] severe PI was observed in six of $107(6 \%)$ patients at late follow-up; some of these patients required surgical replacement of the pulmonary valve. The data from these investigators [29], along with that reported by us [22,78], led the author to conclude [23] that the development of significant PI at late follow-up, as reported by Berman [29], is an important observation and that attempts to establish the causes of late-onset PI, to develop methods to avoid such problems, and to undertake cautious long-term follow-up studies to corroborate Berman's findings are needed.

Berman's study [29] indicated young age, severe degrees of PS, large B/A ratio, use of noncompliant balloons, and low post-BPV peak-to-peak systolic pulmonary valve gradients as features that had a role in the development of late PI. Other investigators, as reviewed elsewhere [8], also documented the late development of PI. Accordingly, methods to avoid such problems should be sought. My independent analysis [23,24] suggested balloons 1.2 and 1.25 times the size of the pulmonary valve annulus may be a correct choice for BPV instead of the previously recommended B/A ratios of 1.2-1.4 [19-21,45]. It was believed that such smaller balloons are likely to provide good relief of pulmonary valve obstruction while at the same time may prevent significant PI at late follow-up. However, careful long-term follow-up studies are necessary to corroborate that this modification in balloon size will indeed prevent lateonset PI [8,23].

\section{Comparison with Surgery}

The comparison of balloon valvuloplasty with surgical pulmonary valvotomy is challenging because: 1 . Extremely few or no studies exist that compare concurrent balloon and surgical procedures, and there are no randomized studies to address this issue, 2 . There are intrinsic problems in comparing "older" historical surgical results with "current" BPV, and 3. There is a relatively short duration of follow-up after BPV. In the past, the author compared the outcomes of surgery from nine papers with those of BPV in 11 publications [4]. In the surgical group, 46 to 234 patients were followed for a few months to 30 years following the surgical relief of PS. The operative mortality varied between $3 \%$ and $14 \%$. Poor results, defined as residual PV gradients $\geq 50 \mathrm{mmHg}$, were seen in 0 to $8 \%$ of patients. The multi-institutional natural history study [26] found poor results in $4 \%$ of the patients. PI was reported in all studies. In the BPV group, six to 53 patients were followed for one week to 34 months after BPV; no mortality was reported. The reappearance of pulmonary valve obstruction varied between $14 \%$ and $23 \%$ based on the criteria used for defining restenosis. These criteria varied between studies, which used 30 , 36,40 or $50 \mathrm{mmHg}$ residual peak gradients respectively. PI was not thought to be problematic in these studies. It is obvious that the number of patients followed is smaller and the follow-up duration is shorter in the 
BPV series than in the surgical cohorts, making it tricky to interpret the data. Nonetheless, this review's [4] conclusions were that the mortality and morbidity rates are higher after surgical therapy, while the recurrence rates are higher after BPV.

\section{ECG Changes}

We have scrutinized ECGs of 35 children who had BPV in an attempt to document ECG changes after BPV and to appraise if such changes reflect decrease in gradients across the pulmonary valve after balloon valvuloplasty [79]. Based on follow-up pulmonary valve gradient data of these 35 children at a mean of 11 months after the procedure, these patients were divided into two groups: Group I $(\mathrm{N}=30)$ with good results with gradients $\downarrow 50 \mathrm{mmHg}$ and Group II $(\mathrm{N}=5)$ with poor results with gradients $\geq 50 \mathrm{mmHg}$. Frontal and horizontal plane mean QRS vectors (axis) (Figure 34), anterior ( $R$ waves in leads $V_{3} R, V_{1}$, and $V_{2}$ ) and rightward ( $\mathrm{S}$ waves in leads $\mathrm{V}_{5}$ and $\mathrm{V}_{6}$ ) $\mathrm{QRS}$ voltages (Figure 35 ) and direction of $\mathrm{T}$ waves in the right chest leads were similar $(\mathrm{p}>0.1)$ in both groups prior to balloon valvuloplasty [79].

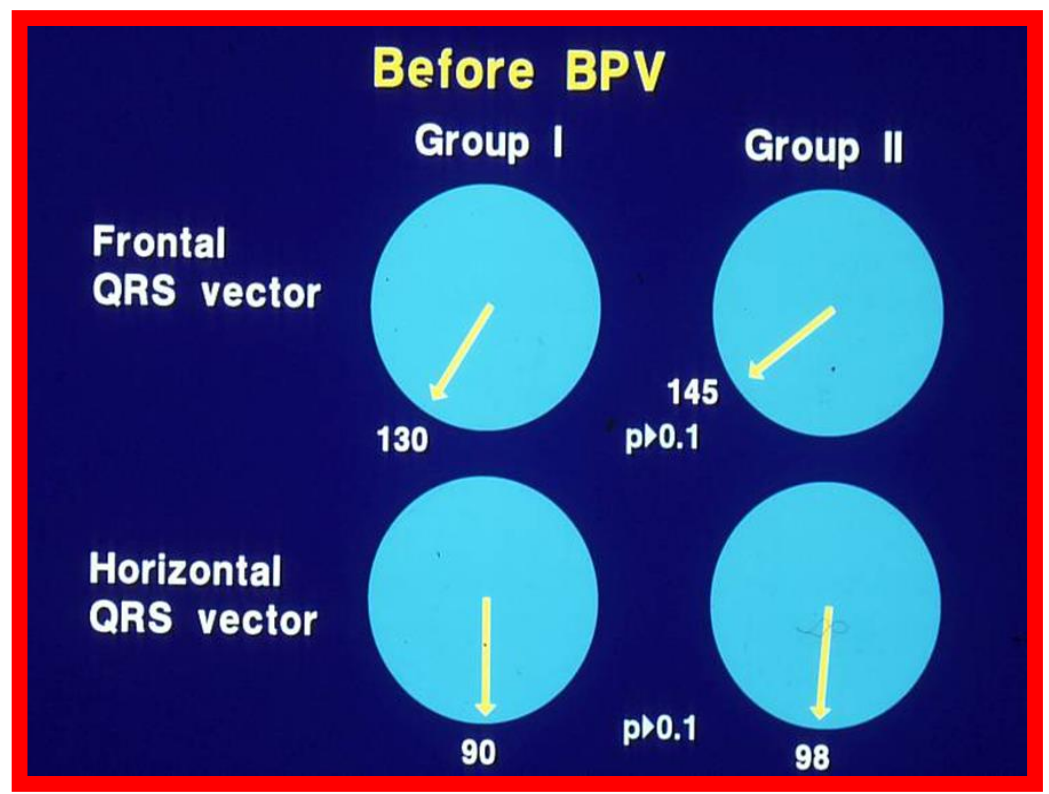

Figure 34. Plots of mean QRS vectors (axis) in the frontal (top) and horizontal (bottom) planes in group I (with good results) (left circles) and group II (with poor results) (right circles) prior to balloon pulmonary valvuloplasty (BPV) are shown. Note that no significant ( $p>0.1)$ difference was seen between groups I and II. Reproduced from Rao PS, "Balloon valvuloplasty for pulmonary stenosis", In: Vijayalakshmi IB, Ed., Cardiac Catheterization and Imaging (From Pediatrics to Geriatrics), Jaypee Publications, New Delhi, India, 2015:149-174 [8].

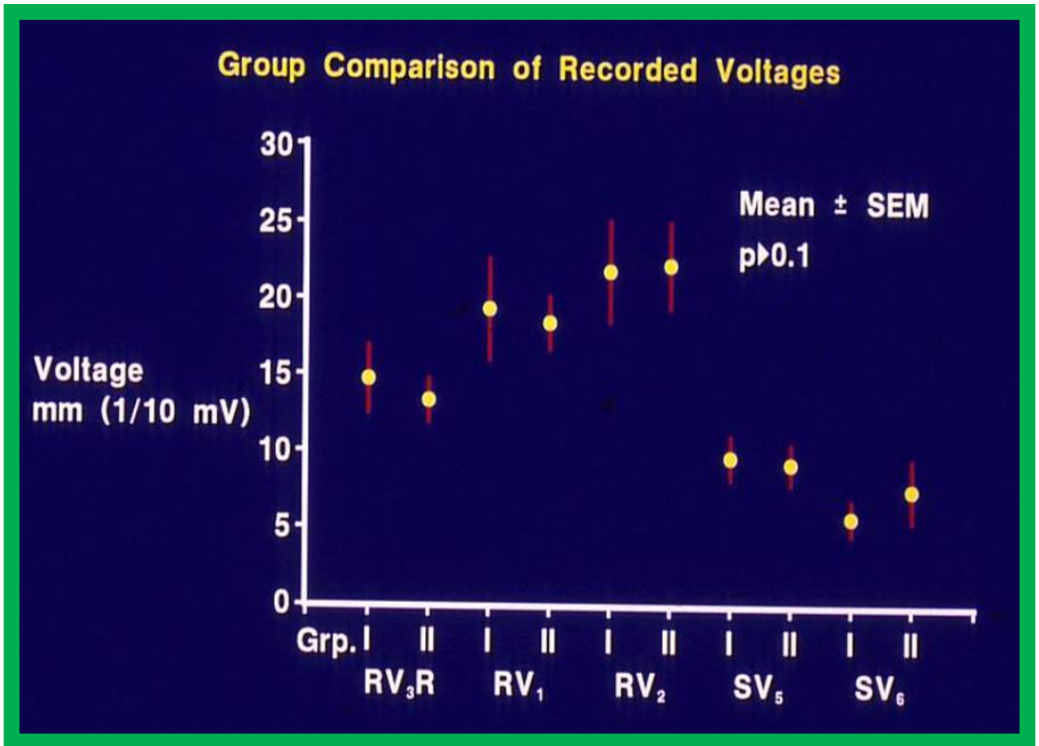

Figure 35. Anterior ( $R$ waves in leads V3R, V1 and V2) and terminal rightward ( $S$ waves in leads V5 and V6) voltages in the electrocardiograms prior to balloon pulmonary valvuloplasty are compared between group (Grp.) I (with good results) and group II (with poor results). Mean and standard error of mean (SEM) are shown. Note that no significant ( $p>0.1)$ difference is shown between groups I and II. Reproduced from Rao PS, "Balloon valvuloplasty for pulmonary stenosis", In: Vijayalakshmi IB, Ed., Cardiac Catheterization and Imaging (From Pediatrics to Geriatrics), Jaypee Publications, New Delhi, India, 2015:149-174 [8]. 
At a mean follow-up of eleven months following balloon valvuloplasty, the frontal $\left(127^{0} \pm 25^{0}\right.$ vs. $\left.81^{0} \pm 47^{\circ}\right)$ and horizontal $\left(88^{0} \pm 36^{0}\right.$ vs. $27^{0} \pm$ $51^{\circ}$ ) plane mean vectors moved leftward ( $\mathrm{p} \uparrow$ 0.05) (Figure 36), the anterior and rightward QRS voltages decreased ( $\mathrm{p}$ Ł 0.001) (Figure 37, left panel) and the upright $\mathrm{T}$ waves got inverted in the Group I patients with good results.

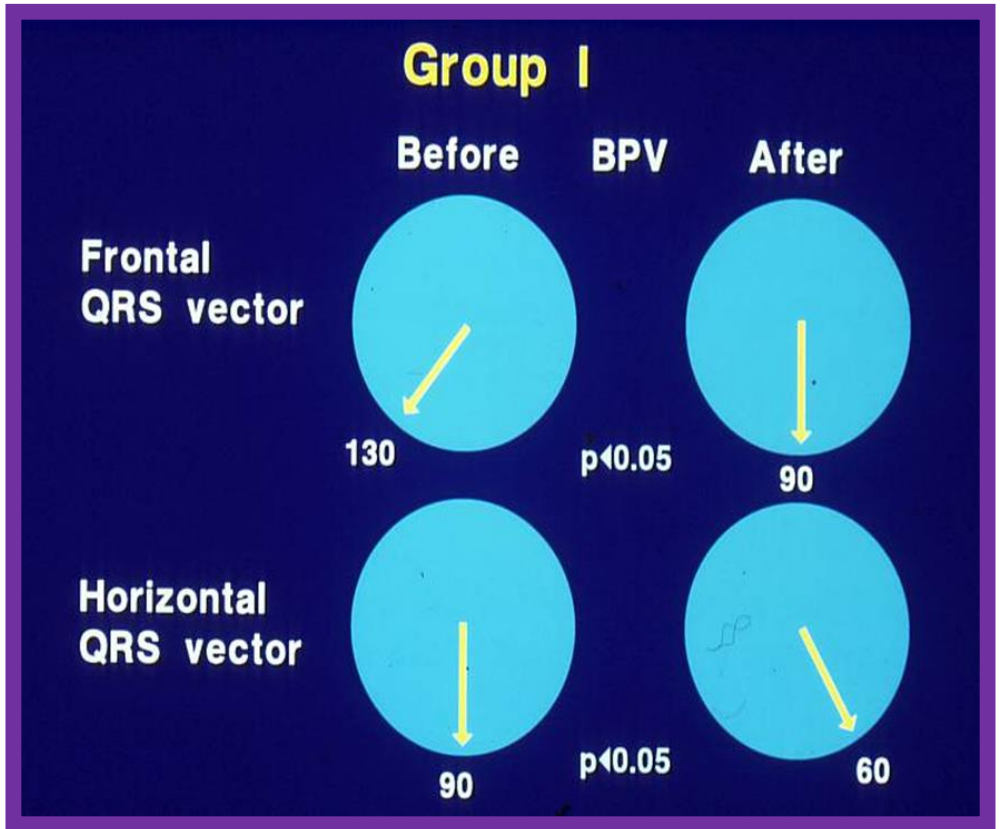

Figure 36. Plots of mean QRS vectors (axis) in the frontal (top) and horizontal (bottom) planes in group I (with good results) prior to balloon pulmonary valvuloplasty (BPV) (left circles) and at follow-up (right circles) are shown. Note the significant ( $p<0.05)$ improvement at follow-up. Reproduced from Rao PS, "Balloon valvuloplasty for pulmonary stenosis", In: Vijayalakshmi IB, Ed., Cardiac Catheterization and Imaging (From Pediatrics to Geriatrics), Jaypee Publications, New Delhi, India, 2015, pp. 149-174 [8].

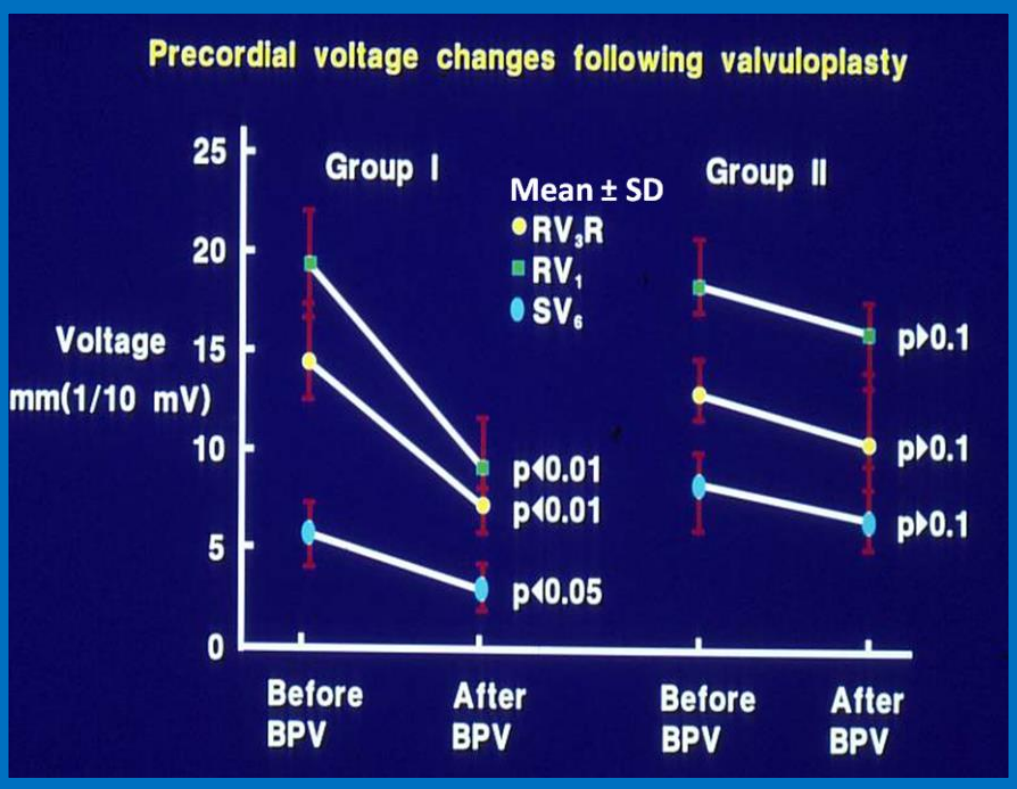

Figure 37. Precordial ECG voltages ( $R$ waves in leads V3R and V1 and S waves in V6) prior to and at follow-up after balloon pulmonary valvuloplasty $(B P V)$ in group I (with good results) (left panel) and group II (with poor results) (right panel) are depicted. The mean and standard deviation (SD) are shown. Note the significant ( $p<0.05$ to 0.01$)$ decrease in the voltages in group I while there was no significant ( $p>0.1)$ change in group II. Reproduced from Rao PS, "Balloon valvuloplasty for pulmonary stenosis", In: Vijayalakshmi IB, Ed., Cardiac Catheterization and Imaging (From Pediatrics to Geriatrics), Jaypee Publications, New Delhi, India, 2015:149-174 [8].

On the other hand, no significant change in frontal $\left(145^{0} \pm 27^{0}\right.$ vs. $145^{0} \pm$ $\left.27^{\circ}\right)$ and horizontal $\left(98^{0} \pm 19^{0}\right.$ vs. $\left.112^{0} \pm 29^{\circ}\right)$ plane mean vectors, anterior and rightward precordial voltages $(\mathrm{p}>0.1)$ (Figure 37, right panel) and upright nature of the $\mathrm{T}$ waves in right chest leads occurred in poor results group. When time course of precordial voltages following balloon valvuloplasty in Group I was scrutinized (Figure 38 and 39), there was no decrease ( $\mathrm{p}\lceil 0.05)$ in the QRS voltages at 3 months, but at 6 and 12 months following successful valvuloplasty the QRS voltages decreased (p $\uparrow 0.05$ to $\nmid 0.001$ ). 


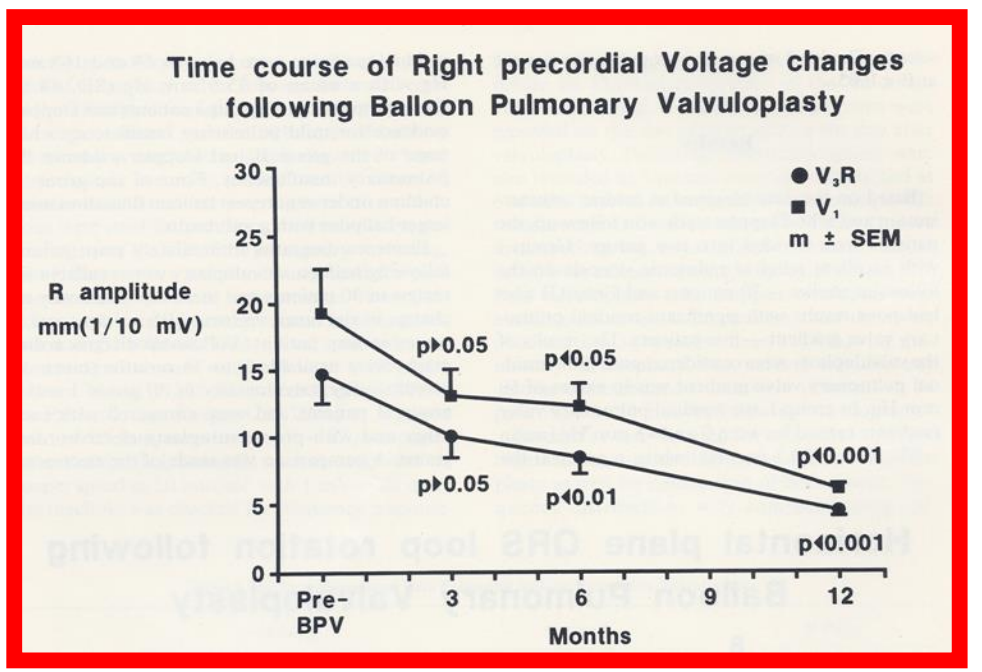

Figure 38. Precordial ECG voltages ( $R$ waves in leads V3R [circles] and V1 [squares]) prior to and at three, six, and 12 months following balloon pulmonary valvuloplasty (BPV) in group I patients (with good results). Note that a gradual improvement was shown; at three month follow-up, there was no statistically significant decrease ( $p>0.05)$, but at six and 12 months, a significant ( $p<0.05$ to 0.001) decrease was observed. The mean and standard error of mean (SEM) are shown. Reproduced from Rao PS, Solymar L, J Interventional Cardiol 1988; 1:189-97 [79].

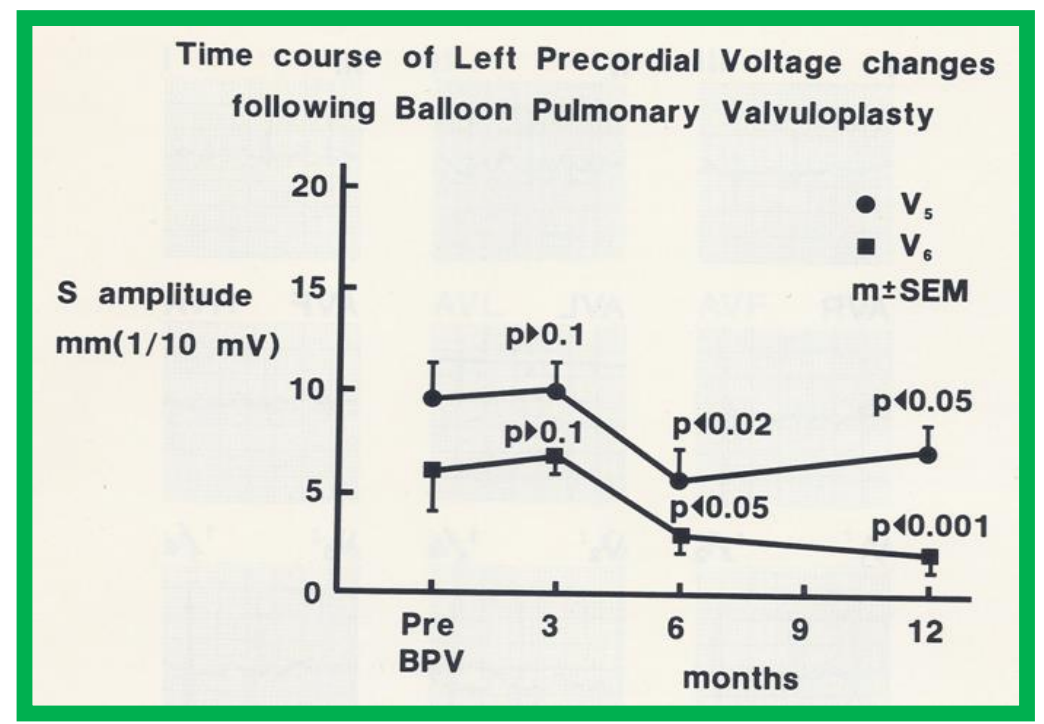

Figure 39. Precordial ECG voltages (S waves in leads V5 [circles] and V6 [squares]) prior to and at three, six, and 12 months following balloon pulmonary valvuloplasty (BPV) in group I patients (with good results). Note that a gradual improvement was shown; at three month follow-up, there was no statistically significant decrease ( $p>0.05)$, but at six and 12 months, a significant ( $p<0.05$ to 0.001$)$ decrease was observed. The mean and standard error of mean (SEM) are shown. Reproduced from Rao PS, Solymar L, J Interventional Cardiol 1988; 1:189-97 [79].

After having demonstrated that the ECG gets better following successful BPV, we looked into whether the post-valvuloplasty ECG reflects residual gradient across the pulmonary valve. Scrutiny of thirty pairs of ECG and catheterization-measured pulmonary valve gradients secured within 24 hours of each other revealed that pulmonary valve gradients $<30 \mathrm{mmHg}$ are likely to be seen in children with normal ECG (Figure 40).
If right ventricular hypertrophy is seen in the ECG recorded at or later than 6 months after balloon valvuloplasty, significant residual gradient is likely (Figure 40). Right ventricular hypertrophy in the ECG obtained prior to 6 months following balloon valvuloplasty does not correctly predict pulmonary valve gradient. 


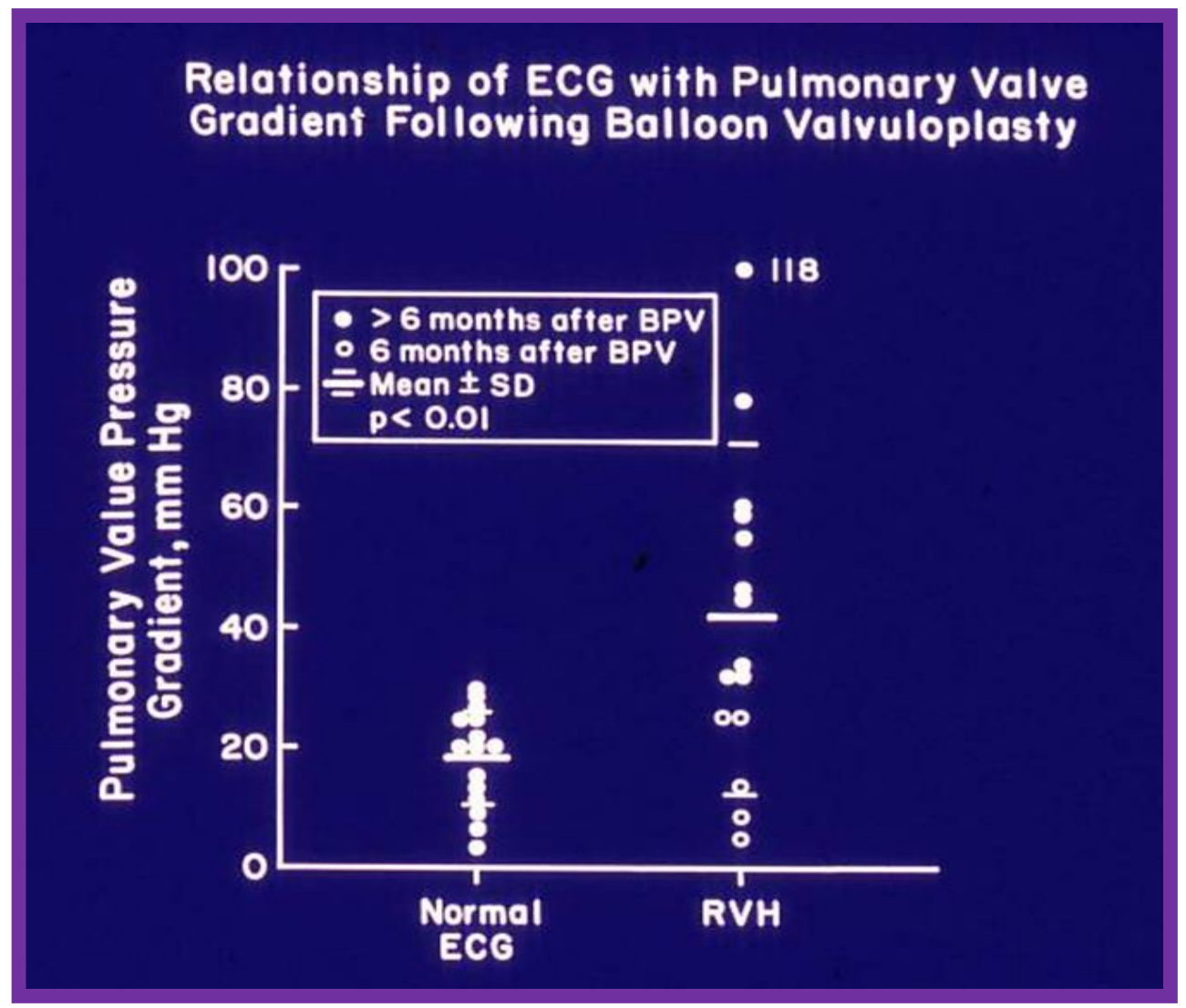

Figure 40. The relationship of residual pulmonary valve gradients at follow-up after balloon pulmonary valvuloplasty (BPV) and electrocardiogram (ECG) is plotted. Note that a normal ECG is found in patients with minimal residual pulmonary valve gradients (left panel) while RVH indicates a significant residual gradient, or that the ECGs were recorded earlier than six months after BPV. The mean and standard deviation (SD) are shown. Filled circles - ECGs recorded six months after BPV. Open circles - ECGs recorded prior to six months after BPV. ECGs recorded prior to six months after BPV exhibited RVH, despite reduced gradients; this may in part be related to not yet having had a chance for the complete resolution of RVH. Reproduced from Rao PS, "Balloon valvuloplasty for pulmonary stenosis", In: Vijayalakshmi IB, Ed., Cardiac Catheterization and Imaging (From Pediatrics to Geriatrics), Jaypee Publications, New Delhi, India, 2015, pp. 149-174 [8].

It was concluded that ECG improves following successful BPV and the ECG is a useful addition in the assessment of results of balloon valvuloplasty. ECG verification of improved pulmonary valve gradient does not become evident until six months after balloon dilatation.

Regression of right ventricular hypertrophy (by ECG) after successful balloon pulmonary valvuloplasty has also been shown in other studies [74,80,81]. Upright $\mathrm{T}$ waves in lead $\mathrm{V}_{1}$ reverted to normal [81], $\mathrm{R}$ wave voltages decreased $[74,80]$ and mean frontal plane vector shifted leftward [74,80]. Observations by these investigators are in line with our observations [79].

\section{Echo-Doppler Studies}

In the beginning, cardiac catheterization (Figure 15) was used to assess the follow-up results of BPV. Following the demonstration of the efficacy of echo-Doppler studies in quantifying the residual gradients $[4,75,78]$, echo-Doppler studies were used almost exclusively by most investigators in the assessment of the results of BPV at follow-up. In 1989, the author reported follow-up echo-Doppler studies of 50 children, 3 to 36 months after BPV [42,59]. The peak Doppler flow velocity (Figure 41) was used to calculate the peak instantaneous Doppler gradient using a modified Bernoulli equation (Figure 42). There was reduction ( $p \nmid 0.001$ ) in Doppler velocities and calculated Doppler gradients immediately after valvuloplasty, with a further reduction ( $\mathrm{p} \uparrow \mathrm{0.001}$ ) at 6-month follow-up. Thereafter, they remain unchanged $(\mathrm{p}\lceil 0.1)$. There was excellent correlation $(\mathrm{r}=0.9)$ between cardiac catheterization-measured and Doppler-derived gradients at follow-up [42,59]. 


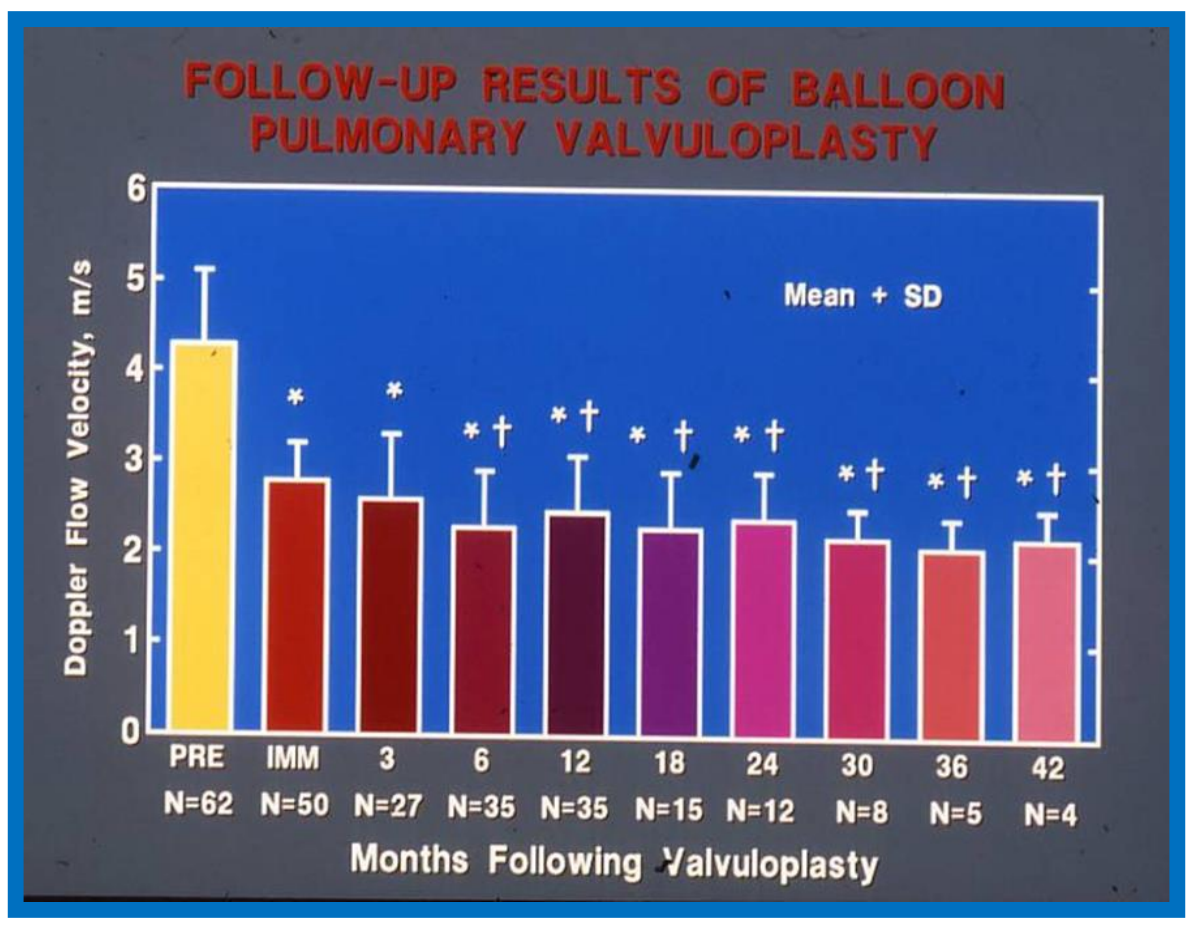

Figure 41. Bar graph demonstrating the peak Doppler velocities in the main pulmonary artery prior to (PRE) and one day following (IMM) balloon pulmonary valvuloplasty, and at follow-up at 3, 6, 12, 18, 24, 30, 36 and 42 months. Note the reduction ( $p$ L 0.001) in Doppler velocities IMM after valvuloplasty, with a further reduction $(p \quad L$ 0.001) at 6-month follow-up. Thereafter, they remain unchanged ( $p$ I0.1). However, all follow-up values are lower than PRE ( $p \quad$ L 0.001) and IMM ( $p$ L 0.05) values. The mean and standard deviation (SD) are shown. Modified from Reference 4.

Figure 42. A bar graph similar to Figure 41, but maximum peak instantaneous Doppler gradients in mmHg are shown instead of peak Doppler velocities. The findings are similar to those shown in Figure 41. Reproduced from Reference 4.

Cardiac catheterization is no longer performed for the evaluation of residual gradients, but may be undertaken if catheter re-intervention is contemplated. The assessment of the immediate, intermediate-term, and long-term results of BPV by echo-Doppler studies in terms of residual gradients (Figures 16,17,21,23,41, and 42), ventricular dimensions
(Figure 25), degree of pulmonary insufficiency (Figure 26 and 43 ), and interventricular septal motion (Figure 27) was demonstrated in Figures $16,17,21,23,25-27$ and 43). Based on these observations, it may be concluded that echo-Doppler studies are excellent tools in the follow-up evaluation of BPV. 


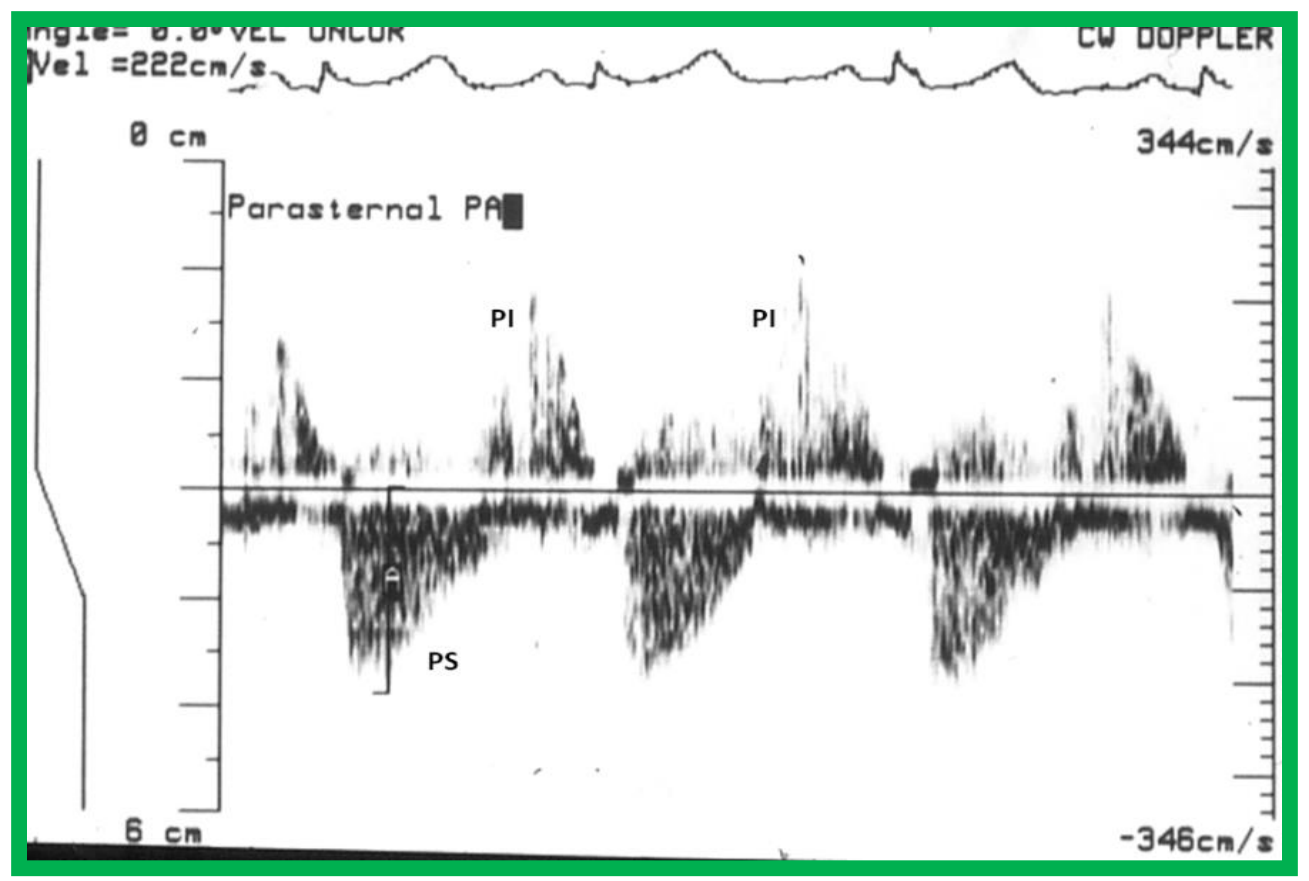

Figure 43. A selected video frame from parasternal short axis view, with continuous Doppler directed along the right ventricular outflow tract/pulmonary artery, similar to Figure 10-50. This demonstrates mild residual pulmonary stenosis (PS) and pulmonary insufficiency (PI). Reproduced from Reference 67.

\section{Balloon Valvuloplasty in Specific Age Groups}

The above review included discussion of BPV which are mostly focused on infants, children, and adolescents. In the ensuing sections the results of BPV in the fetuses, neonates, and adults will be reviewed.

\section{Pulmonary Stenosis/Atresia in the Fetus}

Prenatally diagnosed critical PS and pulmonary atresia with intact ventricular septum (PAIVS) carry poor prognosis for postnatal biventricular repair. The extent to which simple BPV in the fetus prevents severe RV hypoplasia is not clearly understood [82]. The rationale behind using fetal BPV is to establish antegrade flow across the pulmonary valve; augment ventricular filling; decrease tricuspid insufficiency; improve RV diastolic function; and increase normal division of myocardial cells through the remaining fetal life, thereby improving growth of the RV. Hopefully, such interventions increase the chances of a biventricular outcome. The indications for fetal BPV are not clearly established; critical PS or PAIVS in the fetus with signs of impending or near hydrops are suggested indications, but with the intent of producing biventricular outcomes. Nearly one-third of cases of PAIVS in utero may have coronary arterio-venous (CAV) fistulae and fetuses with small, unipartite RVs and those with RV dependant coronary circulation (RVDCC) are not candidates for relief of RV outflow obstruction. But, babies with small $\mathrm{CAV}$ fistulae and a reasonable sized RV may undergo the procedure. Some investigators developed criteria to predict single ventricular outcome [83]; if three of the following four criteria are present, single ventricular outcome is likely: 1 . Tricuspid/mitral valve ratio <0.7, 2 . $\mathrm{RV} /$ left ventricle length ratio $<0.6,3$. Tricuspid valve inflow duration $<31.5 \%$ of cardiac cycle length, and 4 . The presence of RV sinusoids. Consequently, these criteria may be used to decide on which fetus should undergo fetal BPV. Other investigators [84] developed more complicated methodology which include PV and tricuspid valve Z scores, CAV fistula, and fetal right atrial pressure score (which was calculated from the mixture of degree of tricuspid insufficiency, ductus venosus waveform characteristics, and magnitude of the inter-atrial septal restriction). The anatomic criteria for performing the procedure are: presence of either membranous atresia or a critical stenosis, a recognizable RV outflow tract, retrograde flow in the ductus arteriosus, a hypoplastic RV, and high RV pressures (based on tricuspid regurgitant jet velocity magnitude). The procedure is contraindicated in the presence of muscular atresia of the RV outflow tract and large CAV fistula.

The procedure of BPV is usually performed between 21 to 30 weeks of gestation. Maternal general anesthesia is usually used. Although general anesthesia imposes certain risks to the mother, it facilitates re-positioning the fetus to an appropriate lie to assist performing BPV. Fetal anesthesia and paralysis are induced by fetal intramuscular injection of atropine, vecuronium, and fentanyl. The technique of accessing the fetus is similar to that used by Daffos and associates [85] for chorionic villous sampling. A 16 to 19 gauge needle is introduced under ultrasound guidance transcutaneously via the maternal abdominal wall and uterus and then across the fetal chest (or subcostal) into the RV outflow tract. A floppy-tipped 0.014 " coronary guide wire is used to cross the PV. Once the position is confirmed by fetal ultrasound, a coronary balloon angioplasty catheter with a balloon diameter larger than pulmonary valve annulus (B/A ratio of 1.2 to 1.3 ) is positioned across the pulmonary valve and the balloon inflated at the manufacturer's recommended pressure. If the percutaneous route is not successful, the uterus is exposed with a mini-laparotomy

In an early publication by Tulzer and colleagues [86], the authors reported two fetuses who had fetal BPV at 28 and 30 weeks' gestation, respectively. Both babies had successful opening of the pulmonary valve with decrease in the degree of tricuspid insufficiency and improved RV function and were delivered at 38 and 35 weeks, respectively. However, both babies required post-natal BPV and aorto-pulmonary shunts. Nonetheless, both babies eventually achieved biventricular circulation. Subsequently, a number of other investigators reported their experiences 
and results of fetal BPV with one to 2 cases [84, 87-90] as well as larger case series [91-93]. In the larger case studies, 5 to 23 fetuses had BPV at a median of 24 to 28 weeks gestation [91-93]. The procedural success varied between 60 and $100 \%$; deaths related to the procedure were not seen and but some complications (pericardial effusion and bradycardia) occurred. In successful cases, larger RV caused by reduced afterload and increased filling occurred, thus improving the likelihood of biventricular outcome. Despite initial improvement, several babies developed progressive restenosis requiring repeat fetal BPV or early delivery. Most babies required postnatal BPVs and aorto-pulmonary shunts. Postnatal outcomes varied with biventricular outcomes in most, one-one-half ventricular outcomes in a few, and single ventricular outcome in a few [91-93]. While the data is limited, fetal BPV appears safe and effective.

\section{Critical Pulmonary Stenosis in the Neonate}

The term 'critical PS' is generally reserved to describe very severe PV stenosis resulting in supra-systemic right ventricular systolic pressure, a right-to-left atrial shunt across the PFO, ductal-dependent pulmonary blood flow, or a combination thereof. The author has reviewed transcatheter management of critical PS in multiple publications in the past $[4,43,94-99]$, and will only be examined briefly here. Neonates with obstruction that is less than severe/critical should undergo BPV later, past the newborn period $[98,99]$. Tynan and his colleagues [100] extended the BPV technique of Kan [10] to neonates with critical PS. The procedure of $\mathrm{BPV}$ in neonates is similar to that used in older children, with some exceptions. These babies usually require prostaglandin $\mathrm{E}_{1}\left(\mathrm{PGE}_{1}\right)$ infusion to increase systemic arterial oxygen saturation and to decrease the complications associated with BPV. The procedure of traversing the $\mathrm{PV}$ and positioning the balloon dilatation catheter across the PV is slightly more difficult than that encountered in older children. RV cineangiographic frames from sitting-up $\left(15^{\circ} \mathrm{LAO}\right.$ and $30^{\circ}$ cranial $)$ (Figure 44) and lateral (Figure 45) views serve as guides during the procedure to ensure the correct position of the guide wires, catheters and balloons.

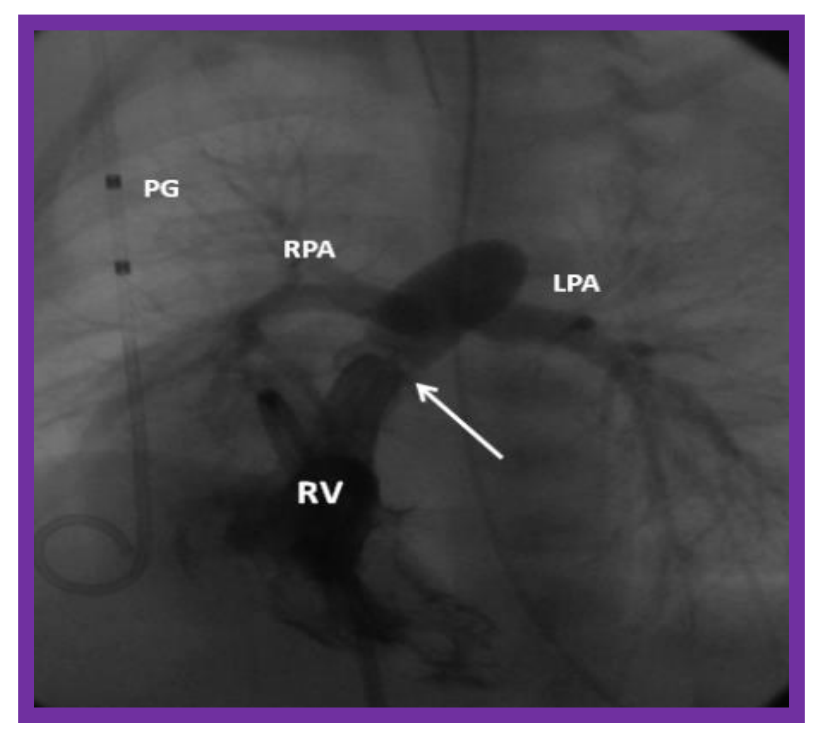

Figure 44. Selected right ventricular (RV) cine frame in sitting-up (150 LAO and 300 cranial) view, demonstrating a thickened and domed pulmonary valve (arrow). Also note the RV hypertrophy with increased trabeculations. LPA, left pulmonary artery; PG, pigtail catheter used for calibration purposes; RPA, Right pulmonary artery. Reproduced from Reference 99.

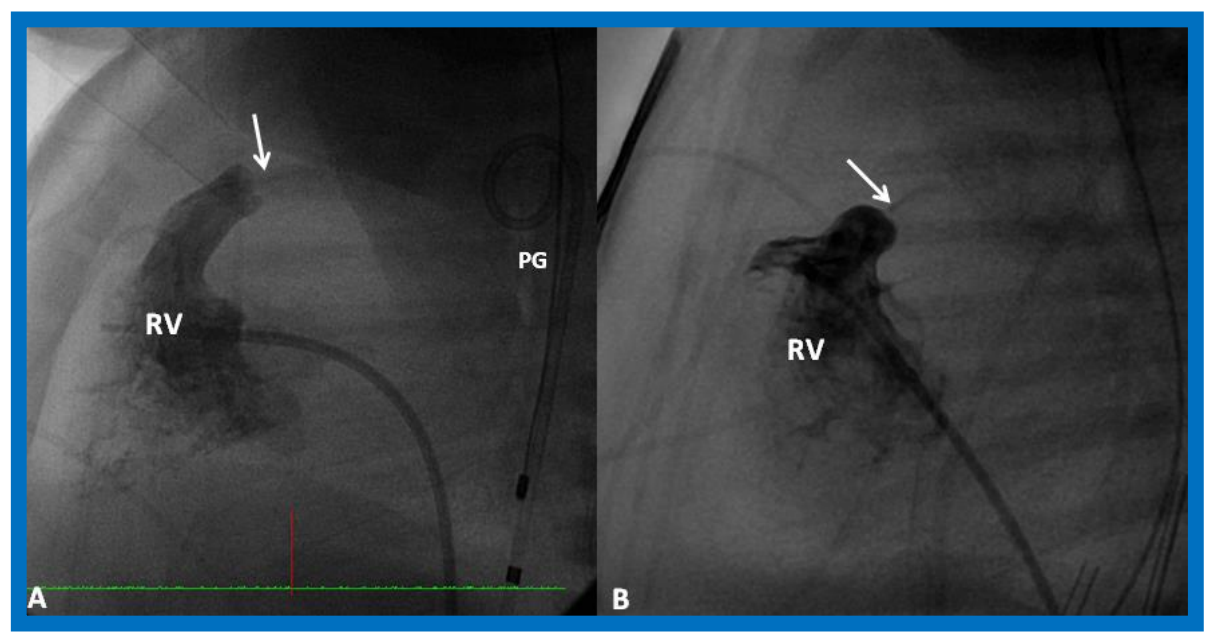

Figure 45. Selected cine frames from right ventricular $(R V)$ cineangiograms in lateral view of two separate newborn infants with critical pulmonary stenosis and intact ventricular septum, demonstrating extremely narrow jets (arrows in A and B). PG, pigtail catheter in the descending aorta. Reproduced from Reference 99. 
A right coronary artery (Cordis), angled Glidecath (Meditech) or cobra (Cook) catheter (usually \#4 French), according to the cardiologist's preference, is placed in the RV outflow tract and a floppy-tipped coronary guide wire is passed across the pulmonary valve. The guide wire is then advanced into either branch pulmonary artery or into the descending aorta via the patent ductus arteriosus (Figure 4); the author prefers the latter because of the improved stability of the guide wire which in turn facilitates positioning a suitable sized balloon catheter across the pulmonary valve. The catheter in the RV outflow tract is advanced over the guide wire, across the pulmonary valve, and into one of the branch pulmonary arteries or the descending aorta. The coronary guide wire is exchanged with a guide wire that is appropriate for the selected balloon valvuloplasty catheter. If it is not possible to advance the catheter across the pulmonary valve, balloon dilatation with smaller balloon catheters (3$4 \mathrm{~mm}$ diameter coronary angioplasty balloon catheters) may be performed prior to using the appropriate-sized balloon catheter (Figures 5 and 46). If an appropriate-sized balloon catheter can be passed across the PV, BPV is performed in a conventional manner (Figure 4). The selection of balloon size for BPV is the same as that used for children (B/A Ratio of 1.2 to 1.25$)$, as discussed in the preceding sections.

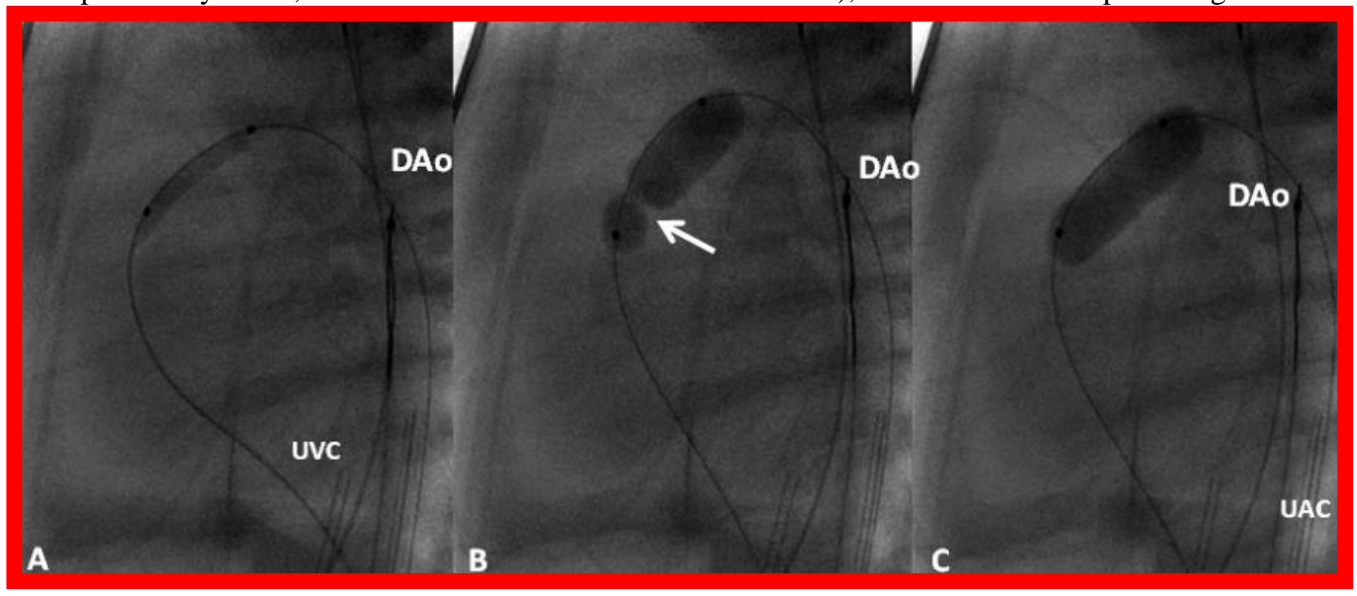

Figure 46. Selected cine frames in a lateral view, demonstrating the use of increasingly larger balloon catheters in a one-day-old baby with critical pulmonary stenosis and intact ventricular septum. Initially a $6 \mathrm{~mm}$ diameter balloon catheter could not be advanced across the pulmonary valve. Then a coronary guide wire was positioned across the pulmonary valve and across the ductus into the descending aorta (DAo) and a 3.5-F catheter carrying a $3 \mathrm{~mm}$ diameter balloon was used to "pre-dilate" the pulmonary valve (A). Then a $6 \mathrm{~mm}$ diameter balloon catheter was easily advanced across the pulmonary valve (B). See the waisting of the balloon in the initial phases of balloon dilatation (arrow in B). On further inflation of the balloon the waisting was completely abolished (C). UAC, umbilical artery catheter; UVC, umbilical venous catheter. Reproduced from Reference 99.

The results are generally good, with a reduction in the pressure gradient across the pulmonary valve, RV peak systolic pressure and RV to aortic systolic pressure ratio, and increased flow-width across the pulmonary valve demonstrated by angiography. Despite the improvement in the pressure gradients, some patients require continued infusion of $\mathrm{PGE}_{1}$ thought to be related to decreased compliance of the RV. Aortopulmonary (modified Blalock-Taussig) shunts or ductal stents are used by some investigators as an alternative to prolonged $\mathrm{PGE}_{1}$ infusion. For additional discussion of the immediate and follow-up results, the reader is referred our prior publications [4,43,67,94-99].

\section{Pulmonary Stenosis in Adult Subjects}

Following Kan's report [10] of BPV in children, Pepine and his associates [101] applied this technique in an adult patient and produced good results. Subsequently other groups of cardiologists [58,102-105] used this procedure to relieve pulmonary valve obstruction in adults.

The technique of balloon pulmonary valvuloplasty is essentially similar to that used in children, however, because of physical size of the pulmonary valve annulus, some adults may need simultaneous use of two balloons for balloon valvuloplasty [58,102]. However, more recently, larger diameter balloons became available for clinical use and therefore, double balloon technique is not necessary in all cases. In addition, as discussed above (Number of Balloons section) and elsewhere [20,56], the double balloon technique is similar to but not superior to the single balloon method, especially when equivalent B/A ratios are used. Subsequently, Inoue balloon were used in adults $[103,106,107]$ with good results. The chief advantage of the Inoue balloon over the conventional balloons is that the balloon diameter can be increased, making stepwise dilatation feasible. Balloon sizes similar to or $1 \mathrm{~mm}$ larger than PV annulus were used in adults which seems to be effective [44,104,105]. But, systematic evaluation of the influence of B/A ratios in adult subjects has not been performed. As stated in the section on Balloon Diameter, I would suggest a B/A ratio of 1.2 to 1.25 in adults also.

Immediate results of balloon valvuloplasty in adult patients are excellent [4,44,58,101-107] and are similar to those observed in children. Good results has been seen even in the sixth and seventh decades of life [107109]. Infundibular obstruction may develop after balloon valvuloplasty; such problem has been shown in teenage $[66,68]$ and adult patients $[58,105]$. Infundibular obstruction appears to be more common in older patients than in younger patients [68]; this is probably related to longstanding right ventricular hypertension with resultant right ventricular infundibular hypertrophy in older patients [68]. However, the infundibular obstruction tends to resolve with time $[68,69]$ after balloon valvuloplasty, as reviewed in the section on Infundibular Obstruction.

Results at follow-up, though reported in a few studies, do signify persistent relief of pulmonary valve obstruction. It may be concluded that that successful balloon pulmonary valvuloplasty is possible in adult patients and we recommend balloon valvuloplasty as preferred treatment option for management of PS for this group of patients also [1].

\section{Additional Issues}

\section{The Mechanism of Valvuloplasty}

Inflation of a balloon placed across the stenotic pulmonary valve applies radial forces on the stenotic pulmonary valve without any axial component $[42,110,111]$. The mechanism of valvuloplasty has been 
evaluated by direct inspection of the valve at surgery [112] and of postmortem specimens [113]. It has also been studied by indirect examination of angiographic [42,114] and echocardiographic [115] changes following BPV. Splitting of the valve commissures, tearing of valve leaflets and avulsion of the valve leaflets have been seen in all these studies and are possibly the mechanism by which pulmonary valve stenosis is relieved by balloon valvuloplasty. The radial dilating force exerted by balloon inflation is likely to rupture/tear the fused valve commissures, the weakest part of the valve mechanism. But, in some patients, if the fused commissures are too strong to be torn, valve cusp tears and even avulsion of valve leaflets may occur. The latter events are likely to produce severe PI. In patients with pulmonary valve dysplasia, successful balloon valvuloplasty may not be possible unless there is associated commissural fusion. For a more detailed discussion of mechanism of balloon valvuloplasty, the reader is referred to detailed discussion presented elsewhere [111].

\section{Right Ventricular Filling and Compliance}

Right ventricular filling abnormalities and decreased compliance of the $\mathrm{RV}$ muscle are expected to be present in children with RV outflow tract obstruction in a manner similar to those of the left ventricle in patients with left ventricular outflow obstruction. Indeed such abnormalities were demonstrated by Vermilion and colleagues [116]; there was decreased RV filling in early diastole and increased filling during atrial contraction. But, their findings suggested no change in the RV filling abnormalities and compliance characteristics following successful BPV [116]. However, these findings are at variance with our clinical observations. Consequently, we investigated this issue with the help our patient data [117]. Of the 75 patients who underwent balloon pulmonary valvuloplasty, 10 children had arterial desturation secondary to right to left shunt across the PFO. Peak to peak pulmonary valve gradients were reduced from $118 \pm 38 \mathrm{mmHg}$ to $28 \pm 17 \mathrm{mmHg}(\mathrm{p}<0.001)$ following balloon pulmonary valvuloplasty in this subset of PS patients. Concurrently, the systemic arterial oxygen saturations ( $83 \pm 8 \%$ vs. $94 \pm$ $5 \%)$, pulmonary flow index $\left(1.9 \pm 0.5\right.$ vs. $\left.2.7 \pm 0.6 \mathrm{~L} / \mathrm{min} / \mathrm{m}^{2}\right)$ and pulmonary to systemic flow ratio $(0.7 \pm 0.1$ vs. $0.95 \pm 0.1)$ increased $(\mathrm{p}<0.001)$. When data on each patient is scrutinized, the arterial oxygen saturations improved in each and every patient (Figure 47) [117].

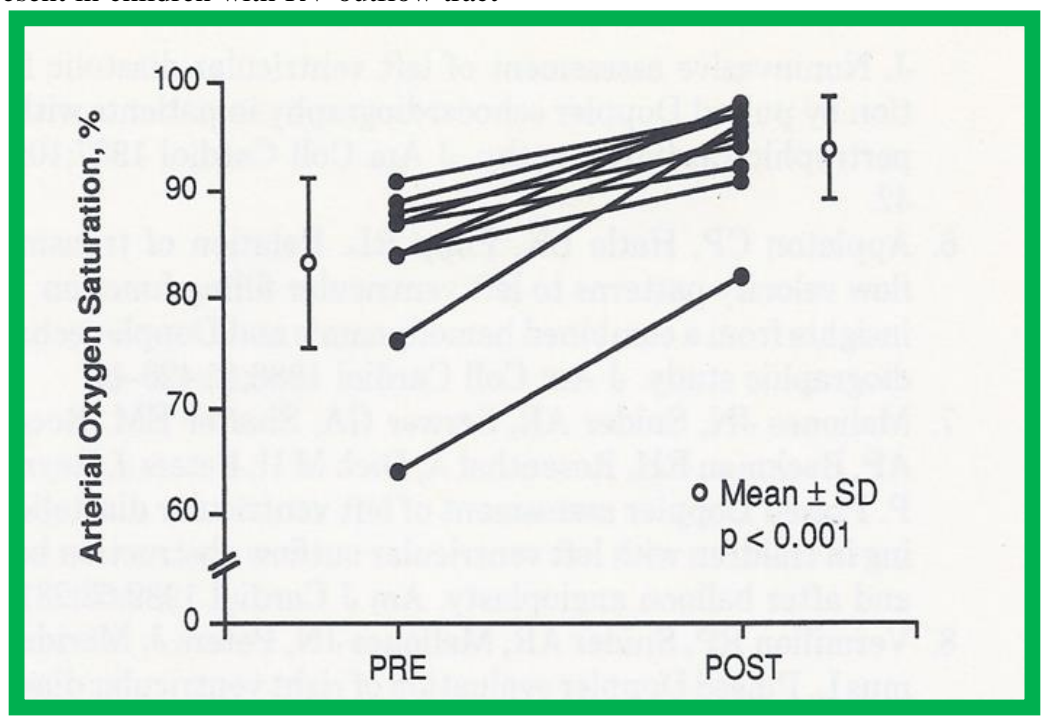

Figure 47. Arterial oxygen saturations prior to (PRE) and 15 minutes after (POST) balloon pulmonary valvuloplasty in each of the 10 patients (solid circles) are shown. There is an increase in saturation in all patients. The mean (open circles) \pm standard deviation (SD) are also shown. There is a statistically significant $(p<0.001)$ increase in oxygen saturation. Reproduced from Rao PS, Am Heart J 1992; 123:1084-6 [117].

Improved $\mathrm{O}_{2}$ saturation following BPV is related to abolished or reduced right to left shunt across the PFO. Th Role of Balloon Pulmonary Valvuloplasty in the Management of Pulmonary Stenosise only difference between pre- and post- valvuloplasty states is decreased pulmonary valve gradients, thereby reducing RV afterload. This decreased RV afterload may have enhanced RV filling with resultant reduction in right to left shunt. Perhaps the Doppler recordings [116] are not sensitive enough to detect improved RV filling after BPV [117].

\section{Pulmonary Stenosis Associated with Other Heart Defects}

Introduction. Cyanotic congenital heart defects (CHDs) constitute 20$25 \%$ of all CHDs. In a subgroup of cyanotic CHDs, obstruction to the pulmonary blood flow by a stenotic pulmonary valve causes arterial oxygen desaturation, and transcatheter management of these will be reviewed. The defects in this group are tetralogy of Fallot (TOF), transposition of the great arteries (TGA), double outlet right (or left) ventricle, double-inlet left ventricle, tricuspid atresia, ventricular inversion (congenital corrected transposition of the great arteries $\{\mathrm{CCTGA}\}$ ) and other types of univentricular hearts, all with non-restrictive inter-ventricular communication and severe pulmonary valve stenosis. These patients are usually symptomatic in the neonatal period or early in infancy. The pathologic, pathophysiologic, clinical, chest x-ray, ECG, echo-Doppler and angiographic features of cyanotic CHD were discussed by the author elsewhere [7,118,119] and will not be reviewed here. Total surgical correction is feasible in some of these patients [7,118-120] while in others, complete surgical correction is not possible. In the latter group of patients, surgical palliation to augment the pulmonary blood flow with aortopulmonary shunts [121,122] is a standard management approach. Following the report by Kan and her associates [10], we applied the BPV technique, initially to isolated PS cases $[64,65]$, as reviewed in the preceding sections of this paper, and subsequently extended the technique to cyanotic CHDs [123-125]. In this section, issues related to BPV in cyanotic CHDs will be reviewed. 
Indications for BPV in Cyanotic CHD. The indications for BPV are cyanotic cardiac defects which are not amenable to surgical correction either due complexity of the defect or to the size of the patient at the time of presentation, but nonetheless require palliation for pulmonary oligemia. In older children, symptoms related to hypoxemia and polycythemia are indications for such interventions. Hypoplasia of the pulmonary valve ring, main, and/or branch pulmonary arteries is another indication, even if symptoms are absent.
The presence of two or more sites of obstruction (Figures 48 and 49) is considered a prerequisite when employing balloon valvuloplasty [123,124]. The reason that we adopted this principle is because if valvar PS is the sole obstruction, relief of such an obstruction may produce a marked increase in the pulmonary blood flow, the elevation of pulmonary artery pressure, and pulmonary vascular resistance. In the presence of two obstructions in series, the relief of one obstruction decreases the total resistance to flow into the lungs, with the resultant relief of pulmonary oligemia; yet the pulmonary artery pressures remain normal (Figure 50).

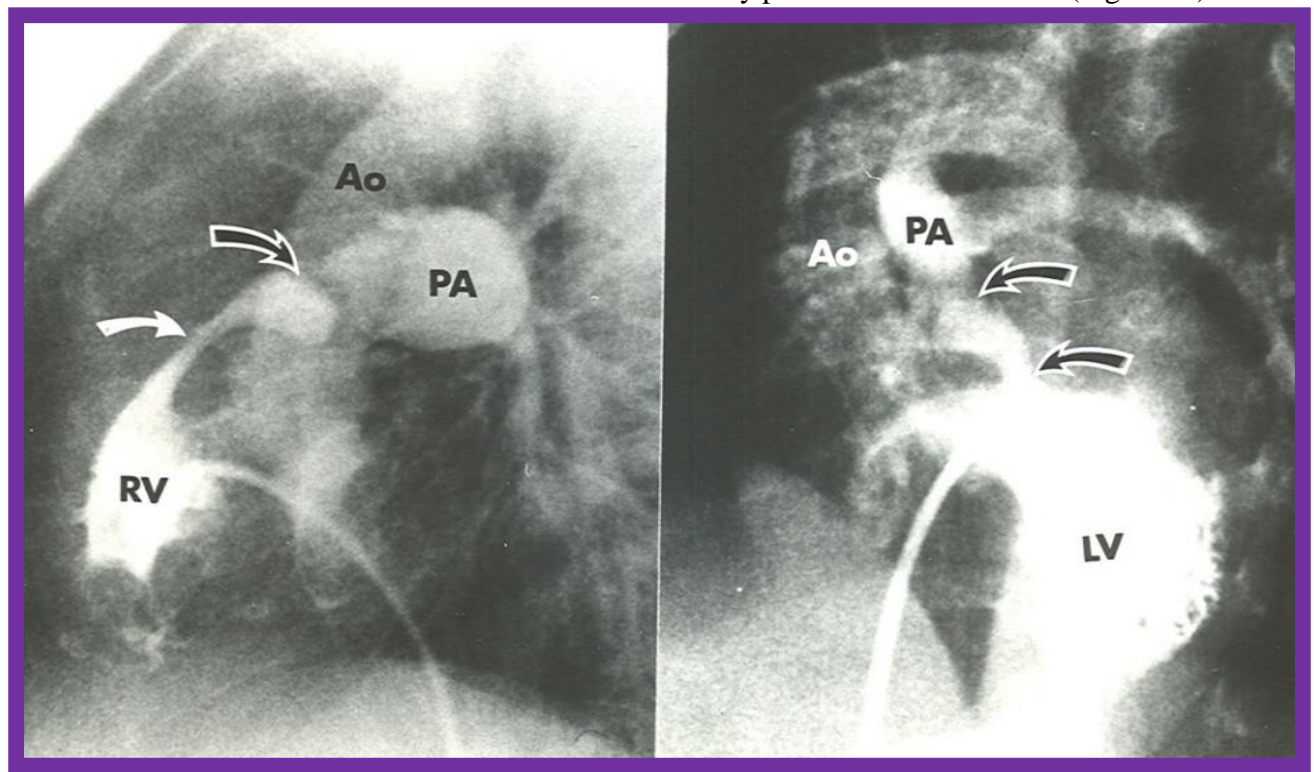

Figure 48. Selected cineangiographic frames from patients with tetralogy of Fallot (A) and d-transposition of the great arteries $(B)$, demonstrating two sites of pulmonary outflow obstruction (two arrows). When the pulmonary valve obstruction is relieved by balloon valvuloplasty, the subvalvar obstruction remains and prevents the flooding of the lungs. Ao, aorta; $L V$, left ventricle; PA, pulmonary artery; RV, right ventricle. Reproduced from Rao PS, et al., Cathet Cardiovasc Diagn 1992; 25:16-24 [125].

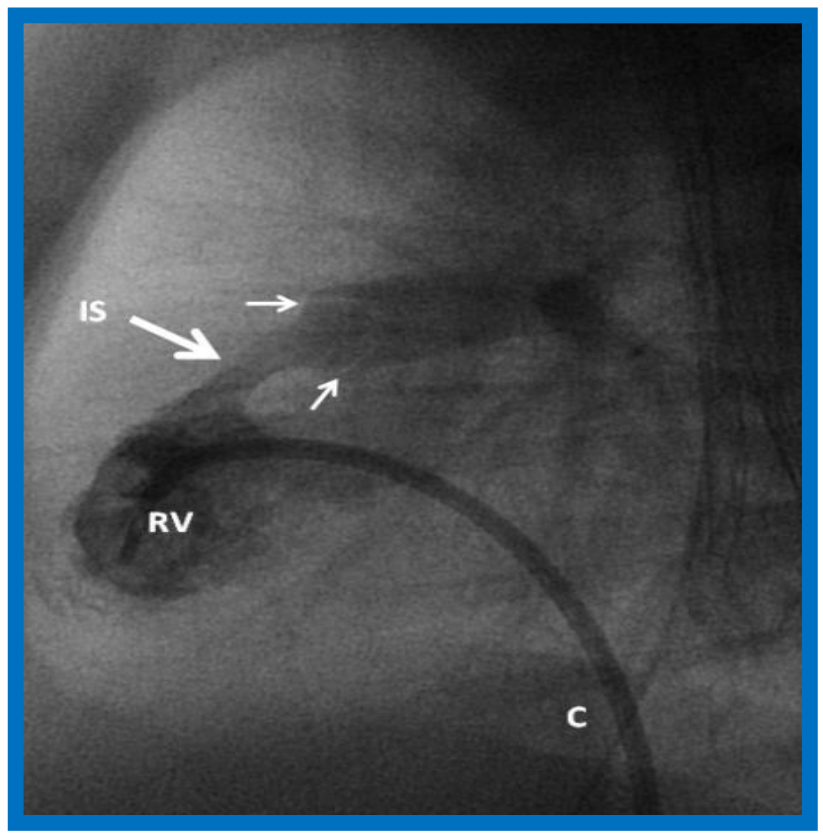

Figure 49. Selected cine frame from right ventricular (RV) cineangiogram in the lateral projection, demonstrating both infundibular (IS) (thick arrow) and valvar (thin arrows) stenosis. Note the thickened and domed pulmonary valve leaflets (thin arrows). As in Figure 10-58 A, after the relief of pulmonary valve obstruction by balloon valvuloplasty, the subvalvar obstruction remains and prevents the flooding of the lungs. $C$, catheter. Reproduced from Reference 99. 


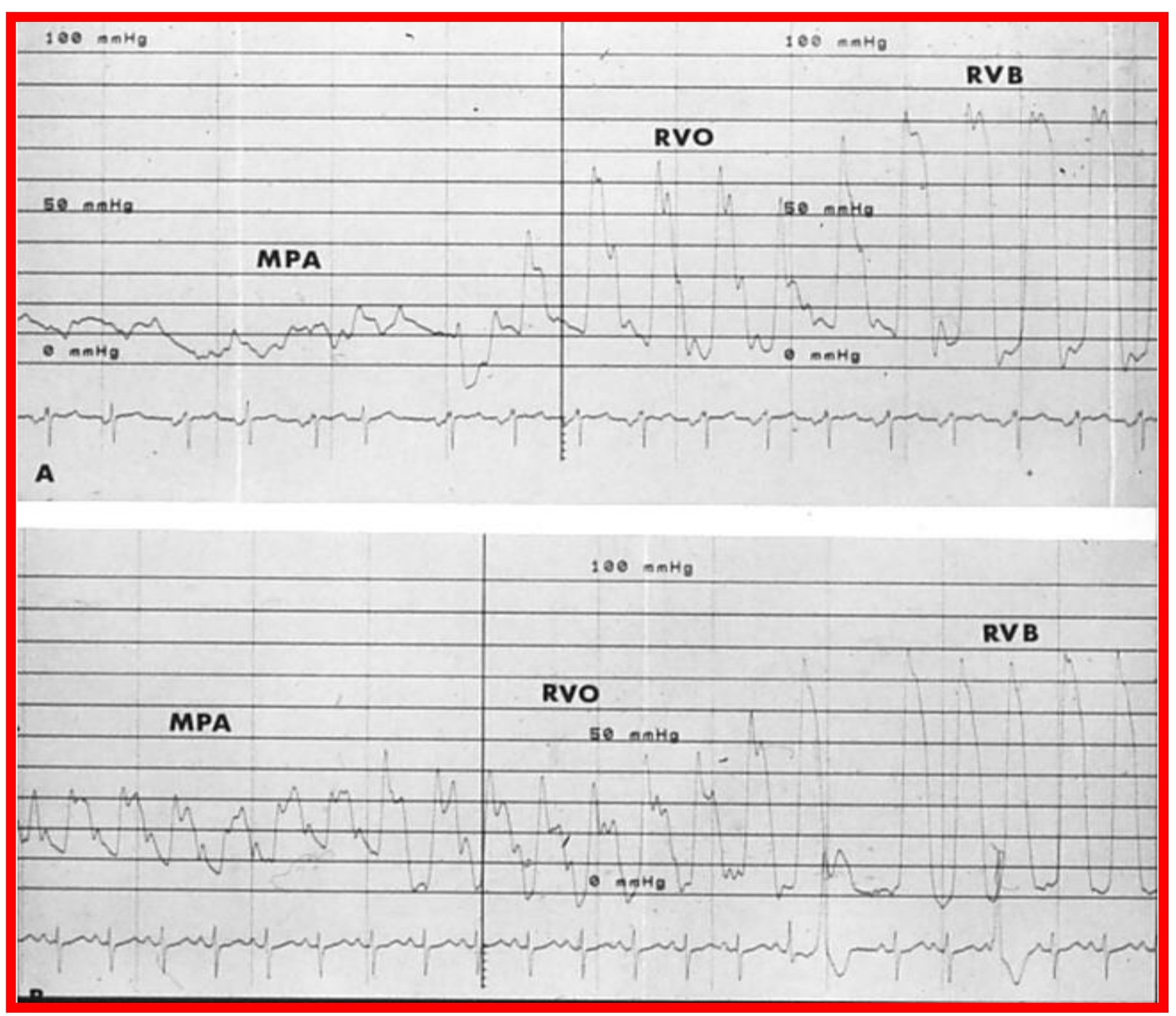

Figure 50. Pressure pullback tracings across the pulmonary valve and right ventricular outflow tract (RVO) before (A) and 15 minutes after (B) balloon pulmonary valvuloplasty in a patient with tetralogy of Fallot. Note that the pulmonary valve gradient disappeared, whereas the infundibular gradient persisted after balloon pulmonary valvuloplasty. Note the increased pulse pressure in the pulmonary artery pressure trace in B, indicating increased pulmonary flow after valvuloplasty. MPA, main pulmonary artery; RVB, right ventricular body. Reproduced from Rao PS, Brais $M$, Am Heart J 1988; 115:1105-10 [124].

Procedure of Balloon Pulmonary Valvuloplasty. The technique of BPV is essentially similar to that used for isolated valvar PS and is described in detail elsewhere [124-129]. In brief, a \# 4- or 5-French multi A-2 catheter (Cordis) or a similar catheter is advanced across the PV and is positioned in the distal branch (left or right) of the pulmonary artery. A suitable-sized ( 0.014 to 0.035 ") flexible tip J guide wire is positioned in the distal left or right pulmonary artery via the catheter already in place, and the catheter is removed. A balloon angioplasty catheter is then positioned across the pulmonary valve and the balloon is inflated (Figures $51 \& 52$ ). The diameter of the balloon is selected to be 1.2-1.25 times that of the pulmonary valve annulus (although this used to be 1.2-1.4 in the past), as discussed in a preceding section of this paper. One or more balloon inflations are usually performed. Ten to 15 minutes after BPV, systemic arterial saturation, adequate oxygen saturation data to enable the calculation of systemic and pulmonary flows, pulmonary artery and/or right (or left in TGA patients) ventricular angiography, and pressure pullback across the pulmonary valve and infundibulum (Figure 50) are recorded. 


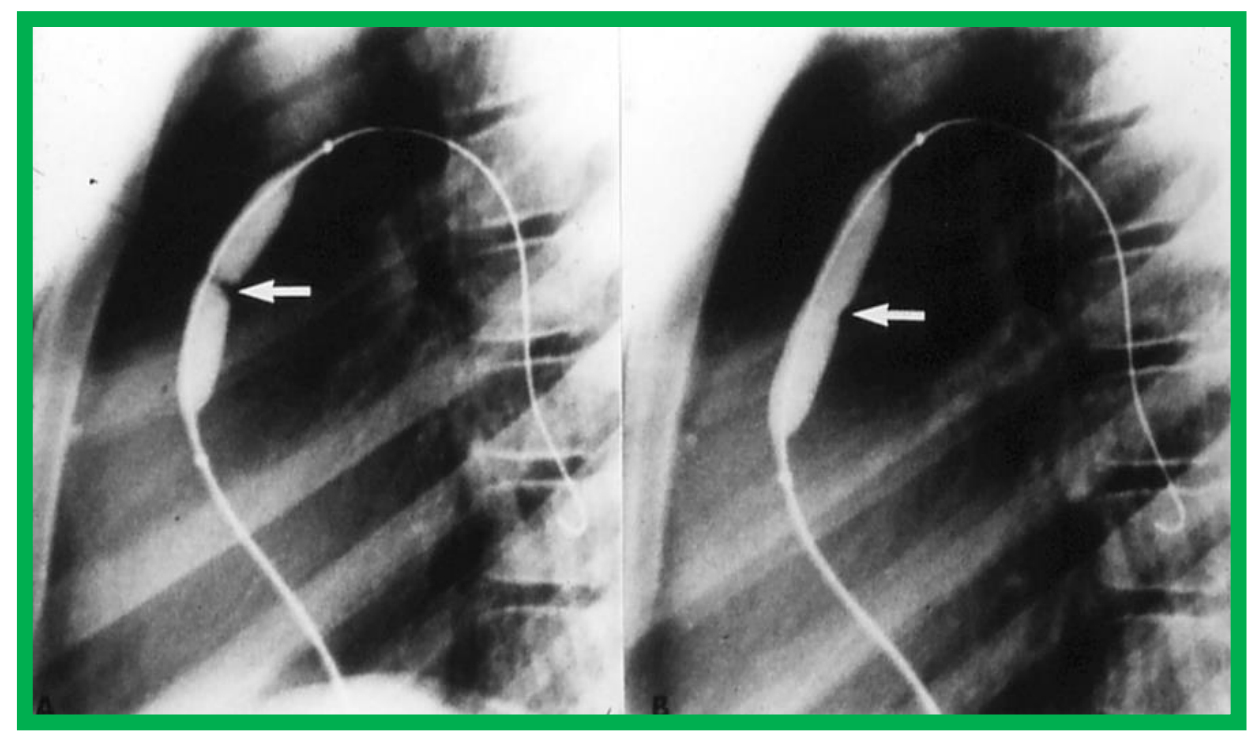

Figure 51. Selected cineradiographic frames of a balloon dilatation catheter placed across the pulmonary valve in an infant with tetralogy of Fallot. Note the waisting of the balloon during the initial phases of balloon inflation (A) which was almost completely abolished during the later phases of balloon inflation. Reproduced from Rao PS, et al., Cathet Cardiovasc Diagn 1992; 25:16-24 [125].

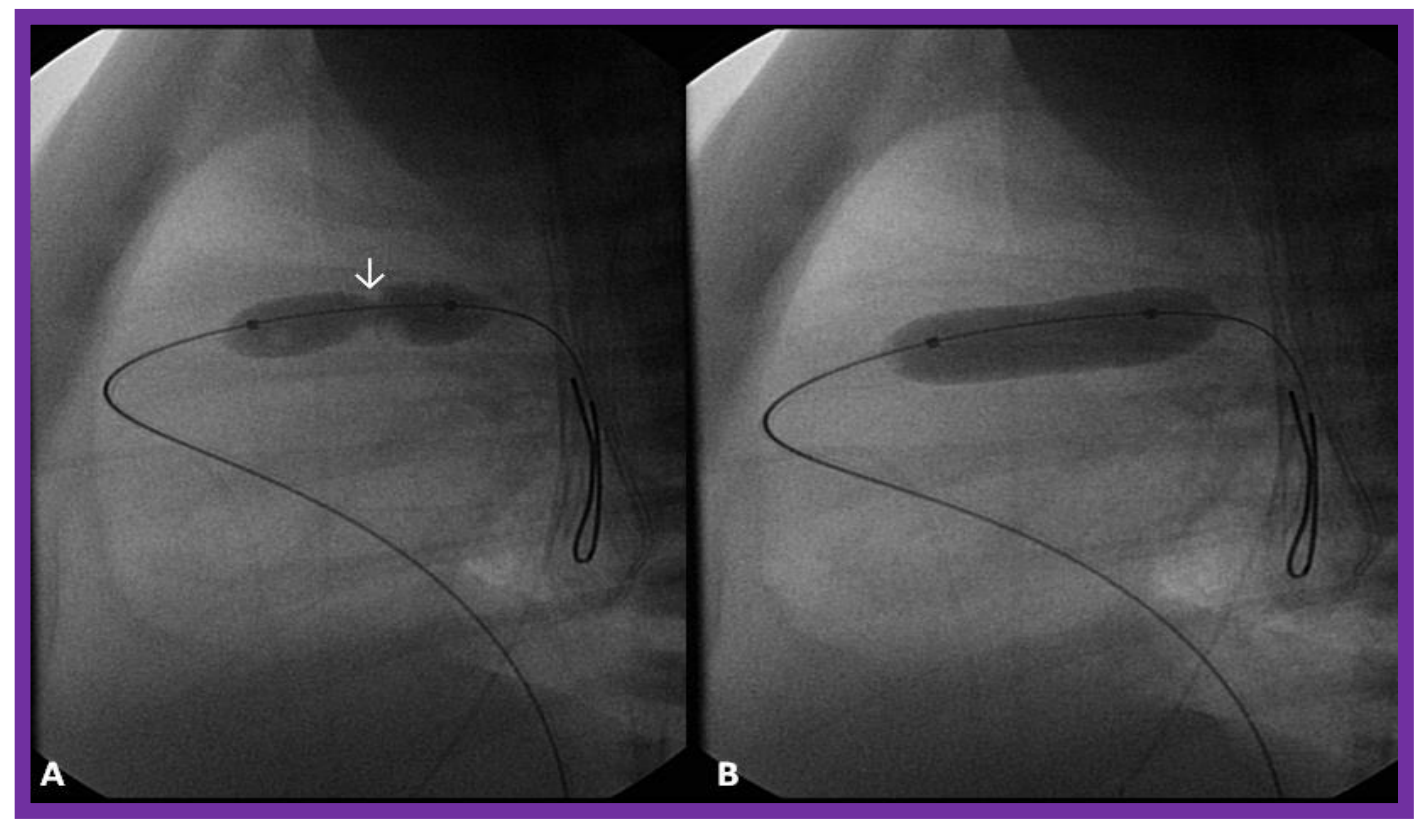

Figure 52. Selected cineradiographic frames of a balloon dilatation catheter placed across the pulmonary valve in an infant with tetralogy of Fallot. Note the waisting of the balloon during the initial phases of balloon inflation (A) which is almost completely abolished during the later phases of balloon inflation. Reproduced from Rao PS, Neonatology Today 2007; 2(10):1-12 [43].

Immediate Results. The immediate results of BPV in cyanotic CHDs were presented by the author in the late 1980s, with the subsequent publication of the immediate results from a larger group of patients [122127]. The diagnoses in these 14 patients were TOF in ten patients, TGA with VSD and valvar and subvalvar PS in three, and dextrocardia and ventricular inversion with VSD and valvar and subvalvar PS in the final patient. The systemic arterial oxygen saturation $(69.9 \pm 11.5 \%$ vs. $81.4 \pm$ $12.3 \% ; \mathrm{p}<0.05)$, pulmonary blood flow index (1.83 \pm 0.55 vs. $3.15 \pm 1.38$ $\left.1 / \mathrm{min} / \mathrm{m}^{2} ; \mathrm{p}<0.05\right)$, Qp:Qs $(0.55 \pm 0.36$ vs. $1.19 \pm 0.63 ; \mathrm{p}<0.05)$, and systolic pulmonary artery pressure $(15.5 \pm 6.6$ vs. $29.1 \pm 12.1 \mathrm{mmHg} ; \mathrm{p}<$ 0.02 ) increased immediately after the BPV. The improvement in pulmonary blood flow and Qp:Qs are demonstrated in Figure 53. Systolic pressure gradients across the PV were either abolished or reduced, but the subvalvar gradient persisted (Figure 50). None of these babies required immediate surgery. All but the seven-day-old infant were discharged home on the day after the BPV procedure. Complications related to the procedure have been surprisingly minimal, with a transient fall in the systemic arterial saturation while the balloon is inflated, but with rapid improvement following balloon deflation. Hypotension during BPV, so frequently seen in isolated PS dilatations, has not been observed in these patients, which is apparently related to the flow through the VSD. Surprisingly, cyanotic spells following BPV in cyanotic CHDs have not been a problem in our experience, presumably due to the improvement of pulmonary blood flow following the procedure. 


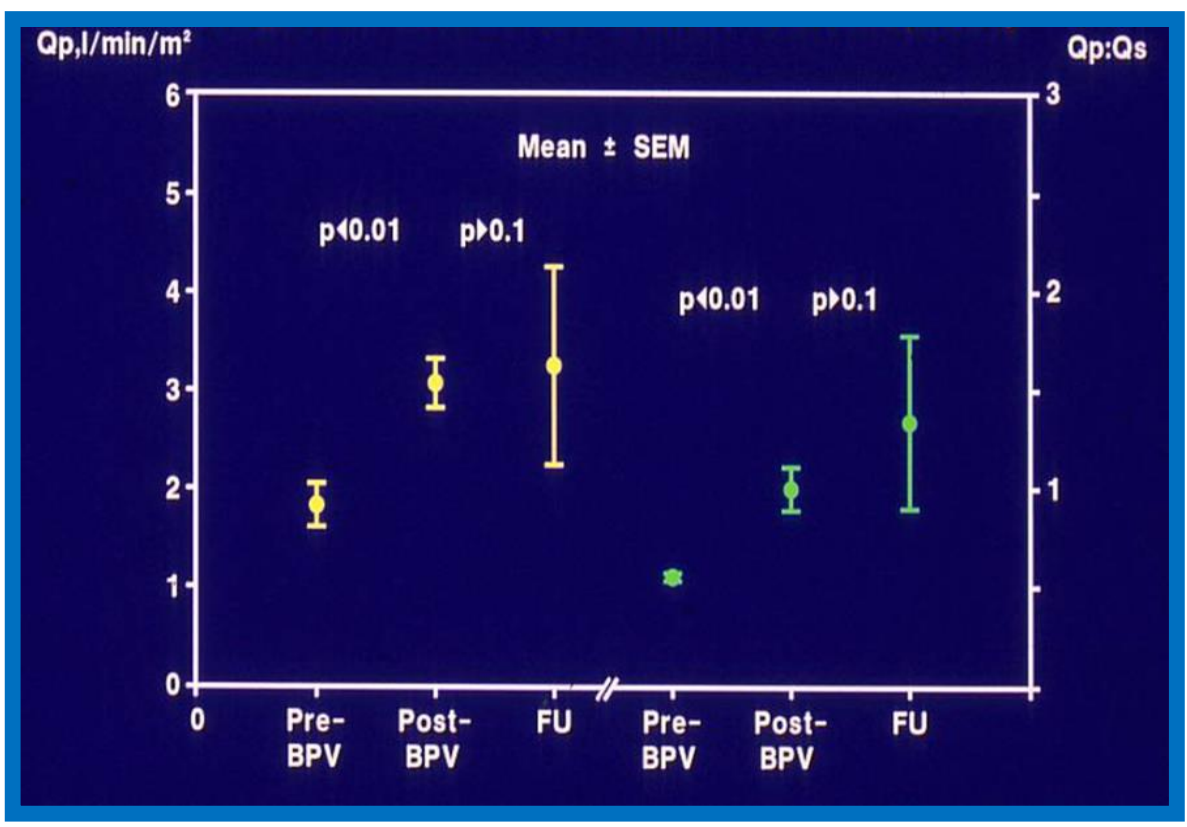

Figure 53. Graph demonstrating the effect of balloon pulmonary valvuloplasty (BPV) on pulmonary flow $(Q p)$ in $l / m i n / m 2(l e f t ~ p a n e l)$ and pulmonary-to-systemic blood flow ratio (Qp:Qs) (right panel) immediately after valvuloplasty and at follow-up (FU). Note the significant ( $p<0.01)$ improvement in $Q p$ and $Q p: Q s$ immediately after BPV. These values remain unchanged ( $p>0.1)$ at FU although the standard errors of mean (SEM) are larger at FU. Pre, prior to BPV; Post, immediately after BPV. Reproduced from reference [67].

Follow-Up Results. Follow-up cardiac catheterization at six to 36 months (13 \pm 10 months) after BPV revealed a persistent increase in the systemic arterial oxygen saturation ( $82 \pm 9 \%$ ), pulmonary blood flow and Qp:Qs (Figure 53). These values remained essentially unchanged $(\mathrm{p}>0.1)$ from the immediate post-BPV values and continued to be better ( $p<0.05$ to 0.01 ) than the pre-BPV values [125]. The gradient across the pulmonary valve $(18 \pm 7 \mathrm{mmHg}$ ) remained improved ( $\mathrm{p}<0.05$ to 0.01$)$ when compared to both the pre- and immediate post-BPV values. However, the infundibular $(53 \pm 18 \mathrm{mmHg})$ and total $\mathrm{RV} / \mathrm{LV}$ outflow tract $(69 \pm 13 \mathrm{mmHg})$ systolic pressure gradients remained unchanged $(\mathrm{p}>0.1)$. An increase in the size of the pulmonary arteries (Figures 54 and 55) occurred. Six children with TOF had successful surgical correction four to 24 months (12 \pm 9 months) after BPV. Four of these children were thought to have very small pulmonary arteries (prior to BPV) and considered not suitable for total surgical correction at that time. Two children with TGA had Blalock-Taussig shunts, which led to improvement. The remaining children were clinically doing well and awaiting further surgery at the time of our report [125].

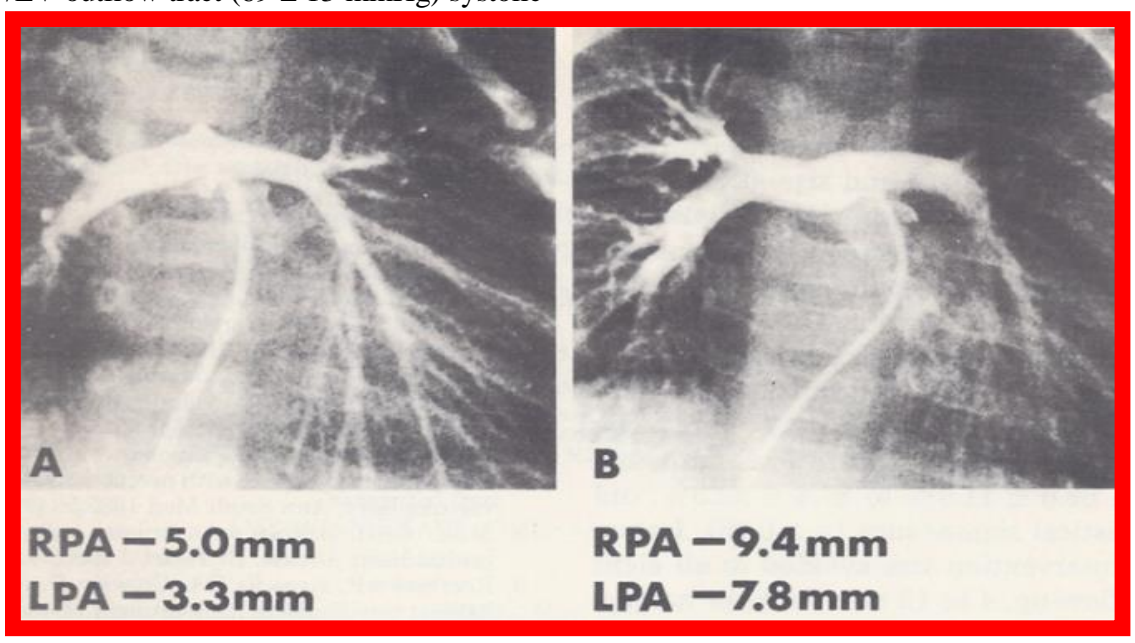

Figure 54. Selected frames from a pulmonary artery cineangiogram immediately prior to (A) and 6 months after (B) balloon pulmonary valvuloplasty in an infant with transposition of the great arteries, ventricular septal defect and subvalvar and valvar pulmonary stenosis, demonstrating the growth of the right (RPA) and left (LPA) pulmonary arteries. Note the differences in magnification; \# 5 French catheters were used in both angiograms. After correction for magnification, the RPA increased from $5.0 \mathrm{~mm}$ to $9.4 \mathrm{~mm}$ and the LPA from $3.3 \mathrm{~mm}$ to $7.8 \mathrm{~mm}$. Reproduced from Rao PS, Brais M, Am Heart J 1988; 115:1105-10 [124]. 


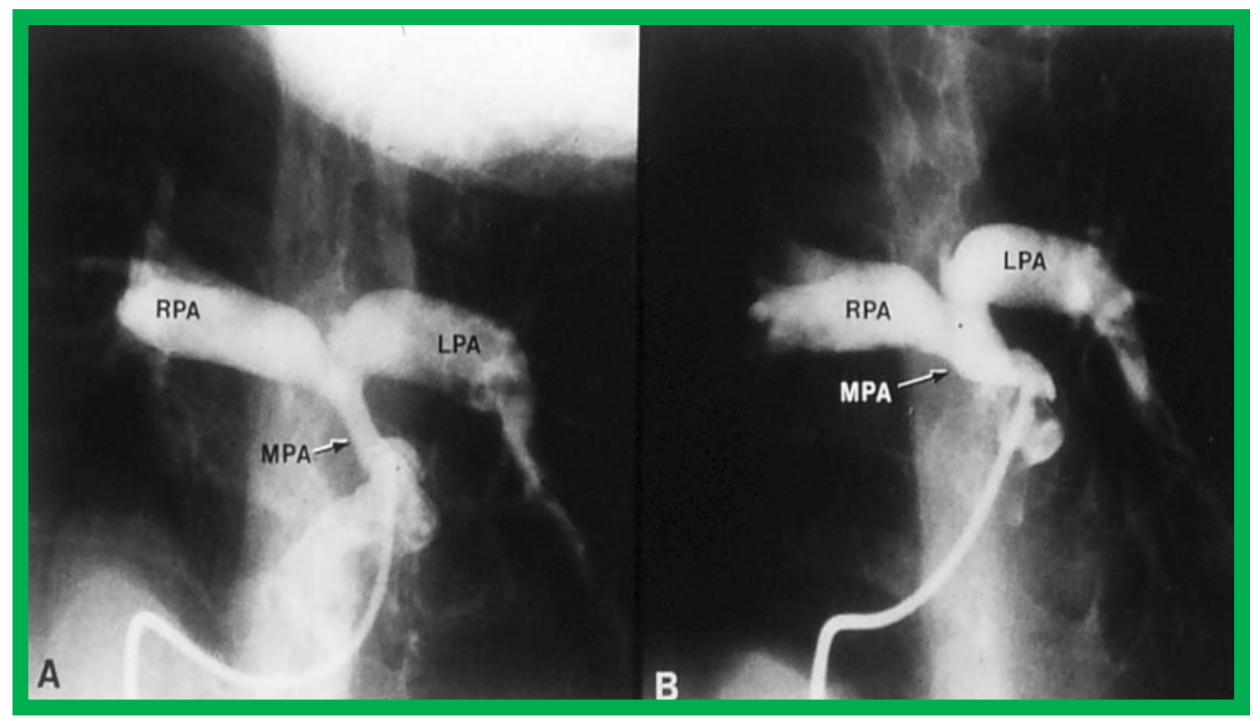

Figure 55. Selected frames from pulmonary artery cineangiograms in a sitting-up view in a patient with tetralogy of Fallot, prior to (A) and 12 months following (B) balloon pulmonary valvuloplasty. Note the significant improvement in the size of the valve annulus and main pulmonary artery (MPA) at follow-up. LPA, left pulmonary artery; RPA, right pulmonary artery. Reproduced from Rao PS, et al., Cathet Cardiovasc Diagn 1992; 25:16-24 [125].

Comments. The successful palliation of pulmonary oligemia in patients with cyanotic CHDs is feasible by BPV; this procedure may be performed in lieu of a conventional Blalock-Taussig shunt. The growth of the pulmonary arteries that we and others observed is similar to that seen following the Brock procedure and systemic-to-pulmonary artery shunts. Consequently, the author recommends BPV in these patients if the pulmonary artery size is marginal for undergoing surgical correction. In view of the current state of the art, with the feasibility of surgical repair at a younger age, it is prudent that BPV is performed in selected patients with tetralogy of Fallot or other cyanotic defects in concert with a surgical colleague's opinion regarding the feasibility of complete repair at a given age and state of the pulmonary arterial anatomy. There is also some controversy as to whether the BPV procedure causes significant growth of the pulmonary valve annulus $[130,131]$. It should also be noted that this technique has been extended [132] successfully to a group of children with truly diminutive pulmonary arteries.

In view of these diverse observations, as alluded to in the preceding paragraph, the author concludes that not all cyanotic CHD patients with PS are candidates for BPV, and suggests that BPV is undertaken in selected patients. The criteria that must be met in such cases are: 1 . The infant/child requires palliation of pulmonary oligemia but is not suitable for total surgical correction because of the size of the patient, the type of the defect or other anatomic abnormalities, 2. The valvar obstruction is a significant component of the RV outflow tract obstruction, and 3. Multiple obstructions in series are present so that there is residual subvalvar obstruction after the relief of PV obstruction, such that flooding of the lungs is prevented. Additional indications are the presence of contraindications for open heart surgery, or refusal of consent for open heart surgical correction by the parents/guardians [128,129].

\section{Other RV Obstructive Lesions.}

There are a number of RV obstructive lesions that may need treatment and these include, intracavitary right ventricular outflow obstructions (isolated infundibular stenosis, double-chamber RV, and hypertrophic cardiomyopathy involving the RV), subpulmonary obstructions in the morphologic left ventricle in patients with CCTGA (secondary to muscular mal-alignment, fibro-muscular ridge \{ similar to the sub-aortic membrane that is normally located in the left ventricle\}, aneurysm of the membranous septum, and intra-cardiac blood cyst, etc.), supravlavar pulmonary artery stenosis (congenital or acquired), external compression causing supravalvar PS following the Nuss procedure, and branch pulmonary artery stenosis. Some of these require medical/surgical interventions and others may be benefited by transcatheter therapy and will not be reviewed in this paper but were addressed elsewhere $[1,67,133]$ for the interested reader.

\section{Summary and Conclusions}

Since the initial description of BPV by Kan and her associates in 1982, the procedure has been widely used by many cardiologists for treatment of valvar PS. We recommend that the procedure be performed for peakto-peak systolic pressure gradients in excess of $50 \mathrm{mmHg}$, although some cardiologists use $40 \mathrm{mmHg}$ as an indication for BPV. Obstructions which are severe and critical, irrespective of age and pulmonary valve dysplasia, should undergo balloon valvuloplasty at the time of presentation. The BPV procedure entails placing one or more balloon angioplasty catheters across the stenotic valve over an extra-stiff guide wire(s) and inflating the balloon(s) two or more times. The radial forces of balloon expansion produce valvotomy. The currently recommended $\mathrm{B} / \mathrm{A}$ ratio is $1.2: 1$ to $1.25: 1$. Immediate reduction of systolic pressure gradient, increase in width of the stenotic jet, and free motion of the pulmonary valve leaflets with less doming have been observed following balloon valvuloplasty. Right ventricular function improves, tricuspid insufficiency gets better, and right-to-left shunt across the atrial septum is abolished or decreases. Complications are rare with a prevalence of $0.35 \%$. At intermediate-term follow-up, peak-to-peak systolic pressure gradient reduction is seen both by catheterization and Doppler-studies for the group as a whole. Yet, restenosis, defined as gradient $\geq 50 \mathrm{mmHg}$, has been observed in nearly $10 \%$ of children. Late follow-up results are scanty. But the available data indicate excellent results with low pulmonary valve gradients and minimal additional restenosis beyond what was observed at intermediateterm follow-up with event-free rates of high-80s and mid-80s at 5 and 10 
years after valvuloplasty, respectively and significant increase in the prevalence of PI.

BPV is also useful in the fetus, in the neonate, in children with dysplastic pulmonary valves, in patients with pulmonary valve stenosis associated with other heart defects, and in adults with PS. Mechanism of valvuloplasty was investigated and it appears that the radial dilating force exerted by balloon inflation is likely to rupture/tear the fused commissures. Right ventricular filling abnormalities appear to improve after balloon valvuloplasty, resulting in reduction of right to left shunt across the atrial septum. Predictors of restenosis were investigated and were found to be B/A ratio $\downarrow 1.2$ and immediate post-valvuloplasty gradient $\geq 30 \mathrm{mmHg}$. Repeat dilatation with balloons that are larger than those used at initial balloon valvuloplasty produces excellent results and redilatation appears to be the procedure of choice in the management of restenosis after prior BPV.

Regression of right ventricular hypertrophy on ECG occurs after balloon valvuloplasty and the ECG is a useful adjunct in the evaluation of results of balloon dilatation. But, ECG evidence for improvement does not become obvious until six months after balloon dilatation. Doppler gradients are generally reflective of residual obstruction, can detect PI and echo-Doppler studies are useful and reliable non-invasive monitoring methods.

Infundibular gradients occur in nearly $30 \%$ patients; higher prevalence is noted in the older patients and in those with severe obstruction. If the residual infundibular gradient is $\geq 50 \mathrm{mmHg}$, beta blockade therapy is recommended. The infundibular obstruction regresses at follow-up to a great degree with only occasional patient requiring surgery. Residual PI is present in the most patients at late follow-up; in most studies surgical intervention was not required. However, a few studies show significant PI to require pulmonary valve replacement. Decreasing the B/A ratio to 1.2 to 1.25 at the time of initial BPV may reduce the PI at follow-up. Studies comparing balloon with surgical treatment are scanty. Surgery is associated with higher incidence of mortality and morbidity and of PI, but with a greater reduction of gradient.

In conclusion, BPV is the treatment of choice for relief of pulmonary valve stenosis in the fetuses, neonates, children and adults. Use of balloons 1.2 to 1.25 times larger than PV annulus may produce optimal results. Fifteen-to-twenty year follow-up studies to 1. Identify the significance of residual PI and 2. If reduction of B/A ratio to less than 1.25 has any beneficial effect in reducing late PI are recommended.

\section{References}

1. Rao PS. Pulmonary valve disease. In: Valvular Heart Disease. $3^{\text {rd }}$ edition, Alpert JS, Dalen JE, Rahimtoola S (eds.), Lippincott Raven. Philadelphia, PA 2000: 339-376.

2. Rao PS. Percutaneous balloon valvuloplasty/angioplasty in congenital heart disease. In: Percutaneous Valvuloplasty and Related Techniques. Bashore TM and Davidson CT (eds), Williams \& Wilkins, Baltimore, MD, 1990: 251-277.

3. Rao PS. Percutaneous balloon pulmonary valvuloplasty. In: Percutaneous Balloon Valvuloplasty. Cheng T, (ed.) IgakuShion Med Publishers, New York 1992: 365-420.

4. Rao PS. Balloon pulmonary valvuloplasty for isolated pulmonic stenosis. In. Rao PS (ed). Transcatheter Therapy in Pediatric Cardiology. Wiley-Liss, Inc., New York, 1993: 59-104.

5. Rao PS. Pulmonary valve in children. In: Sigwart U, Bertrand M, Serrays PW (eds.). Handbook of Cardiovascular Interventions. Churchill Livingstone, New York, 1996: 273-310.

6. Rao PS. Diagnosis and management of acyanotic heart disease:
Part I - obstructive lesions. Indian J Pediatr 2005; 72: 496-502.

7. Rao PS. Congenital heart defects - A review. In. Rao PS (Editor). Congenital Heart Disease - Selected Aspects, ISBN 978-953307-472-6; InTech, Rijeka, Croatia, January 2012: 3-44.

8. Rao PS. Balloon valvuloplasty for pulmonary stenosis. In. Vijayalakshmi IB, ed. Cardiac Catheterization and Imaging (From Pediatrics to Geriatrics), Jaypee Publications, New Delhi, India, 2015: 149-174.

9. Brock RC. Pulmonary valvulotomy for the relief of congenital pulmonary stenosis; report of three cases. $\mathrm{Br}$ Med J. 1948;1(4562): 1121-1126.

10. Kan JS, White RJ, Jr, Mitchell SE, Gardner TJ. Percutaneous balloon valvuloplasty: A new method for treating congenital pulmonary valve stenosis. New Engl J Med 1982; 397:540-542.

11. Rao PS. Historical aspects of therapeutic catheterization. In. Rao PS (ed). Transcatheter Therapy in Pediatric Cardiology. WileyLiss, Inc., New York, 1993: 1-6.

12. Rao PS. Historical aspects of transcatheter treatment of heart disease in children. Pediatr Therapeut 2012; S5:002. doi:10.4172/2161-0665.S5-002.

13. Rao PS. History of transcatheter interventions in pediatric cardiology. In. Vijayalakshmi IB, ed. Cardiac Catheterization and Imaging (From Pediatrics to Geriatrics), Jaypee Publications, New Delhi, India, 2015: 3-20.

14. Rubio-Alvarez V, Limon-Lason R, Soni L. [Intracardiac valvulotomy by means of a catheter]. Arch Inst Cardiol Mex. 1953; 23(2): 183-192.

15. Rubio V, Limon-Lason R. Treatment of pulmonary valvular stenosis and tricuspid valve stenosis using a modified catheter. Program Abstract II. Second World Congress of Cardiology, Washington DC. 1956. pp. 205.

16. Semb BK, Tjönneland S, Stake G, Aabyholm G. "Balloon valvotomy" of congenital pulmonary valve stenosis with tricuspid valve insufficiency. Cardiovasc Radiol. 1979; 2(4): 239-241.

17. Dotter CT, Judkins MP. Transluminal treatment of arteriosclerotic obstruction: Description of a new technique and a preliminary report of its application. Circulation 1964; 30: 654-670.

18. Grüntzig AR, Senning A, Siegothaler WE. Non-operative dilatation of coronary artery stenosis: Percutaneous transluminal coronary angioplasty. N Engl J Med 1979; 301: 61-68.

19. Rao PS. Influence of balloon size on short-term and long-term results of balloon pulmonary valvuloplasty. Texas Heart Institute J 1987; 14: 57-61.

20. Rao PS. How big a balloon and how many balloons for pulmonary valvuloplasty? (editorial) Am Heart J 1988; 116: 577 580.

21. Rao PS, Thapar MK and Kutayli F. Causes of restenosis following balloon valvuloplasty for valvar pulmonic stenosis. Am J Cardiol 1988; 62: 979-982.

22. Rao PS, Galal O, Patnana M, et al. Three-to-ten-year follow-up results of balloon pulmonary valvuloplasty. Heart 1998; 80: 591-595.

23. Rao PS. Late pulmonary insufficiency after balloon dilatation of the pulmonary valve (Letter). Cathet Cardiovasc Intervent 2000; 49: 118-119.

24. Rao PS. Percutaneous balloon pulmonary valvuloplasty: State of the art. Cath Cardiovasc Intervent 2007; 69: 747-763.

25. Rao PS. Indications for balloon pulmonary valvuloplasty (editorial). Am Heart J 1988; 116: 1661-1662.

26. Nugent EW, Freedom RM, Nora JJ, et al. Clinical course of 
pulmonic stenosis. Circulation 1977; 56 (Suppl I): I18-I47.

27. Rao PS. Pulmonary valve stenosis. In: Percutaneous Interventions in Congenital Heart Disease, Sievert H, Qureshi SA, Wilson N, Hijazi Z (eds.), Informa Health Care, Oxford, UK, 2007: 185-195.

28. Rao PS. Pulmonary valve disease: Pulmonary valve stenosis. In: Sievert H, Qureshi SA, Wilson N, Hijazi Z (Eds): Interventions in Structural, Valvular and Congenital Heart Disease, CRC Press, 2014: 297-308. Print ISBN: 978-1-4822-1563-2; eBook ISBN: 978-1-4822-1564-1569.

29. Berman W, Jr, Fripp RR, Raiser BD, Yabek SM. Significant pulmonary valve incompetence following oversize balloon pulmonary valvuloplasty in small infants: a long-term follow-up study. Cathet Cardiovasc Intervent 1999; 8: 61-65.

30. Rao PS. Balloon pulmonary valvuloplasty (Letter). Cathet Cardiovasc Diagn 1997; 40: 427-428.

31. Feltes TF, Bacha E, Beekman RH 3rd, et al. for American Heart Association Congenital Cardiac Defects Committee of the Council on Cardiovascular Disease in the Young; Council on Clinical Cardiology; Council on Cardiovascular Radiology and Intervention; American Heart Association. Indications for cardiac catheterization and intervention in pediatric cardiac disease: a scientific statement from the American Heart Association. Circulation 2011; 123: 2607-2652.

32. Singh GK, Marino C, Oliver D, Balfour I, Chen S, Jureidini SB, Rao PS. Pressure gradients in outflow stenotic lesions: A simultaneous Doppler and catheter correlative study in pediatric patients. J Am Soc Echocardiogr 2000; 13: 455.

33. Singh GK, Mowers KL, Marino C, Balzer D, Rao PS. Effect of pressure recovery on pressure gradients in congenital stenotic outflow lesions in pediatric patients-clinical implications of lesion severity and geometry: A simultaneous Doppler echocardiography and cardiac catheter correlative study. J Am Soc Echocardiogr 2020; 33: 207-217. doi: 10.1016/j.echo.2019.09.001. Epub 2019 Nov 4. PMID: 31699474.

34. Rao PS. Balloon dilatation in infants and children with dysplastic pulmonary valves: short-term and intermediate-term results. Am Heart J 1988; 116: 1168-1173.

35. Marantz PM, Huhta JC, Mullins CE, et al. Results of balloon valvuloplasty in typical and dysplastic pulmonary valve stenosis: Doppler echocardiographic follow-up. J Am Coll Cardiol 1988; 12: 476-479.

36. Johnson LW, Grossman W, Dalen JE, Dexter L. Pulmonary stenosis in the adult: long-term follow-up results. New Engl $\mathbf{J}$ Med 1972; 287: 1159-1163.

37. Krabill KA, Wang Y, Einzid S, Moller JH. Rest and exercise hemodynamics in pulmonary stenosis: comparison of children and adults. Am J Cardiol 1985; 36: 360-365.

38. Rao PS. The femoral route for cardiac catheterization in infants and children. Chest 1973; 63: 239-241.

39. Sideris EB, Baay JE, Bradshaw RL, et al. Axillary vein approach for pulmonary valvuloplasty in infants with iliac vein obstruction. Cathet Cardiovasc Diagn 1988; 15: 61-63.

40. Chaara A, Zniber L, Haitem NE, et al. Percutaneous balloon valvuloplasty via the right internal jugular vein for valvar pulmonic stenosis with severe right ventricular failure. Am Heart J 1989; 117: 684-685.

41. Shim D, Lloyd TR, Cho KJ, et al. Transhepatic cardiac catheterization in children: evaluation of efficacy and safety. Circulation 1995; 92: 1526-1530.

42. Rao PS. Balloon angioplasty and valvuloplasty in infants, children and adolescents. Current Problems in Cardiology.
YearBook Medical Publishers, Inc. Chicago, 1989; 14(8): 417500.

43. Rao PS. Role of interventional cardiology in neonates: Part II Balloon angioplasty/ valvuloplasty. Neonatology Today 2007; 2(10): 1-12.

44. Bahl VK, Chandra S, Goel A, et al. Versatility of Inoue balloon catheter. Internat J Cardiol 1997; 59: 75-83.

45. Radhke W, Keane JF, Fellows KE, et al. Percutaneous balloon valvotomy of congenital pulmonary stenosis using oversized balloons, J Am Coll Cardiol 1986; 8: 909-915.

46. Rao PS. Further observations on the effect of balloon size on the short-term and intermediate-term results of balloon dilatation of the pulmonary valve. Br Heart J 1988; 60: 507-511.

47. Ring JC, Kulik TT, Burke BA, et al. Morphologic changes induced by dilatation of pulmonary valve annulus with overlarge balloons in normal newborn lamb, Am J Cardiol 1986; 52: 210-214.

48. Rao PS. Long-term follow-up results after balloon dilatation of pulmonic stenosis, aortic stenosis and coarctation of the aorta: a review. Progr Cardiovasc Dis 1999; 42: 59-74.

49. Abu Haweleh A, Hakim F. Balloon pulmonary valvuloplasty in children: Jordanian experience. J Saudi Heart J 2003; 15: 31-34.

50. Garty Y, Veldtman G, Lee K, Benson L. Late outcomes after pulmonary valve balloon dilatation in neonates, infants and children. J Invasive Cardiol 2005; 17: 318-322.

51. Rao PS. Balloon pulmonary valvuloplasty (Editorial). J Saudi Heart Assoc 2003; 15: 1-4.

52. Rao PS. Balloon pulmonary valvuloplasty in children (Editorial). J Invasive Cardiol 2005; 17: 323-325.

53. Moguillansky D, Schneider HE, Rome JJ, Kreutzer J. Role of high-pressure balloon valvotomy for resistant pulmonary valve stenosis. Congenit Heart Dis 2010; 5: 134-140.

54. Attia I, Weinhaus L, Walls JT, Lababidi Z. Rupture of tricuspid papillary muscle during balloon pulmonary valvuloplasty. Am Heart J 1987; 114: 1233-1234.

55. Lo RNS, Lau KC, Leung MP. Complete heart block after balloon dilatation of congenital pulmonary stenosis. Br Heart J 1988; 59: 384-386.

56. Rao PS and Fawzy ME. Double balloon technique for percutaneous balloon pulmonary valvuloplasty: Comparison with single balloon technique. J Interventional Cardiol 1988; 1:257-262.

57. Narang R, Das G, Dev V, et al. Effect of the balloon-annulus ratio on the intermediate and follow-up results of pulmonary balloon valvuloplasty. Cardiology 1997; 88: 271-276.

58. Al Kasab S, Riberiro PA, Al Zaibag M et al. Percutaneous double balloon pulmonary valvotomy in adults: one-to-two year followup. Am J Cardiol 1988; 62: 822-825.

59. Rao PS. Balloon pulmonary valvuloplasty: A review. Clin Cardiol 1989; 12: 55-72.

60. De Giovanni JV, Edgar RA, Cranston A. Adenosine induced transient cardiac standstill in catheter interventional procedures for congenital heart disease. Heart 1998; 80: 330-333.

61. Daehnert I, Rotzsch C, Wiener M, Schneider P. Rapid right ventricular pacing is an alternative to adenosine in catheter interventional procedures for congenital heart disease. Heart 2004; 90: 1047-1050.

62. Agu NC, Rao PS. Balloon Aortic Valvuloplasty. Pediatr Therapeut 2012; S5: 004. doi: 10.4172/2161-0665.S5-004

63. Bonnhoeffer P, Piechaud J, Stumper O, et al. The multi-track angiography catheter: a new tool for complex catheterization in congenital heart disease. Heart 1996; 76: 173-177. 
64. Rao PS, Mardini MK. Pulmonary valvotomy without thoracotomy: The experience with percutaneous balloon pulmonary valvuloplasty. Ann Saudi Med 1985; 5: 149-155.

65. Rao PS. Transcatheter treatment of pulmonic stenosis and coarctation of the aorta: The experience with percutaneous balloon dilatation. Brit Heart J 1986; 56: 250-258.

66. Rao PS, Fawzy ME, Solymar L, Mardini MK. Long-term results of balloon pulmonary valvuloplasty. Am Heart J 1988; 115 : 1291-1296.

67. Rao PS. Pulmonary stenosis. In. Rao PS. Pediatric Cardiology: How It Has Evolved Over The Last 50 Years. Cambridge Scholars Publishing, New Castle upon Tyne, 2020: 185-230. ISBN-13: 9781527548886.

68. Thapar MK, Rao PS. Significance of infundibular obstruction following balloon valvuloplasty for valvar pulmonic stenosis. Am Heart J 1989; 118: 99-103.

69. Fontes VF, Esteves CA, Eduardo J, et al. Regression of infundibular hypertrophy after pulmonary valvotomy for pulmonic stenosis. Am J Cardiol 1988; 62: 977-979.

70. Stranger P, Cassidy SC. Girod DA, et al. Balloon pulmonary valvuloplasty: results of the Valvuloplasty and Angioplasty of Congenital Anomalies Registry. Am J Cardiol 1990; 65: 775783.

71. Shuck JW, McCormick DJ, Cohen IS, et al. Percutaneous balloon valvuloplasty for pulmonary valve: role of right to left shunt through patent foramen ovale. J Am Coll Cardiol 1984; 4: 132-135.

72. Martin GR, Stanger P. Transient prolongation of the QTc interval after balloon valvuloplasty and angioplasty in children. Am J Cardiol 1986; 58: 1233-1235.

73. Levine JH, Guarnieri T, Kadish AH, et al. Changes in myocardial repolarization in patients undergoing balloon valvuloplasty for congenital pulmonary stenosis: Evidence for contractionexcitation feedback in humans. Circulation 1988; 77: 70-77.

74. Kveselis DA, Rocchini AP, Snider AR, et al. Results of balloon valvuloplasty in the treatment of congenital valvar pulmonary stenosis in children. Am J Cardiol 1985; 56: 527-532.

75. Rao PS. Doppler ultrasound in the prediction of transvalvar pressure gradients in patients with valvar pulmonic stenosis. International J Cardiol 1987; 15: 195-203.

76. Rao PS, Galal O, Wilson AD. Feasibility and effectiveness of repeat balloon dilatation of restenosed obstructions following previous balloon valvuloplasty/angioplasty. Am Heart J 1996; 132: 403-407.

77. Rao PS, Thapar MK. Balloon pulmonary valvuloplasty (Letter). Am Heart J 1991; 121: 1839-1840.

78. Rao PS. Value of echo-Doppler studies in the evaluation of the results of balloon pulmonary valvuloplasty. J Cardiovasc Ultrasonography 1986; 5: 309-314.

79. Rao PS, Solymar L. Electrocardiographic changes following balloon dilatation of valvar pulmonic stenosis. J Intervent Cardiol 1988; 1: 189-197.

80. Fontes VF, Sousa JEMR, Esteves CA, et al. Pulmonary valvuloplasty: experience of 100 cases. Internat J Cardiol 1988; 21: 335-342.

81. Lloyd TL, Donnerstein RL. Rapid T wave normalization after balloon pulmonary valvuloplasty in children. Am J Cardiol 1989; 64: 399-400.

82. Kovacevic A, Gardiner HM. In utero intervention for severe congenital heart disease. In. Rao PS, Vidyasagar D. (editors). A Multidisciplinary Approach to Perinatal Cardiology, Volume 1.
Cambridge Scholars Publishing, New Castle upon Tyne, UK. 2021: 751-776.

83. Roman KS, Fouron JC, Nii M, Smallhorn JF, Chaturvedi R, Jaeggi ET. Determinants of outcome in fetal pulmonary valve stenosis or atresia with intact ventricular septum. Am J Cardiol 2007; 99: 699-703. doi: 10.1016/j.amjcard.2006.09.120. Epub 2007 Jan 8.

84. Gardiner HM, Belmar C Tulzer G, et al. Morphological and functional predictors of eventual circulation in the fetus with pulmonary atresia or critical pulmonary stenosis with intact septum. J Am Coll Cardiol 2008; 51: 1299-1308.

85. Daffos F, Capella-Pavlovsky M, Forestier F. Fetal blood sampling during pregnancy with use of a needle guided by ultrasound: a study of 606 consecutive cases. Am J Obstet Gynecol. 1985; 153: 655-660.

86. Tulzer G, Arzt W, Franklin RC, et al. Fetal pulmonary valvuloplasty for critical pulmonary stenosis or atresia with intact septum. Lancet 2002; 360: 1567-1568.

87. Arzt W, Tulzer G, Aigner M, Mair R, Hafner E. Invasive intrauterine treatment of pulmonary atresia/intact ventricular septum with heart failure. Ultrasound Obstet Gynecol. 2003; 21: 186-188. doi: 10.1002/uog.48

88. Galindo A, Gutiérrez-Larraya F, Velasco JM, de la Fuente P. Pulmonary balloon valvuloplasty in a fetus with critical pulmonary stenosis/atresia with intact ventricular septum and heart failure. Fetal Diagn Ther 2006; 21: 100-104. doi: $10.1159 / 000089058$

89. Pang CC, Pan W, Zhang ZW, Zhou CB, Li YF, Zhang X, Han FZ, Sun YX, Wang S, Zhuang J. [Prenatal interventional therapy in two cases with critical pulmonary stenosis or pulmonary atresia with intact ventricular septum]. Zhonghua Er Ke Za Zhi. 2018; 56: 445-450. doi: 10.3760/cma.j.issn.05781310.2018.06.008.

90. Xing QS, Sun Y, Luo G, Zhang A, Chen TT, Pan SL. Intrauterine Intervention of Pulmonary Atresia at 26th Gestational Week. Chin Med J (Engl). 2018; 131: 2880-2881. doi: 10.4103/03666999.246074.

91. Tworetzky W, McElhinney DB, Marx GR, et al. In utero valvuloplasty for pulmonary atresia with hypoplastic right ventricle: Techniques and outcomes. Pediatr 2009; 124; e510e518.

92. Tulzer A, Arzt W, Gitter R, et al. Immediate Effects and Outcome of In-Utero Pulmonary Valvuloplasty in Fetuses With Pulmonary Atresia With Intact Ventricular Septum or Critical Pulmonary Stenosis. Ultrasound Obstet Gynecol 2018; 52: 230237.

93. Pang C, Zhou C, Zhang Z, Li Y, Zhang X, Han F, Sun Y, Wang S, Zhuang J, Pan W. Fetal Pulmonary Valvuloplasty in Fetuses with Right Ventricular Outflow Tract Obstructive Disease: Experience and Outcome of the First Five Cases in China. Pediatr Cardiol 2021; 42: 340-348. doi: 10.1007/s00246-02002488-8. Epub 2020 Oct 22.

94. Rao PS. Technique of balloon pulmonary valvuloplasty in the neonate (Letter). J Am Coll Cardiol 1994; 23: 1735.

95. Rao PS. Balloon valvuloplasty in the neonate with critical pulmonary stenosis (Editorial). J Am Coll Cardiol 1996; 27: 47980.

96. Jureidini SB, Rao PS. Critical pulmonary stenosis in the neonate: Role of transcatheter management. J Invasive Cardiol 1996; 8: 326-331.

97. Rao PS. Role of interventional cardiology in neonates: Part II Balloon angioplasty/ valvuloplasty. Congenital Cardiol Today 2008; 6(1): 1-14. 
98. Rao PS. Catheter interventions in the neonate: Part II - Balloon angioplasty/valvuloplasty. In. Rao PS, Vidyasagar D. (editors), Perinatal Cardiology: A Multidisciplinary Approach, Minneapolis, MN, Cardiotext Publishing, 2015.

99. Rao PS. Neonatal catheter interventions. In. Vijayalakshmi IB, Ed. Cardiac Catheterization and Imaging (From Pediatrics to Geriatrics), Jaypee Publications, New Delhi, India, 2015: 388432.

100. Tynan M, Jones O, Joseph MC, et al: Relief of pulmonary valve stenosis in first week of life by percutaneous balloon valvuloplasty. Lancet 1984; 1:273.

101. Pepine CJ, Gessner IH, Feldman RI: Percutaneous balloon valvuloplasty for pulmonic valve stenosis in the adult. Am J Cardiol 1982; 50: 1442-1445.

102. Fawzy ME, Mercer EN, Dunn B. Late results of pulmonary balloon valvuloplasty in adults using double balloon technique. J Intervent Cardiol 1988; 1: 35-42.

103. Silvert H, Kober G, Bussman J, et al. Long-term results of percutaneous pulmonary valvuloplasty in adults. Eur Heart $\mathbf{J}$ 1989, 10: 712-717.

104. Chen CR, Cheng TO, Huang T, et al. Percutaneous valvuloplasty for pulmonic stenosis in adolescents and adults. New Engl J Med 1996; 335: 21-25.

105. Teupe CHJ, Burger W, Schrader R, Zeiher A. Late (five to nine years) follow-up after balloon dilatation of valvar pulmonary stenosis in adults. Am J Cardiol 1997; 80: 240-242.

106. Lau KW, Jung JS, Wu JJ, et al. Pulmonary valvuloplasty in adults using the Inoue balloon catheter. Cathet Cardiovasc Diagn 1993; 29: 99-104.

107. Gibbs JL, Stanley CP, Dickenson DF. Pulmonary balloon valvuloplasty in late adult life. Internat J Cardiol 1986; 11: 237 139.

108. Cooke JP, Seward JB, Holmes DR, Jr. Transluminal balloon valvotomy for pulmonic stenosis in adults. Mayo Clin Proc 1987; 62: 306-311.

109. Feugelman MY, Lewis BS. Pulmonary balloon valvuloplasty in the seventh decade of life. Isr J Med Sci 1988; 24: 112-.113

110. Abels JE. Balloon catheters and transluminal dilatation: technical considerations Am J Roentgenol 1980; 135: 901.

111. Thapar MK, Rao PS. Mechanism of valvuloplasty/angioplasty for In: Rao PS (ed.) Transcatheter Therapy in Pediatric Cardiology. New York: Wiley-Liss; 1993: 45-58.

112. Walls JT, Lababidi Z, Curtis JJ, et al. Assessment of percutaneous balloon pulmonary and aortic valvuloplasty. J Thorac Cardiovasc Surg 1984; 88: 352-356.

113. Ettedgui JA, Ho SY, Tynan M, et al. The pathology of balloon pulmonary valvuloplasty. Internat J Cardiol 1987; 16: 285-293.

114. Burrows PE, Benson LN, Smallhorn JS, et al. Angiographic features associated with percutaneous balloon valvotomy for pulmonary valve stenosis. Cardiovasc Intervent Radiol 1988; 11: 111-116.

115. Benson LN, Smallhorn JS, Freedom RM, et al. Pulmonary valve morphology after balloon dilatation of pulmonary valve stenosis. Cathet Cardiovasc Diagn 1985; 11: 161-166.Vermilion RP, Snider AR, Meliones JN, Peters J, Merida-Asmus L. Pulsed Doppler evaluation of right ventricular diastolic filling in children with pulmonary valve stenosis before and after balloon valvuloplasty. Am J Cardiol 1990; 66: 79-84.

116. Rao PS. Right ventricular filling following balloon pulmonary valvuloplasty. Am Heart J 1992; 123: 1084-1086.

117. Rao PS. Diagnosis and management of cyanotic congenital heart disease: Part I. Indian J Pediat 2009; 76: 57-70.

118. Rao PS. Diagnosis and management of cyanotic congenital heart disease: Part II. Indian J Pediat 2009; 76: 297-308.

119. Rao PS. Consensus on timing of intervention for common congenital heart diseases: Part II - Cyanotic heart defects. Indian J Pediatr 2013; 80: 663-674. DOI 10.1007/s12098-013-1039-2.

120. Blalock A, Taussig HB. The surgical treatment of malformations of the heart in which there is pulmonary stenosis or pulmonary atresia. J Am Med Assoc 1945; 128: 189-194.

121. de Leval MR, McKay R, Jones M, et al. Modified BlalockTaussig shunt. Use of subclavian artery orifice as flow regulator in prosthetic systemic-pulmonary artery shunts. J Thorac Cardiovasc Surg 1981; 81: 112-119.

122. Rao PS. Balloon pulmonary valvuloplasty for complex cyanotic heart defects. Presented at the Pediatric Cardiology International Congress, Vienna, Austria, February 21-25, 1987.

123. Rao PS, Brais M. Balloon pulmonary valvuloplasty for congenital cyanotic heart defects. Am Heart J 1988; 115: 1105-1110.

124. Rao PS, Wilson AD, Thapar MK, Brais M, Balloon pulmonary valvuloplasty in the management of cyanotic congenital heart defects. Cathet Cardiovasc Diagn 1992; 25: 16-24.

125. Rao PS. Transcatheter management of cyanotic congenital heart defects: A review. Clin Cardiol 1992; 15: 483-496.

126. Rao PS. Role of balloon dilatation and other transcatheter methods in the treatment of cyanotic congenital heart defects. In: Rao PS, (Ed), Transcatheter Therapy in Pediatric Cardiology, Wiley-Liss, New York, 1993: 229-253.

127. Rao PS. Pulmonary valve in cyanotic heart defects with pulmonary oligemia. In: Sievert H, Qureshi SA, Wilson N, Hijazi Z (Eds), Percutaneous Interventions in Congenital Heart Disease, Informa Health Care, Oxford, UK, 2007: 197-200.

128. Rao PS. Pulmonary valve disease: Pulmonary valve in cyanotic heart defects with pulmonary oligemia. In: Sievert H, Qureshi SA, Wilson N, Hijazi Z (Eds): Interventions in Structural, Valvular and Congenital Heart Disease, CRC Press, 2014: $297-$ 308. Chapter 33. Print ISBN: 978-1-4822-1563-2; eBook ISBN: 978-1-4822-1564-9.

129. Battistessa SA, Robles A, Jackson M, et al, Operative findings after percutaneous pulmonary balloon dilatation of right ventricular outflow tract in tetralogy of Fallot. Br. Heart J 1990; 64: 321-314

130. Sreeram N, Saleem M, Jackson M, et al. Results of balloon pulmonary valvuloplasty as a palliative procedure in tetralogy of Fallot. J Am Coll Cardiol 1991; 8: 159-165.

131. Kreutzer J, Perry SB, Jonas RA, et al. Tetralogy of Fallot with diminutive pulmonary arteries: Preoperative pulmonary valve dilatation and transcatheter rehabilitation of pulmonary arteries. $\mathrm{J}$ Am Coll Cardiol 1996; 27: 1741-1747.

132. Rao PS, Thapar MK. Balloon dilatation of other congenital and acquired stenotic lesions of the cardiovascular system. In. Rao PS (Ed). Transcatheter Therapy in Pediatric Cardiology. WileyLiss, Inc., New York, 1993: 275-319. 
This work is licensed under Creative Commons Attribution 4.0 License

To Submit Your Article Click Here: Submit Manuscript

DOI: $10.31579 / 2641-0419 / 195$
Ready to submit your research? Choose Auctores and benefit from:

* fast, convenient online submission

* rigorous peer review by experienced research in your field

* rapid publication on acceptance

* authors retain copyrights

* unique DOI for all articles

* immediate, unrestricted online access

At Auctores, research is always in progress.

Learn more auctoresonline.org/journals/clinical-cardiology-andcardiovascular-interventions 